\title{
Changing autonomy : new perspectives on the care for stroke patients in nursing homes
}

Citation for published version (APA):

Proot, I. M. (2000). Changing autonomy : new perspectives on the care for stroke patients in nursing homes. [Doctoral Thesis, Maastricht University]. Datawyse / Universitaire Pers Maastricht. https://doi.org/10.26481/dis.20010126ip

Document status and date:

Published: 01/01/2000

DOI:

10.26481/dis.20010126ip

Document Version:

Publisher's PDF, also known as Version of record

\section{Please check the document version of this publication:}

- A submitted manuscript is the version of the article upon submission and before peer-review. There can be important differences between the submitted version and the official published version of record.

People interested in the research are advised to contact the author for the final version of the publication, or visit the DOI to the publisher's website.

- The final author version and the galley proof are versions of the publication after peer review.

- The final published version features the final layout of the paper including the volume, issue and page numbers.

Link to publication

\footnotetext{
General rights rights.

- You may freely distribute the URL identifying the publication in the public portal. please follow below link for the End User Agreement:

www.umlib.nl/taverne-license

Take down policy

If you believe that this document breaches copyright please contact us at:

repository@maastrichtuniversity.nl

providing details and we will investigate your claim.
}

Copyright and moral rights for the publications made accessible in the public portal are retained by the authors and/or other copyright owners and it is a condition of accessing publications that users recognise and abide by the legal requirements associated with these

- Users may download and print one copy of any publication from the public portal for the purpose of private study or research.

- You may not further distribute the material or use it for any profit-making activity or commercial gain

If the publication is distributed under the terms of Article $25 \mathrm{fa}$ of the Dutch Copyright Act, indicated by the "Taverne" license above, 


\section{CHANGING AUTONOMY}

New perspectives on the care for stroke patients in nursing homes 
The study presented in this thesis was performed at the Research institute for Extramural and Transmural health care (ExTra), which participates in the Netherlands School of Primary Care Research (CaRe), acknowledged in 1995 by the Royal Dutch Academy of Science (KNAW).

Lay-out:
Angelique Heinnen

Printing:

Dalawyse | Universitaire Pers Maastricht

Cover design:

Jean Bouxrie, Hoensbroek

ISBN 90-5278-284-1

(C) 2000, Ireen Proot

All chapters previously published are reprinted with the permission of the original copyright holders. 


\section{CHANGING AUTONOMY}

New perspectives on the care for stroke patients in nursing homes

\section{PROEFSCHRIFT}

ter verkrijging van de graad van doctor aan de Universiteit Maastricht, op gezag van de Rector Magnificus, Prof. dr. A.C. Nieuwenhuijzen Kruseman volgens het besluit van het College van Decanen, in het openbaar te verdedigen op vrijdag 26 januari 2001 om 14.00 uur

door

Ireen Proot

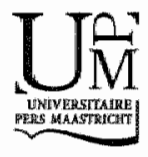




\section{Promotores:}

Prof. dr. R.H.J. ter Meulen

Prof. dr. H.F.J.M. Crebolder

Prof. dr. H. Huijer Abu-Saad

\section{Beoordelingscommissie:}

Prof. dr. J.A. Knottnerus (voorzitter)

Dr. G.H.M.I. Beusmans

Prof. dr. J. Troost

Prof. dr. G.A.M. Widdershoven

Dr. L.P. de Witte (iRv Kenniscentrum voor Revalidatie en Handicap)

The study presented in this thesis was supported by grant $94 / 53806 \mathrm{~F}$ from the Prowince of Limburg, the Netherlands, and by grant 940936 from the National Center for Nursing \& Care (LCVV), Utreeht, the Netherlands.

Financial support by the Netherlands Heart Foundation for the publication of this thesis is gratefully ackmowledged.

The publication of this thesis was supported by:

- Boehringer Ingelheim

- Sappi Maastricht B.V. 
'Woorden zijn tijdelijk. Wanneer je ze uitspreekt of neerschrijft, moet je je bewust zijn van hun tijdelijkheid."

Kahlil Gibran 



\section{CONTENTS}

Chapter 1 General introduction 9

Chapter 2 Autonomy in the rehabilitation of stroke patients in nursing homes. A concept analysis.

Chapter 3 Autonomy in stroke rehabilitation: the perceptions of health professionals in nursing homes

Chapter 4 Facilitating and constraining factors on autonomy: the views of stroke patients on admission into nursing homes

Chapter 5 Patient autonomy during rehabilitation: the experiences of stroke patients in nursing homes

Chapter 6 Stroke patients' needs and experiences regarding autonomy at discharge from nursing home

Chapter 7 Changing autonomy. Facilitating stroke patients' autonomy in the different phases of rehabilitation

Chapter $8 \quad$ Empirical research in bioethics

Chapter 9 General discussion

Chapter 10 Summary

Chapter 11 Samenvatting

Dankwoord/Acknowledgement

Curriculum Vitae

List of publications 



\section{Chapter 1}

\section{General introduction}

\section{AUTONOMY}

In the 1990 s patient autonomy began to acquire increasing importance in health care policies regarding chronically ill people (Ter Meulen, 1994). Autonomy is an important value in our western society, and also determines quality of life (Raad voor Gezondheidsonderzoek, 1997). The term autonomy is derived from the Greek 'autos' (self) and 'nomos' (rule, governance or law), and was finst used related to the ancient Greek city states (Dworkin, 1995). When citizens made their own laws, a city had "autonomia", as opposed to cities being under the law of a foreign power. In biomedical ethics, the word autonomy generally refers to "what makes a life one's own; viz. that it is shaped by personal preferences and choices'. (Beauchamp \& Childress, 1994, p. 58). This definition of autonomy presumes people to be independent, responsible persons, who can live their lives in a rational, individual way. Does such a definition fit the situation of chronically ill people? And does such a definition provide health professionals enough guidance in the approach towards the autonomy of chronically ill people (Agich, 1993; Caplan, 1988)? Stroke patients rehabilitating in a nursing home, for example, are at least partly dependent on other people, particularly in the first months post-stroke. In this thesis the autonomy of stroke patients rehabilitating in nursing homes is explored and elaborated.

\section{STROKE}

Stroke (or cerebrovascular accident) is the third leading cause of death (Central Bureau of Statistics [Centraal Bureau voor de Statistiek], 1998) and causes high morbidity in developed countries (Bergman, van der Meulen, Limburg \& Habbema, 1995). In the Netherlands, the annual incidence of stroke is estimated at $1.74 / 1000$, the prevalence at $6.8 / 1000$ (Meyboom-de Jong \& Buis, 1995). The "social prevalence' of stroke, however, is substantially higher. The concept "social prevalence" indicates that more people than simplly the patient are involved with the disease (Knottnerus, Metsemakers, Höppener \& Limonard, 1992). Stroke survivors often experience health problems post-stroke: impaiments, disabilities and handicaps (Anderson, 1992), and mostly are in need of further rehabilitation. Recovery from stroke includes dealing with residual dysfunction (physical, sensory-perceptual, cognitive, and/or psychosocial) (Barton \& Sullivan Black, 1993). Rehabilitation aims at decreasing the consequences of the illness for daily functioning, and focuses more on the health 
problems caused by the illness than on the illness per se (Raad voor Gezondheidsonderzoek, 1997). Heallih problems are often classified according to the International Classification of Functioning and Disability (ICIDH-2) for clinical and research purposes (World Health Organization, 1999). In the Netherlands, stroke rehabilitation frequently takes place in a hospital, and subsequently (if continuation is necessary) in a rehabilitation center or nursing home (Bergman et al., 1995). Stroke rehabilitation programs are intensive and diverse, and require a multidisciplinary team of health professionals specially trained in how to approach stroke patients. In any case doctors (specialists in neurology or rehabilitation, nursing home physicians, general practitioners), nurses, physiotherapists, occupational therapists, speech therapists and social workers are involved in stroke rehabilitation (Dutch Institute for Health Care Improvement CBO [Kwaliteitsinstituut voor de Gezondheidszorg CBO], 2000). Indeed, to underscore the importance of stroke care, adequate care for stroke patients accounts for $3.2 \%$ of total health care costs in the Netherlands (Konings-Dalstra \& Reitsma, 1999).

This thesis focuses on those stroke patients temporarily admitted into nursing homes for rehabilitation. In 1997 the total number of stroke patients admitted into a nursing home was estimated to be 9375 , of whom about $11 \%$ had been discharged from hospital (Konings-Dalstra \& Reitsma, 1999). The stroke patients temporarily admitted are mostly placed in a rehabilitation ward or stroke unit (short stay), where their rehabilitation is supported by a multidisciplinary team.

\section{STROKE, AUTONOMY AND LONG-TERM CARE}

Stroke patients admitted to a rehabilitation ward are mostly older patients, and have often multi-morbidity. In these patients, autonomy is threatened not only by the occurrence of the stroke (Nilsson, Jansson \& Norberg, 1997, 1999), by post-stroke disabilities and multi-morbidity, but also by the institutionalization (first in the hospital, second in the nursing home). They are at least partly dependent on other people, and are less autonomous than they were pre-stroke, as could be expected. After discharge from nursing home, they are supposed to live their lives in their own home or in an old people's home, which requires them to be autonomous to a greater or lesser degree. However, after discharge there are often problems. 'Samen Verder' ['Continuing Together'], a Dutch organization of stroke patients and spouses, refers to this situation as the "black hole', a phenomenon which occurs when stroke patients return to their homes and do not know how to continue their lives. This situation requires much social support given by the spouse or the family. In the long run social support may be too heavy a burden for informal caregivers (Scholte op Reimer, de Haan, Rijnders, Limburg, \& van den Bos, 1998).

The stroke patients' preparation for the situation after discharge leaves much to be desired, and psychosocial rehabilitation has not received adequate attention 
(Meyboom-de Jong \& Buis, 1995; Konings-Dalstra \& Reitsma, 1999). In a previous study, it was found that health professionals in nursing homes felt themselves responsible for guiding the stroke patients and for shaping conditions for regaining autonomy and active learning. However, providers added that their attention for autonomy decreased during rehabilitation (Proot, Crebolder \& ter Meulen, 1996). A conference held in 1995 in Hoensbroek, the Netherlands, on multidisciplinary guidelines focussing on the care for patients with stroke, rheumatoid arthritis or diabetes mellitus underlined the inadequate attention paid to the patient's role and patient's autonony in these multidisciplinary guidelines (Proot \& Ritzen, 1996). Elsewhere too, patient autonomy in chronic illness and. long-term care has been seen as deserving more attention. In the United States, in 1993 a consensus conference was held in Oregon on current barriers to autonomy of residents in long-term care facilities, and on how to prevent these barriers in future programs and policies (Gamroth, 1995).

\section{STUDIES ON AUTONOMY AND LONG-TERM CARE}

Several empirical studies have investigated patient autonomy in long-term care. In a qualitative study on autonomy in the setting of home care, nurses and patients with a chronic illness living at home were interviewed (Pool, 1995). The conclusion was that nursing care in the home care situation should include not only respect for patient autonomy but also restoration of autonomy. According to Pool, autonomy regarding long-term care can be best interpreted as a process, because illness affects autonomy. Pool did not investigate whether different phases in this process needed different approaches. Stüssgen (1997) interviewed 33 chronic patients in specialist care (type 1 diabetics and lung patients) on personal autonomy. Using a qualitative approach (grounded theory), he identified different types of patients. Self-willed patients primarily orient themselves on their own experiences and wishes. Submissive patients primarily are oriented by medical norms and rules prescribed by the doctor. Balancing parients value their own expertise as well as the medical expertise of the doctor.

In a study on the quality of nursing home care, Mattiasson \& Andersson (1997) interviewed 60 competent nursing home residents (the average length of stay in the nursing home was two years) suffering from chronic illness about quality of nursing home care. They operationalized the quality of nursing home care as the discrepancy between individual priorities (i.e. degree of perceived personal autonomy) and institutional possibilities. The questionnaire used in the interviews included questions with fixed responses and open response questions (data from the open response questions were not reported on). The respondents interviewed appreciated developing and maintaining social contacts more than influencing daily routines. Taes, van Campen \& Kerkstra (1996) reported on the first phase of the development of a measurement scale concerning experienced autonomy intended for nursing home residents. After studying literature, focusstatements were developed via the method known as "concept mapping". Group 
sessions with residents of two nursing homes resulted in a number of statements on "experienced autonomy". Based on this study, a subscale 'perceived autonomy' has been developed and tested as subscale of an instrument assessing perceiwed quality of life of physically firail elderly patients in nursing homes by Van Campen \& Kerkstra (1998). They concluded that this subscale warranted further study.

In sum, the existing empirical studies on patient autonomy focus on home care, on specialist care, and on nursing home residents (long-stay). To the best of our knowledge, there is no study that focuses particularly on the autonomy of (stroke) patients rehabilitating in nursing homes. Future research on this topic is thus warranted.

\section{OBJECTIVES AND METHOD OF THE STUDY}

This thesis reports on a research project with regard to the promotion of the autonomy of stroke patients rehabilitating in nursing homes. The long-term purposes of this project are twofold: firstly, to identify what areas need special attention regarding patient autonomy during different phases in the rehabilitative process; secondly, to make recommendations about the providers" approach to the stroke patients" autonomy in view of the patients' returning home. The project started with the following global research question:

In which way can providers contribute to the maintenance and/or recovery of the stroke patient's autonomy during rehabilitation post-stroke?

The project aims to contribute to the quality of care and the quality of life of stroke patients. Attention to patient autonomy may improve the patients" quality of life (during admission and after discharge), may decrease the patients' problems after discharge, and may diminish the families' care burden.

In 1995-1998 the study was performed in three nursing homes in the region of Limburg, the Netherlands: Martinushof in Tegelen, Schuttershof in Brunssum and St. Camillus in Roemond. A qualitative research method, the grounded theory approach (Strauss \& Corbin, 1990), was used to explore the perspectives and experiences of stroke patients and health providers on patient autonomy and on the approach to patient autonomy. This approach was chosen because very little is known about the phenomenon under study, and because the final recommendations of the project are intended to be used by providers. The study aimed at the description of the phenomenon itself, and did not focus on quantitative outcomes. The grounded theory approach provides strategies for developing theories and concepts fitting to a particular field or practice. Theories and concepts are "discovered, developed and provisionally verified through systematic data collection and analysis pertaining to that phenomenon' (the phenomenon studied) (Strauss \& Corbin, 1990, p. 23). Important principles in 
the grounded theory approach are constant comparison and theoretical sampling of the data.

Semi-structured interviews with patients and health professionals were chosen to investigate how respondents themselves describe and value autonomy, and which facilitating and constraining factors they experience and identify. The interviews of patients and providers have been analyzed separately, in order to spot different perspectives and needs, if any, which is important with regard to the long-term purposes of the project, that is improving the quality of care. The patient interviews have been analyzed on group level (the interviews of all participating patients on a particular moment, e.g. on admission) to describe specific needs and experiences in a particular phase of the rehabilitation process (see chapters 4-6), and on patient level (longitudinal analysis: all interviews of one particular patient analyzed as a whole) to identify particular patterns in the patients' changing needs and experiences during the rehabilitative process (see chapter 7). The provider interviews have been analyzed on group level. Data collection and analysis proceeded simultaneously. The categories used to organize the results from the study are not derived from theory and predefined, but are based on the orientations and values of patients and providers. Interviews and field notes were coded. Themes related to autonomy of stroke patients were grouped, compared and categorized. Both descriptive coding and theoretical coding were used: descriptive coding to explore stroke patients' autonomy, and theoretical coding to develop a theory in order to clarify relationships between concepts and to facilitate the development of a theoretical framework.

Data triangulation, investigator triangulation and methodological triangulation (Denzin, 1989) were used to broaden the analysis of the phenomenon of stroke patient's autonomy, and to secure content validity (Sim \& Sharp, 1998). Respondents admitted to (patients) or working in (providers) different nursing homes and with varying socio-demographic variables participated in the study (data triangulation). There were two interviewers, and peer debriefing during analysis was used (investigator triangulation). Apart from individual in-depth interviews, member checks were held (methodological triangulation). 'Member checks" means that group meetings were organized with the respondents (patients and providers separately), where the results of the analysis were discussed.

In the study the core category 'Changing autonomy' was developed, based on the interviews with the stroke patients and the health professionals. "Changing autonomy' identifies the process of stroke patients regaining their autonomy, and the different factors affecting this process.

\section{OUTLINES OF THE THESIS}

The structure of this thesis follows the respective phases of the study.

Chapter 2 reports on a literature survey and a concept analysis on the phenomenon of autonomy in relation to the rehabilitation of stroke patients. 
What is meant precisely by patient autonomy? What are the theoretical underpinnings of this concept? And what is the role of caregivers regarding patient autonomy?

In chapter 3 the perspectives on autonomy of health professionals in nursing homes are described. Which aspects of the stroke patient's autonomy during the different phases of the rehabilitative process and which factors influencing patient autonomy during this process do health professionals identify?

Several studies were undertaken with regard to the stroke patients' experiences and perceptions on autonomy. Patients were interviewed shortly after admission, during rehabilitation, and just before discharge. Chapters 4 through 6 focus on the patients" autonomy as experienced by stroke patients themselves during the different phases of their rehabilitative processes, and on the factors influencing their autonomy during this process.

In chapter 7 , the results of a longitudinal analysis of the patient interviews are presented. The interviews of one particular patient were analyzed together looking for facilitating patterns in the health professionals" approach. In which way can health professionals facilitate the restoration of the stroke patients" autonomy in the different phases of the rehabilitative process?

Chapter 8 discusses the results of the study in the context of theoretical discussions in bioethics. Advantages and limitations of empirical ethical research mentioned in the bioethical literature are summarized. The contribution of the present study to the field of bioethics in long-term care and rehabilitation, and the method used are discussed. Finally, conclusions with regard to empirical studies in bioethics are drawn and recommendations are advanced.

In chapter 9 , the main results of the study are discussed. The methodological strengths and limitations of the study, and implications for clinical practice, for education and training, for policies in nursing home care, and for further research are elaborated. Finally, a summary of the content of this thesis was given in chapter 10 .

This thesis is compiled of articles, which have been published or submitted separately. This is the reason for some overlap in description of literature, methods and results.

\section{REFERENCES}

Agich, G.1. (1993). Autonomy and long-term care. Oxford: Oxford University Press.

Anderson, R. (1992). The aftermath of strote. The experiences of patients and their families. Cambridge: Cambridge University Press.

Barton, L.A., \& Sullivan Black, K. (1993). Learning treatment strategies applied to stroke relabilitation. In Gordon, W. A. (Ed.), Adrances in stroke rehabilitation. Boston: Andover Medical Publishers.

Beauchamp, T.L., \& Childress, J.F. (1994). Principles of biomedical ethics. Oxford: Oxford University Press.

Bergman, L., van der Meulen, J.H.P., Limburg, M., \& Habbema, J.D.F. (1995) . Costs of medical care after first-ever stroke in the Netherlands. Stroke, 26, 1830-1836. 
Caplan, A.L. (1988). Informed consent and provider-patient relationslups in rehabilitation medicine. Archives of Physical Medicine and Rehabilitation, 69,312.317.

Central Bureau of Statistics (CBS). (1998). Deaths by causes of decaths, age and gender. Voorburg: CBS

Denzin, N. K. (1989). The research act: a theorerical introduction to sociological methods. Englewood Cliffs: Prentice Hall.

Dutch Institute for Health Care Improvement CBO. (2000). Richtijn Beroerfe. [Stroke guideline]. Utrecht: $\mathrm{CBO}$.

Dworkin, G. (1995). The theory and practice of autonomy. Cambridge: Cambridge University Press.

Gamroth, L. (1995). Introduction: setting the stage for change. In L. M. Gamroth, J. Semradek, \& EM. Tornquist (Eds.). Enhancing autonomy in long-ferm care. Concepts and strategies (Xv-Xviii). New York: Springer.

Knotnerus, J.A., Metsemakers J., Höppener P., \& Limonard, C. (1992). Chronic illness in the community and the concept of "social prevalence'. Family Practice, $9,15-21$.

Konings-Dalstra, J.A.A., \& Reitsma, J.B. (1999). Hart-en vaatziekten in Nederland. Ciffers over ziekile en sterfte. [Cardiovascular diseases in the Netherlands. Morbidity and mortality rates]. Den Haag: the Netherlands Heart Foundation.

Mattiasson, A., \& Andersson, L. (1997). Quality of nursing home care assessed by competent nursing home patients. Joumal of Advanced Nursing, 26, $1117-1124$.

Meyboom-de Jong, B., \& Buis, J. (Eds.). (1995). Zorg ma een beroerte. [Care after a stroke] Den Haag: the Netherlands Heart Foundation.

Nilsson, I., Jansson, L., \& Norberg. A. (1997). To meet with a stroke: patients' experiences and aspects seen through a screen of crises. Joumal of Advonced Nursing, 25, 953-963.

Nilsson, 1., Jansson, L., \& Norberg, A. (1999). Crisis phenomena after stroke reflected in an existential perspective. Intemational Joumal of Aging and Human Developmen, 49, 259. 277.

Pool, A. (1995). Autonomie, afhankelijkheid en langdurige zorgverlening. [Autonomy, dependence and long-term care]. Utrecht: Lemma.

Proot, I.M., Crebolder, H.F.J.M., \& ter Meulen, R.H.J. (1996). Protocollaire zorgverlening aan CVA-patienten in een verpleeghuis: autonomie en verantwoordelijkheid. Een exploratieve studie [Guidelines in the care for stroke patients in nursing homes: autonomy and responsibility. An exploration]. Neuroniewus, II, 567-571.

Proot, LM., \& Ritzen, W. (Eds.). (1996). Prolocollering van Zorg. Verslag van de werkonferentie over multidisciptinate protocollen in de zorg voor menwen met CVA. reuma en diabetes. ICare guidelines. Procedings of a conference on multidisciplinary guidelines in the care of people with stroke, rheumatoid strthritis and diabetes.] Hoensbroek: Synchron.

Raad voor Gezondheidsonderzoek (RGO). (1997). Advies revalidatieonderzoeh. Advice on rehabilitation research]. Den Haag: RGO.

Scholte op Reimer, W.J.M., de Haan, R.J., Rijnders, P.T., Limburg, M., \& wan den Bos, G.A.M. (1998). The burden of caregiving in partners of long-term stroke survivors. Stroke, 29,1605-1611.

$\operatorname{Sim}_{y}$ J., \& Sharp, K. (1998). A critical tappraisal of the role of triangulation in nursing research. International Jounal of Nursing Studies, 35, 23-31.

Stüssgen, R.A.I. (1997). De mieuwe patient op weg naar amonomie. [The new palticnt on the way to atunomy]. Amsterdam: Thesis/Thela.

Strauss, A., \& Corbin, J. (1990). Basics of qualiative reseanch: grounded theory procedures and techniques. Newbury Park: Sage.

Taes, C.G.I., van Campen, C., \& Kerkstra, A. (1996). Ervarcn autonomic en ervaren veiligheid bij somatische verpleeghuisbewoners. [Experienced autonomy and experienced safety for somatic nursing home patients]. Kwaliteit en Zorg [Quality and Carc], 4, 52-62. 
Ter Meulen, R.H.J. (1994). Verschraalde zorg? Over aulonomie, "dentiteit en zingeving in de zorg yoor hulpbehoevende ouderen. Oratie. [Decreased care? About autonomy, identity and giving meaning in the care for dependent elderly. Inaugural lecture]. Vught: Radboudstichting.

Van Campen, C., \& Kerkstra, A. (1998). Ervaren kwaliteit van leven van oudere somatische verpleeghuispatiënten. Constructie van een meetinstrument. [Perceived quality of life of physically frail elderly patients in nursing homes. Construction of a measuring instrument]. Tijdschrift woor Gerontologie en Geriatrie [Journal for Gerontology and Geriatrics], $29,11-18$.

World Health Organization. (1999). ICIDH-2: International Classiffeation of Functioning and Disability. Beta-2 draft, Full Version. Geneva: WHO. 


\title{
Chapter 2
}

\section{Autonomy in the rehabilitation of stroke patients in nursing homes. A concept analysis}

\begin{abstract}
This article presents a concept analysis of autonomy in relation to the rehabilitation of stroke patients. Analysis of the results of a literature survey provided three important concepts of autonomy in the field of biomedical ethics: self-governance, self-realization and actual autonomy. These concepts are compared with concepts from caring sciences and summarized in a table. The results indicate the importance of the social environment (formal and informal caregivers) for the restoration of autonomy. Because of the patient's condition and context, a social concept of autonomy makes more sense in the rehabilitation of stroke patients in nursing homes than does an individual concept. The concept analysis sheds light on the fact that the majority of studies regarding patient autonomy are primarily based on theoretical reflections, not on empirical studies. More research is warranted to gather information on how patients themselves consider and appreciate autonomy during rehabilitation, to explore the views of stroke patients' formal and informal caregivers and to investigate whether a social concept of autonomy is suitable for all phases of rehabilitation. Concerning the practice of rehabilitation, no definite conclusion can be given as yet.
\end{abstract}

Published as:

IM Proot, HFJM Crebolder, H Huijer Abu-Saad, RHJ ter Meulen. (1998). Autonomy in the rehabilitation of stroke patients in nursing homes. A concept analysis. Scandinavian formal of Caring Sciences, 12, 139-145.

Will be re-published as:

IM Proot, HFJM Crebolder, H Huijer Abu-Saad, RHJ ter Meulen: Autonomie bei der Rehabilitation von Schlaganfallpatienten in Pflegeheimen - eine Konzeptanalyste. In: BM Hack (Ed), : Ethik in der ergotherapie. Springer. Berlin/Heidelberg, 2001 (in press). 


\section{INTRODUCTION}

Stroke patients temporarily admitted to nursing homes for rehabilitation often feel confused, anxious and insecure in the first months after the stroke. They are dependent on other people. Yet, after discharge they are supposed to live more or less independently. One problem after discharge mentioned by "Samen Verder", a Dutch organization of stroke patients and spouses, is what is called 'the black hole'. This phenomenon occurs when stroke patients return to their homes and do not know how to live their lives, because the situation is completely different from that before their strokes.

An important aim of the rehabilitation process is the transition from dependence to independence. One major theme is patient autonomy. To be autonomous means not only to be independent of others, but to act according to your own standards and ideals as well. Patient autonomy is decreased in most cases post-stroke: not only are the physical capabilities of the patient diminished, but also patient's life plans are suddenly interrupted as a result of the stroke. What precisely is meant by patient autonomy? What are the theoretical underpinnings of this concept? And what is the role of caregivers regarding patient autonomy?

This article presents a concept analysis of the phenomenon of autonomy in relation to the rehabilitation of stroke patients. To this end, concepts and theoretical formulations have been analyzed and concisely summarized.

\section{METHODS}

In order to identify different concepts of autonomy, a literature survey was carried out: A Medline search using the keywords 'stroke', 'rehabilitation' and 'ethics' simultaneously yielded one single related article, and a Psyclit search using the same keywords found no articles. Next, a Medline search was carried out using the keyword 'stroke' combined with the keywords 'rehabilitation', 'ethics', 'autonomy', 'independence', 'psychosocial', 'motivation' and 'nursing homes' (for the period January 1966 to May 1997). This crude search resulted in 364 articles. In addition, the Psyclit index was consulted with the same keywords (for the period January 1974 to May 1997), yielding 441 articles. These articles were examined further by means of the abstracts. Articles concerning medical treatment, stroke prevalence, technology, other diagnoses, cuthanasia, comparison of delivered care, validity of measurement scales, predictive models, studies of patients six months or longer post-stroke, and articles not written in English, Dutch, German or French were excluded. Thirtyone articles appeared to be related to rehabilitation, stroke and autonomy.

Furthermore, the libraries of a number of institutes were consulted, such as the Cochrane Collaboration Center, Maastricht University, Institute for Bio- 
ethics (IGE) and the Dutch Institute for Health Care Improvement CBO. Finally the snowball method was used to cover as much territory as possible.

While scarcely any literature was found concerning autonomy and the rehabilitation of stroke patients, secondary literature was found about patient autonomy and related concepts in rehabilitation practices and residential longterm care. The concepts found were analyzed in relation to the rehabilitation of stroke patients in nursing homes.

\section{RESULTS}

In this section, the results of the concept analysis are summarized and discussed. Firstly, concepts of autonomy from biomedical ethics are presented with regard to the patient, the formal caregiver and the informal caregiver (mostly husband, wife, daughter or son, but also friends). Secondly, concepts from rehabilitation practices and nursing home care are summarized under self-care and self-care limitations, and formal care. These concepts from caring sciences are juxtaposed with the concepts from biomedical ethics.

\section{Patient autonomy in biomedical ethics}

In biomedical ethics, there are four important principles along which decisionmaking in health care should take place: non-maleficence, beneficence, respect for autonomy, and justice (1). Respect for patient autonomy has increased in importance over the last two decades. It has been developed in reaction to the paternalistic attitude of doctors towards their patients, i.e. "the doctor knows what's good for you'. Regarding patient autonomy, three sensitizing concepts are often encountered in the bioethical literature: self-governance, selfrealization and actual autonomy.

\section{Autonomy as self-governance}

The concept of autonomy emphasizes the informed self-governance of the patient. In medical ethics, autonomy is generally defined as 'to act voluntarily and consciously without any constraint'. Informed consent is fundamental in respect to patient autonomy, according to Beauchamp and Childress (1). They distinguished between personal autonomy and autonomous choices. Personal autonomy is defined as follows: '(...) as distinguished from political self-rule: personal rule of the self that is free from both controlling interferences by others and from personal limitations that prevent meaningful choice, such as inadequate understanding." (1:121). Autonomous choices indicate consents and refusals (e.g. about treatment) and concern actions, not persons (1). An autonomous person can make non-autonomous choices, and vice versa.

Autonomy as self-governance is related to the political, liberal ideal of freedom, which is seen mainly as freedom from political and social restraints. The liberal concept of autonomy has had an important impact in our western 
society, and has been the object of study for philosophers, particularly J.S. Mill (2). He defended an idea of individual autonomy or self-governance unrestricted by political and social rule. The only limit to individual autonomy is the autonomy of other persons. In this liberal view on autonomy, there is a sharp division between the social and the political spheres on the one hand, and the individual sphere on the other. Conceptions of "the good life" should not be promoted in the political sphere by the state or society in general. Such societal views on "the good life" would result in restrictions on personal autonomy. Society should restrict itself to procedures which enable individuals to develop their own conceptions of 'the good life' in their private lives. For this reason, the liberal concept of autonomy has also been termed 'negative freedom" (3), as it emphasizes the ideas of non-interference in the lives of individuals.

Autonomy as self-govemance presumes people to be autonomous, responsible persons, who can live their lives in a rational, individual way. In the rehabilitation of stroke patients admitted to mursing homes, such an individual definition is problematic, because these patients are at least partly dependent on other people, particularly in the first months post-stroke.

\section{Autonomy as self-realization}

In medical ethics, several authors emphasized another sense of the concept of autonomy, namely self-realization. Self-realization is more than doing freely what one chooses. This concept includes the way one shapes and lives one's own life and expresses individuality. This sense of autonomy, which emphasizes the content of autonomy, has been also termed 'positive freedom" (3), as distinguished from 'negative freedom' in the liberal tradition. For example, Miller (4) stated that here are at least four senses of the concept as it is used in medical ethics: autonomy as free action, autonomy as authenticity, autonomy as effective deliberation, and autonomy as moral reflection' (4:24). The first and third senses are related to 'negative freedom', the second and fourth senses to 'positive freedom'. Autonomy as authenticity means that one acts consistent with one's attitudes, values, dispositions and life plans. Furthemore, autonomy as moral reflection presumes that one accepts the moral values on which one acts as one's own values.

What is important here is the way one discovers and accepts moral values. What is the role of society and culture in this respect? From a philosophical point of view, Taylor (5) has pointed out the risk of a limited and individualistic interpretation of the concept of authenticity. Authenticity merely used as discovery and development of the self as an unencumbered being does not do justice to a cultural and societal influence on the moral development of the individual person. Discovery and development of the self always take place against the background of social and cultural walues.

Stroke patients meet unexpected barriers with regard to self-realization. An important aim of the rehabilitation process is to integrate impairments and disabilities into a new 'post-stroke identity'. Full self-realization is an important, long-term goal in this process. 


\section{Actual autonomy}

Agich (6) made a plea for a dynamic and concrete concept of autonomy. He stated that autonomy in long-term care is not a static concept, but one that changes over time. Expressions of autonomy show not only who the person is, but also who the person is becoming. If the concept of autonomy is to play a significant analytical and practical role in the long-term care setting, where people are in need of help from others, then it must be a concept that acknowledges the essential social nature of human development and recognizes dependence as a nonaccidental feature of the human condition" (7: 12). Agich defined autonomy in chronic care as "actual autonomy". Actual autonomy means that autonomy depends on a person's current development and environment. In fact, this sense of autonomy emphasizes the contextuality of autonomy: one can only realize one's autonomy in relation to one's social and physical context. This is particularly true for long-term care, where one is highly dependent on one's context.

\section{Patient autonomy and formal care}

Actual autonomy means that patient autonomy is contextual, as we have seen in the previous section. Autonomy depends, for example, on the relationships with professional caregivers. In the Netherlands, a multidisciplinary team (nurses, therapists, doctors, social workers and other caregivers) is involved in the rehabilitation of stroke patients in nursing homes. These health professionals try to support the patient in such a way that he or she can make a choice according to his or her identity. However, autonomy depends on the choices available: only meaningful choices will increase individual development and thus enhance autonomy. This means that care providers should proffer choices with which the patient can identify himself or herself (6). For example, therapeutic activities should harmonize with a patient's life history.

Jennings et al. (8) allso emphasized the relationship between the patient and the caregiver regarding patient autonomy in chronic care. They did not tackle the notion of autonomy, but wamed against an individualist interpretation of the concept in practices of chronic care. In their opinion, "Autonony is not some a priori property of persons abstractly conceived. It is an achievennent of selves who are socially embedded and physically embodied'. (8: 12). Autonomy develops within the relationship between the patient and the care provider, while the patient gets used to the new situation, namely having a chronic disease. For example, stroke patients have to deal with impairments and disabilities (sensorymotor, communicatiwe and/or cognitive).

\section{Patient autonomy and informal care}

Medical ethics predominantly focuses on the protection of patient autonomy visw $a-v i s$ the formal caregiver (most of the time the doctor), but not $v i s-i \omega v i s$ the informal caregiver (most of the time the family). The reason is that the principle of respect for patient autonomy has been developed in reaction to the paternalistic attitude of doctors towards their patients and not in relation to the 
patient's family. In medical ethics, the role of the family has only been described in relation to the incompetent patient, for example, when the family acts as legal representative of the patient, but mot with regard to enhancing the exercise of autonomy. However, one can imagine that the family might restrict the autonomy of the patient by taking care of everything, for example, when the patient has communicative impaiments.

\section{Patient autonomy in rehabilitation practices and nursing home care}

The following sections concern autonomy-related concepts from rehabilitation practices and nursing home care. These concepts are summarized under self-care and self-care limitations, and formal care, and are juxtaposed with the concepts from biomedical ethics.

\section{Patient autonomy, self-care and self-care limitations}

Autonomy relates to self-care, a concept much used in literature about nursing and rehabilitation. Self-care is essential for human functioning. Human beings learn to care for themselves and develop knowledge about self-care. In her studies of nursing practice, Orem (9) described self-care as follows: 'The practice of activities that maturing or mature persons initiate and perform, within time frames, on their own behalf in the interests of maintaining life, healthful functioning, continuing personal development, and well-being' (9: 461). Selfcare implies an investigative and decision-making phase (determining what you do and can do) as well as a production phase (acting) (9). Orem's definition of self-care combines with the ethical concept of autonomy as self-realization. Self-care implies psychological, physiological and social activity in which one expresses and develops one"s own identity, which is central to the concept of autonomy as self-realization.

In relation to self-care, Orem developed the concept 'dependent care". Dependent care is defined as 'the practice of activities that responsible maturing and mature persons initiate and perform on behalf of socially dependent persons. for some time on a continuing basis in order to maintain their lives and contribute to their health and well-being' (9:457). Dependent care mostly develops when family or friends are in need of help.

Self-care limitations influence the operations of self-care restrictively. Orem identified three kinds of limitations: of knowledge, for making judgements and decisions, and for engagement in result-achieving courses of action. Orem stated that self-care limitations are 'restricting human and environmental influences within time frames on persons" performance of the investigative, judgement and decision making, and production operations of self-care" $(9: 461)$.

Self-care limitations are related to both personal and environmental restrictions. Stroke patients experience personal restrictions especially in the beginning of their rehabilitation processes, for example, because of sensory-motor 
impaiments which might influence performance tasks. Environmental restrictions include the roles of the caregivers, both formal and the informal. When one is dependent on others, e.g. in activities of daily living, it depends partly on the caregiver's way of helping if one feels dependent or autonomous. This view corresponds with the concept of 'actual autonomy' as advacated by Agich (6).

\section{Patient autonomy and formal care: rehabilitation practices}

Banja (10) described ethical issues in staff development conceming rehabilitation of patients suffering from brain injury. Autonomy is a challenging ethical theme in this particular setting. Brain injury affects the patient"s autonony to greater or lesser degree especially in the beginning of the rehabilitation process. On the other hand, the final purpose of this process is the restoration of the patient's autonomy: the patient becomes more and more responsible for his or her actions and decisions. During the rehabilitation process, the careprovider, as a part of the rehabilitation environment, changes his or her approach. "(...) the ideal rehabilitation outcome will be one that advances the client toward a return of decisional and functional capacity and a proportional restoration of the client's autonomy. That restoration inevitably implies the client" assuming responsibility for this or her actions and decisions, which in turn requires the provider's gradually relinquishing the protective orientation he or she may have assumed initially toward the client" (10:26-27). In Banja's opinion, professional caregivers often interpret independence as only physical non-dependence. He states that independence emphasizes one's capacity and desire to express who one is, to express one's uniqueness, plans, and life projects. Professional caregivers working in a rehabilitation unit should be keenly sensitive to those expressions and not regard them as instances of non-compliance when they seem to contradict or oppose the treatment plan. Rather, they may be the client"s first attempts to reclaim his or her dignity, assertiveness, and sense of control. Thus, a change in approach and much attentiveness on the part of the careprovider are of major importance.

The same could be expected to apply in the rehabilitation processes of stroke patients. Banja's view on autonomy and rehabilitation underlines the importance of the social context of the patient as a vital condition in the restoration of patient autonomy.

\section{Patient autonomy and formal care: nursing home care}

This section particularly concerns studies regarding residents of nursing homes. Although the research question concerns stroke patients temporarily admitted to mursing homes, a short presentation of the results of these studies seems worthwhile.

Van Campen \& Kerkstra (11) studied the quality of life concept among mursing home residents with somatic diseases. In the literature, they found 'autonomy' as a component of quality of life, and operationalized "experienced autonomy' of nursing home residents as privacy, authority and independence (the latter intended as more than physical independence). They concluded that 
there are no measurement scales concerning experienced autonomy. Taes et al. (12) reported on the first phase of the development of a measurement scale concerning experienced autonomy intended for nursing home residents. Mattialsson \& Andersson (13) interviewed sixty chronically ill but competent nursing home patients (the average length of stay in the nursing home was two years) about quality of nursing home care. They operationalized quality of nursing home care as the discrepancy between individual priorities (i.e. degree of perceived personal autonomy) and institutional possibilities. The patients interviewed appreciated developing and maintaining social contacts more than having an influence on daily routines.

Van der Wulp (14) studied the lives of nursing home residents, focussing especially on their perceptions of their impairments, of living in a nursing home and of time frames. He found a state of conflict, a gap between their will and physical disabilities, and concluded that the autonomy of physically dependent people is at stake when they need help from others. Careproviders should be wary of what he called 'the dependency conflict'. It is important to pay attention not only to how careproviders help the patient, but also to how the care recipient reacts in turn, and to talk with him or her about this reaction. This view links up with the ethics of care as advocated by Tronto (1.5), who emphasized the responsibility of the care provider. Responsibility includes caring about the needs of the other, taking care of those needs and recognizing that you can meet them. However, in Tronto's opinion, this can only be realized on the condition that the other person is responsive to the help given. The views of van der Wulp and Tronto correspond with Agich's concept of 'actual autonomy' (6). Because dependency conflicts could be expected in the rehabilitation of stroke patients, an attentive approach is required.

\section{DISCUSSION}

There are three concepts of autonomy from biomedical ethics related to the rehabilitation of stroke patients: self-governance, self-realization and actual autonomy. These concepts have implications for the patient, for the environment of the patient (the formal and informal caregivers), or for both. Table 1 presents an overview of the results.

The keywords from the concepts of autonomy and related concepts regarding the rehabilitation of stroke patients in nursing homes are plotted against the three concepts of autonomy (rows) and against the patient and his or her environment (columns).

The third row (actual autonomy) shows many more keywords in the environmental columns than the first two rows (self-governance and selfrealization). This is not surprising, because the concept of actual autonomy is a social concept of autonomy, which includes support by the environment. On the other hand, the concepts of self-governance and self-realization represent an individual concept of autonomy, which stresses independence and authenticity. 
Table 1. Concepts and keywords with regard to autonomy of the stroke paticnt.

\begin{tabular}{|c|c|c|c|}
\hline \multirow{2}{*}{$\begin{array}{l}\text { CONCEPTS } \\
\text { Concepts of autonomy }\end{array}$} & \multirow{2}{*}{$\begin{array}{l}\text { PATIENT } \\
\text { Patient autionony }\end{array}$} & \multicolumn{2}{|l|}{ ENVIRONMENT } \\
\hline & & Fomal Care & Informal Care \\
\hline Self-governance & $\begin{array}{l}\text { independence } \\
\text { personal rule } \\
\text { individuality } \\
\text { competence } \\
\text { autonomous choices } \\
\text { informed consent } \\
\text { privacy } \\
\text { incompetence }\end{array}$ & $\begin{array}{l}\text { information } \\
\text { respect for privacy }\end{array}$ & Iegal representative \\
\hline Self-realization & $\begin{array}{l}\text { authenticity } \\
\text { own moral values } \\
\text { uniqueness } \\
\text { individuality } \\
\text { development } \\
\text { self-care } \\
\text { self-care limitations }\end{array}$ & meaningful choices & $\begin{array}{l}\text { self-care limitations } \\
\text { dependent care }\end{array}$ \\
\hline Actual autonomy & $\begin{array}{l}\text { relationship } \\
\text { identity } \\
\text { development } \\
\text { dependence } \\
\text { responsiveness } \\
\text { contextuality }\end{array}$ & $\begin{array}{l}\text { relationship } \\
\text { meaningful choices } \\
\text { attentiveness } \\
\text { support } \\
\text { responsibility } \\
\text { changing approach }\end{array}$ & $\begin{array}{l}\text { relationship } \\
\text { attentiveness } \\
\text { dependent care } \\
\text { responsibility }\end{array}$ \\
\hline
\end{tabular}

The results suggest that a social concept of autonomy makes more sense in the practice of rehabilitation of stroke patients than does an individual concept. Stroke patients often feel confused, anxious and insecure within the first months post-stroke, and they are heavily dependent on other people. Therefore, a social concept of autonomy will provide a better ethical framework for the rehabilitation of these patients than will an individual concept of autonomy. Moreover, emphasizing "negative freedom", which advocates non-interference by others, does not have much relevance in the care of stroke patients in the first months post-stroke.

A critical question is whether a social concept is suitable with regard to all phases of the rehabilitation of stroke patients. A significant rehabilitation goal is the transition from dependence to independence. Bearing in mind that the patient is in the process of regaining his or her capabilities, a dynamic approach with 
regard to autonomy is definitely required. Several authors seek convenient models, such as alternating between beneficence and autonomy (16) or a model based on interdependence and deliberation (17). Pool (18) empirically studied autonomy, dependence and long-term care, particularly in the home care setting. He interviewed district nurses, auxiliary nurses and patients with a chronic illnesses living at home. He argued that nursing care should include not only respect for patient autonomy, but also restoration of autonomy. Autonomy regarding long-term care could be best understood as a process, because illness affects autonomy. Pool did not unvestigate whether different phases in this process need different approaches.

In all, this concept analysis sheds light on the fact that the majority of studies regarding patient autonomy are primarily based on theoretical reflections, not on empirical studies. Thus, the concepts found were also theoretical. Empiricallybased studies on patient autonomy deal almost solely with residents of nursing homes, and do not concern patients temporarilly admitted to nursing homes for rehabilitation, e.g. stroke patients.

The analysis indicates at least three major areas for further research on the phenomenon of autonomy in relation to stroke patients. Firstly, more research seems warranted to gather information on how stroke patients themselves conceptualize and appreciate autonomy during the various phases of rehabilitation. Secondly, our analysis of the literature (from bioethics and caring sciences) indicates the importance of context for the restoration of the autonomy of patients with chronic diseases. For this reason, there is also a need for more research to explore the views of formal and informal caregivers of stroke patients. Thirdly, the question as to whether a social concept of autonomy is suitable with regard to all phases of the rehabilitation of stroke patients in the nursing home clearly deserves further investigation.

Concerning the practice of rehabilitation, no definite conclusion can be given as yet. However, the results of our concept analysis indicate the importance of the relationship between health professionals and stroke patients. The multidisciplinary team of health professionals should focus on patient autonomy as a dynamic process which demands a constant fine-tuning of therapeutic interventions and caring practices.

\section{Acknowledgement}

We express our thanks to Prof. George J. Agich, Ph.D., Cleveland Clinic Foundation, for his helpful comments on an earlier draft of this article.

\section{REFERENCES}

1. Beauchamp TL, Childress JF. Principles of biomedical ethies. Oxford: Oxford University Press, 1994.

2. Mill JS. On liberty. Harmondsworth: Penguin Books, 1985. [first published 1859]. 
3. Berlin I. Two concepts of liberty. Four essays on liberty. Oxford: Oxford Universily Press, 1969.

4. Miller BL. Autonomy \& the refusal of tifesaving treatment. Hastings Cent Rep $1981 ; 11(4): 22-8$.

5. Taylor C. The malaise of modernity. Don Mills: Stoddart Publishing. 1991. Republished as: The ethics of authenticity. Cambridge: Harvard University Press, 1992.

6. Agich G.I. Autonomy and long-tem care. Oxford: Oxford University Phess, 1993.

7. Agich GJ Reassessing autonomy in long-term care. Hastings Cent Rep 1990;20(6): 12-7.

8. Jennings $B$, Callahan D, Caplan AL. Ethical challenges of chronic illness. Hastings Cent Rep 1988;18(Suppl 1): 1-16.

9. Orem DE. Nursing: concepts of practice. St. Louis: Mosby, 1995.

10. Banja JD. Ethical issues in staff development. In: Durgin CJ, Schmidt ND, Fryer LJ, eds. Staff development and clinical intervention in brain injury. Maryland: Aspen, 1993:23-41.

11. Van Campen C, Kerkstra A. Kwaliteit van leven van somattische verpleeghuispatiënten. Een begripsverheldering en overzicht van meetinstrumenten. [Quality of life of somatic nursing home patients. A summary of concepts and measurement scales]. Utrecht: NIVEL, 1995.

12. Taes $\mathrm{CGJ}$, van Campen $\mathrm{C}$. Kerkstra $\mathrm{A}$. Ervaren autonomie en ervaren veiligheid bij somatische verpleeghuisbewoners. [Experienced autonomy and experienced safety for somatic nursing home patients]. Kwaliteit en Zorg [Quality and Care] 1996:4:52-62.

13. Mattiasson A, Andersson L. Quality of nursing home care assessed by competent nursing home patients. In: Autonomy in nursing home settings. Mattiasson A, ed. Stockholm: Karolinska Institute, 1995: Sudy 5, I-14.

14. Van der Wulp JC. Verstoring en verwerking in verpleeghuizen. [Lmpairments and their resolution in nursing homes]. Nijkerk: Intro, 1986.

15. Tronto IC. Moral boundaries: a political argument for an ethic of care. New York: Routledge, 1994.

16. Meier RH, Purtilo RB. Ethical issues and the patient-provider relationship. Am J Phys Med Rehabil 1994;73:365-6.

17. Wegener ST. The rehabilitation ethic and ethics. Rehabilitation Psychology 1996;41:5 17.

18. Pool A. Autonomie, afhankelijkheid en langdurige zorgverlening. [Autonony, dependence and long-term care]. Utrecht: Lemma, 1995. 



\title{
Autonomy in stroke rehabilitation: the perceptions of health professionals in nursing homes
}

\begin{abstract}
Twenty-seven providers from three nursing homes were interviewed on the autonomy of stroke patients in rehabilitation wards. Data were analyzed using the grounded theory method for concept development recommended by Strauss \& Corbin (1990). The core category "Changing autonomy" was developed, which identifies the process of stroke patients regaining their autonomy (dimensions: self-determination, independence, and self-care), and the factors affecting this process (conditions and strategies of patients, strategies of providers and families, and the nursing home). Teamwork on patient autonomy is recommended, which can be stimulated by multidisciplinary guidelines and courses, and by co-ordination of the process of changing autonomy, e.g. by a nurse. Before guidelines and courses can be developed the experiences of stroke patients and their families should be studied.
\end{abstract}




\section{INTRODUCTION}

Stroke survivors experience problems post-stroke: impairments, disabilities, and handicaps (Anderson, 1992). In the Netherlands, patients with considerable residual disability are often admitted to hospital and subsequently to a rehabilitation center or nursing home (Bergman, van der Meulen, Limburg, \& Habbema, 1995). Those stroke patients admitted temporarily into a nursing home for rehabilitation are often placed in a rehabilitation ward (short stay), where their rehabilitation needs a team approach (Caplan \& Stein, 1986; Johnstone, 1987; Stonnington \& Browne, 1987). An important aim of the rehabilitative process is the transition from dependence to independence (Wade, 1992). Indeed, in most cases patient autonomy will be decreased post-stroke; not only are the physical capabilities of the patient diminished, but also the patient's life plans are suddenly interrupted as a result of the stroke. How can one then facilitate patient autonomy during the rehabilitative process?

In a concept analysis on autonomy in relation to the rehabilitation of stroke patients, the authors showed that literature on this particular topic scarcely exists, but that literature on patient autonomy in general does (Proot, Crebolder, Huijer Abu-Saad, \& ter Meulen, 1998). Ethicists have discussed at least three concepts which are important with regard to the stroke patients' autonomy and rehabilitation: self-governance (Beauchamp \& Childress, 1994; Mill, 1985), self-realization (Miller, 1981; Taylor, 1991), and actual autonomy (Agich, 1993). The majority of studies regarding patient autonomy are based on theoretical reflections and not on empirical evidence (see, for example, Beauchamp \& Childress, 1994; Agich, 1993; Banja, 1993). In the literature on rehabilitation practices and nursing home care, related concepts were found which describe the aims of rehabilitation and care, and the environmental support in reaching these aims (Proot et al., 1998). These concepts are, self-care, self-care limitations, and dependent care (Orem, 1995), restoration of autonomy (Banja, 1993; Pool, 1995), privacy, authority, and independence (Van Campen \& Kerkstra, 1995), and attentiveness and responsibility (Van der Wulp, 1986; Tronto, 1994).

Empirically-based studies on patient autonomy deal almost exclusively with permanent residents of nursing homes. Taes, Van Campen, \& Kerkstra (1996) reported on the development of a measurement scale concerning experienced autonomy intended for nursing home residents. Mattiasson \& Andersson (1995) interviewed sixty nursing home residents about quality of nursing home care. They operationalized quallity of nursing home care as the discrepancy between individual priorities (i.e. degree of perceived personal autonomy) and institutional possibilities. The patients interviewed appreciated developing and maintaining social contacts more than influencing daily routines.

In this article, we report on a study of providers caring for stroke patients rehabilitating in nursing homes. This study is part of a large-scale research 
project regarding the autonomy of stroke patients rehabilitating in nursing homes. The long-term purposes of this project are twofold: firstly, to identify what areas need special attention regarding patient autonomy during different phases in the rehabilitative process; secondly, to make recommendations how stroke patients can be best prepared for their return home regarding their own autonomy. Specifically, though, this article seeks to pinpoint which dimensions of autonomy are identified by providers, and to determine which factors, in the providers' perception, influence patient autonomy during the rehabilitative process.

\section{METHOD}

A qualitative research method was chosen because very little is known about the autonomy of stroke patients rehabilitating in mursing homes. Grounded theory (Strauss \& Corbin, 1990) was used to explore the providers' views on the stroke patients' autonomy. This method starts with the descriptions and perceptions of the respondents participating in the study, and not from concepts derived from the literature.

\section{Setting and sample}

The sample consisted of 27 health professionals, 7 men and 20 women, aged between 25-54 years ( $M=36 ; S D=7$ ). All participants were Dutch, and reside and work in the province of Limburg in the south of the Netherlands. Equall numbers of health professionals were recruited from the rehabilitation wards of three nursing homes. These nursing homes had somatic and psycho-geriatric wards, respectively having 224 (12), 256 (5) and 270 (34) inpatient beds in total (between parentheses the respective numbers of temporarily admitted stroke patients at a particular moment). Six (registered) nurses, 7 nursing aides, 3 doctors, 3 physiotherapists, 3 occupational therapists, 3 speech therapists and 2 social workers participated in the study. Their work-experience in the rehabilitation of stroke patients ranged from 2-29 years $(M=10 ; S D=6)$.

The selection of disciplines was based on rehabilitation literature, expertise of the researcher and discussions with nursing home staff. It was decided to interview in each nursing home, 2 nurses and 2 nurses aides (because nurses and nursing aides play an important role in daily care), and one representative of each of the following disciplines, medicine, physiotherapy, occupational therapy, speech therapy and social work. Criteria for the selection of persons being invited for the study were (a) involvement in daily care and rehabilitation for stroke patients on a rehabilitation ward, and (b) a minimum of two years experience with the rehabilitation of stroke patients. In each nursing home, a liaison person from the management gave the researcher the names of persons to be invited. The selected persons received a letter of invitation with information about the study, and were telephoned. After consent was given, arrangements 
were made for an interview. All persons invited responded positively. One intervicw was cancelled because the respondent was ill; he was replaced by a colleague.

An interview guide was developed in the absence of a relevant schedule for questioning about autonomy. Experiences from a previous study (Proot, 1994) and sensitizing concepts derived from literature (Proot et al, 1998) were used to develop an open-ended interview guide. This guide was reviewed by project group members and selected experts (nursing home physicians, ethicists, patient organization, neuroscience nurses, researchers), and accordingly revised. The revised version was used in two pilot intervilews, after which some probing questions were revised.

An important goal of grounded theory is to understand the participants' world as they understand it. Therefore, autonomy and patient autonomy were not defined for the respondents. Respondents were asked how they defined autonomy in general (e.g. "What words do you associate with autonomy?'), and how they defined the stroke patient's autonomy. They were interviewed about constraints on and improvements in autonomy during the rehabilitative process (e.g. "Could you list constraining/facilitating factors for the stroke patient's autonomy?'), and about how health professionals and family approached the patients with regard to autonomy. The interviewer introduced topics and used follow-up probes if necessary to encourage respondents to give more information or examples. The interviews were tape-recorded and transcribed with all identifying data removed. Field notes were kept during and after each interview.

\section{Data analysis}

Analysis of the first interviews began while interviewing was ongoing. The data were analyzed using the constant comparative method as described in grounded theory (Strauss \& Corbin, 1990) with the goal of concept development and beginning theory development. Interviews and field notes were coded. Codes were grouped, compared, and categorized into concepts. Both descriptive coding and theoretical coding were used: descriptive coding to explore the phenomenon, and theoretical coding to develop a theory in order to clarify relationships between concepts and to facilitate the development of a theoretical framework. After analysis of 15 interviews, saturation was reached. The remaining 12 interviews were used to validate the theory developed. The computer program Kwalitan 4.0 was used to store and organize the quallitative data.

Data triangulation, investigator triangulation and methodological triangulation (Denzin, 1989) were used to broaden the analysis of the phenomenon of stroke patient's autonomy, and to secure content validity (Sim \& Sharp, 1998). Representatives of all disciplines involved in daily care, working in different nursing homes, and with varying socio-demographic variables participated in the study (data triangulation); peer debriefing during analysis was used (investigator 
triangulation); apart from individual in depth interviews, member checks were held (methodological triangulation). "Member checks" means that group meerings were organized with the health professionals participating in the study, where the results of the analysis were discussed.

\section{RESULTS}

In this section, dimensions of autonomy in general, and the core category 'Changing autonomy' are discussed. 'Changing autonomy' identifies the process in which stroke patients regain their autonomy. Patient and environmental factors constrain or facilitate this process. Patient factors concern conditions and strategies of the patient. Environmental factors concern the approach and strategies of health professionals and families, and the nursing home as a context (see figure 1, p. 34).

\section{Dimensions of autonomy}

Providers, being asked how they defined autonomy in general, started from their own life experiences. Three dimensions of autonomy were identified, selfdetermination, independence and self-care. Self-determination points at making choices and decisions about one's own life and health, and includes freedom of choice. For example, a provider said:

"To organize my own affairs so that nobody else has to decide for me (...). "To be able to make my own decisions."

Independence (physical, psychological, and social) concerns planning and organizing one's own life, including social contacts and role-taking, and refers to responsibility for one's own life and health care. For example, a provider stressed:

"To do the things I like to do. (..) Without having to bother somebody else. Which means I have to find a way to learn the things I cannot do."

Self-care includes skills (mobility, communication, cognition) and activitics of daily living, necessary for functioning. For example, in the words of a provider:

"In the first place, with the least amount of help from others, and with as few aids as possible. But that last one is not as important. If you can be independent with an aid, then it is better to have it."

The three dimensions identified are related to each other. For example, independence requires making choices and freedom of choice (self determination), which require decision-making skills (self-care). 

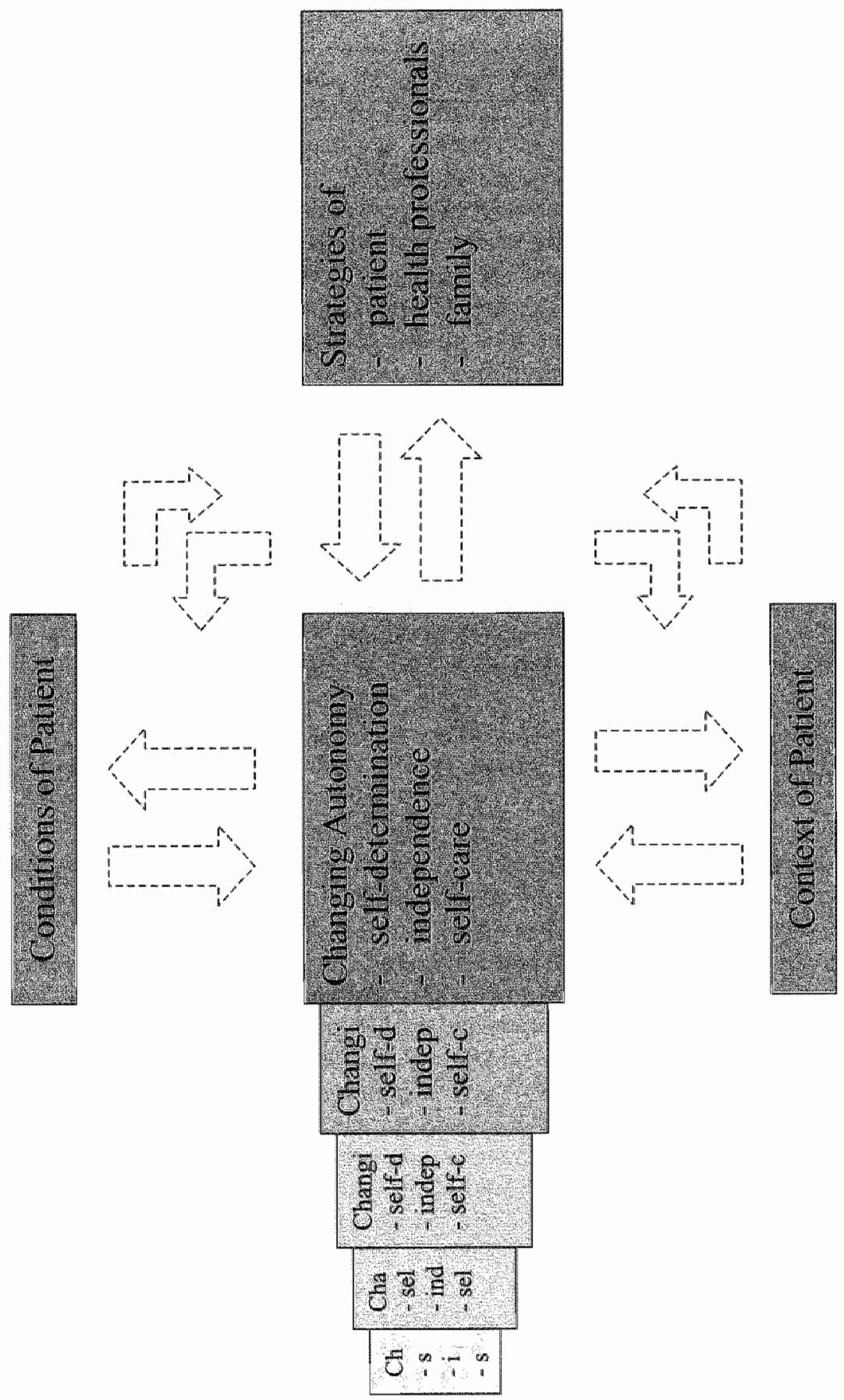

0
0
0
0
0
0
0
0
0
0
0
0
0
0
0
0
0
0
0
0
0
0 


\section{Changing autonomy}

Asked about the autonomy of stroke patients, providers identified the same three dimensions, but stressed the changes in autonomy. On admission, autonomy had been heavily diminished in comparison to autonomy pre-stroke.

"[Autonomy] ... anyway is totally changed. And maybe not impossible, but everything is different and has changed. Very difficult for the patient and his environment to adjust, to give meaning to being alive. To understand what you want, and expect from each other. What you expect and want for yourself. Because your body, your body image, and everything else has changed."

This provider illustrated that all dimensions of autonomy had been changed post-stroke. However, during rehabilitation patient autonomy increases step by step due to a learning process.

"When they first come here, they are quite dependent, and have to ask for" help with everything, granted they can speak. (...) In fact, during that rehab period, you work towards the autonomy of being allowed to, being able to do things by yourself safely. In the last rehab phase when you show you can be independent safely, you work towards discharge whether that is to your home or an old people's home."

At discharge autonomy further increases.

"The discharge phase (..), you work towards as great an autonomy as possible. That they are again, as much as possible, independent without needing help from others."

\section{Patient factors}

\section{Conditions of the patient}

Patient conditions which influence patient autonomy can be divided in conditions post-stroke (disabilities, multi-morbidity, emotional state, expectations (of the nursing home and of the future), feeling like a layperson) and conditions pre-stroke (life history, activity rate, character, multi-morbidity) (sce table 1, p. 36).

Severity and comprehensiveness of disabilities post-stroke changed and constrained patient autonomy. In particular communicative and cognitive disabilities constrained autonomy, and the need for autonomy. 
Table 1. Facilhtating and constraining patient factors regarding autonomy, as identifed by providers in nursing homes.

\begin{tabular}{lll}
\hline Patient factors & Faciliting factors & Constraining factors \\
\hline Prewstroke conditions & $\begin{array}{l}\text { life history } \\
\text { character } \\
\text { high activity rate }\end{array}$ & $\begin{array}{l}\text { life history } \\
\text { character } \\
\text { low activity rate } \\
\text { multi-norbidity }\end{array}$ \\
Post-stroke conditions & $\begin{array}{l}\text { hopeful expectations } \\
\text { responsiveness }\end{array}$ & $\begin{array}{l}\text { pessimistic expectations } \\
\text { disabilities posi-stroke } \\
\text { multi-morbidity } \\
\text { emotional state } \\
\text { feeling like a layperson }\end{array}$ \\
& responsibility/initiative & (no strategies mentioned) \\
\hline
\end{tabular}

"Apraxia. When someone sees his shoelace in his shirt pocket and realizes that shoelace does not belong there. He is mortified when he realizes it, and is so occupied with that mistake that he does not think to fight for own rights."

The providers stressed that in particular when rehabilitation starts, patients often are not ready for self-determination.

"All of this is overwhelming in the beginning, there are so many things they have to get used to, they are digesting all of it. Sometimes that process lasts a long time and can also, as often happens, continue in the rehabilitation phase."

As a result of their disabilities and emotional state, on admission patients were heavily dependent on others:

"Well, then they have to call a nurse, which they don't like - especially the first fow weeks after the stroke."

"They would like to be more independent, but they can't."

Patients were unhappy and frustrated about their dependency on other people, particularly on admission, when patients' possibilities, e.g. self-care, were diminished compared to the situation pre-stroke. 
Providers stressed that life history, character and activity rate pre-stroke, partly determine the way the patient plays a role in the rehabilitative process, takes initiative and responsibility. For example:

"Someone who has always been very active, may be pushing himself, may be quite self-motivated to try new, or different ways."

On the contrary, when the patient was rather passive pre-stroke, the patient was not expected to take initiative and responsibility.

"Maybe his partner" or children looked after him. I think that it is impossible to expect to see someone become more independent all of a sudden..."

Thus, life history, character and activity rate pre-stroke might influence autonomy post-stroke. It happens, however, that the stroke affects the patient's character and activity rate.

"Afterwards we leamed that she thad always been an active lady and now she does nothing but smoke all day. We thought she had always been this way, and never thought that due to the stroke someone's behavior may change totally."

Regarding this patient, conditions pre-stroke did not detemine the patient's role in rehabilitation because the stroke changed everything.

Although disabilities post-stroke mostly constrain autonomy, some providers argued that disabilities post-stroke might facilitate autonomy:

"It can be facilitating [for autonomy] that nothing happens "normally" anymore (...). The fact that you have to think again, to plan again how to do things, how to accomplish a certain task."

Because the stroke changed everything, the patient has to review own customs and activities, and is thrown back on his or her own, which might challenge autonomy.

\section{Strategies of the patient}

Strategies of the patient are taking initiative and responsibility (see table 1 ). These strategies were mostly used by patients accustomed to the providers and the rules of the nursing home.

"The patient indicates that other activities [this is, other than activities of daily living (ADL)] are also important to her, but she is not able to practice, as all her energy is spent while doing ADL care." 
This initiative was followed by a staff meeting where a choice was made to have staff take over some of the ADL care, so that the patient could save energy for othar activitics. Patients also take their own responsibility, which is the case in the following example recounted by a provider.

"[The patient said] "And I want to go home, and I'm able to do that [walking unaided]. And if I happen to fall, then that is my choice"."

The provider, reflecting on this example, asked. who should decide in this case, the patient or the provider. She let the patient go (taking a risk), and apparently it went very well.

Refusing is a strong form of taking one's own responsibility. The following example concerns a stroke patient with a serious communicative disonder:

"He [the patient] wanted to ask or know something, but she [the caregiver] did not quite understand, and he was told: "Why don"t you get your communication book, otherwise I can't talk with you." But he didn"t want to do that. He is a man who finds it difficult to be told - he felt as if he were a child - to get his communication book, and to point to what he needs. He finds that hard, and so he refused to get his communication book, with the result that the caregiver refused to have a conversation with him [The patient tried another provider, and succeeded]."

This patient showed a lot of own responsibility. He did not accept the provider's approach, and, when the provider persisted, took initiative to get what he wanted.

\section{Environmental factors}

\section{Strategies of the health professionals}

Providers' strategies that facilitate autonomy are teamwork, attentiveness and respect (see table 2). In addition, a range of strategies was applied in a particular phase. On admission, giving information, assessment/training (ADL, mobility, communication), and paternalism (deciding for patients) were used to enhance autonomy. During rehabilitation, giving information, training (ADL, mobility, communication), decreasing paternalism/enhancing patient choice, and cooperation with patients and their families were applied to facilitate autonomy. At discharge, decreasing paternalism, co-operation with patients and families, and risk taking were used to stimulate patient autonomy.

Teamwork is important to molivate providers in the approach of autonomy: 
Table 2. Strategies of the health professionals regarding patient autonomy in the diferent phases of rehabilitation, as identifred by care prowiders in nursing homes.

\begin{tabular}{|c|c|c|c|}
\hline & Admission & Rehabilitation & Discharge \\
\hline \multicolumn{4}{|l|}{ Facilitaing for autonomy } \\
\hline Teamwork & $X$ & $x$ & $X$ \\
\hline Attentiveness/respect & $X^{\prime}$ & $x$ & $x$ \\
\hline Giving information & $\mathrm{X}$ & $x$ & \\
\hline Assessment/raining & $\mathrm{x}$ & & \\
\hline Training & & $x$ & \\
\hline Paternalism & $x$ & & \\
\hline Decreasing paternalism & & $x$ & $\mathrm{X}$ \\
\hline Enhancing patient choice & & $x$ & \\
\hline Co-operation with patient/tamily & & $x$ & $\mathrm{X}$ \\
\hline Risk-taking & & & $x$ \\
\hline \multicolumn{4}{|l|}{ Constranng for autonomy } \\
\hline Providers" institutionalization & & $x$ & $x$ \\
\hline
\end{tabular}

"Sometmes when someone doesn"t feel too well or simply refuses to do something, then I think by myself: come on, I'll help you a little bit. But when that happens too often, then it would be better to decide - with the team - if a different approach is necessary."

On admission, when the patient is dependent, giving information, and assessment/training are very important:

"Allow the patient to discover his abllities (...) his own sensation: what do I still feel, what can I do with that leg. Gradually you're finding out what the possibilities are, how you move around. And then through exercising on the plinth you start rolling over all by yourself? Then comes standing up independently, sitting down on the edge of your bed, just like the NDT theory [Neuro Developmental Treatment]."

In this way providers tried to decrease the patients' fear, to let the patient see what they were able to do, and to get information on the patients" abilities and disabilities. In the meantime, a little bit of training was giwen already.

On admission, providers decide for patients.

"You determine your goals in the beginning. You agree with someone: "I will come and get you so and so often for arm-hand therapy." That is my decision. And the other person thas absolutely no input, no autonomy, I think." 
Providers decide for patients because they think that patients do not come across with choices regarding the rehabilitative approach.

"I think that you have to guide them in this matter, that you often have to give advice. They have no insight into their illness or handicap and think they can just go home.(...) You will have to hellp them to make the right decisions."

Other reasons for a paternalist approach are a decreased need for selfdetermination or diminished decision-making skills.

"He doesn't have that insight, he has fallen a couple of times just because be thinks he is able to go to bed without help and then things go wrong. So we had to take a couple of firm actions to prevent more falls.(..) He has an adjustable height bed, which we put in a high position, with the bedrails up so that he could not climb in. "This makes it clear to him that something isn"t quite right. Now, in the evening, he comes to ask for help. We lower the bed and rails, and help him into bed. And that works well."

For security reasons short-term autonomy was constrained, in view of the patient"s long-term autonomy. When patients cannot make choices anymore, because they have no knowledge of their handicaps, or because they are cognitively impaired, providers try to develop self-determination in a respectful way.

"And then you try to encourage them to make a choice. And I feel that it needs a different approach. But I find it difficult to explain what kind of approach."

This provider felt that, although at this moment decision-making was impossible, the patient's self-determination should be encouraged and developed. However, the provider hesitated how to enhance patient choice and self-detemination.

Attentiveness is an important strategy to see whether the patient is able to make a decision. Respondents used less paternalism, and took more risks when patients became more informed:

"And during the course of their admission you often notice that people are better able to realize the consequences of what they do or of what they choose. That they become aware of the possibilities and limitations.(..) Not always finding a solution, but also showing what the possibilities and the limitations are." 
Only if providers do not solve all problems for patients, which involves risktaking, patients are challenged to solve their own problems, which facilitates autonomy (all dimensions). Gradually, providers take the role of consultant:

"[ clearly make them responsible: "You request these [adaptations], that is your choice, but I would advise you such and such"."

In this way providers try to leave more room for autonomy (self-determination and independence), and try to co-operate with patients.

Co-operation with the patients' families is a strategy also used to enhance patient autonomy:

"And don't forget about the family. (...) You have to include them and tell them what is happening, what is being done."

For stroke patients rehabilitating in mursing homes, families" support is important. After discharge, but also during rehabilitation, families help patients with choices and activities. How support is given is vital for patient autonomy. Therefore, providers co-operate with families, discuss with them, give then instructions how to help the patient, and train together. In addition, co-operation with families provides information about the patient's person, customs, prior life, etc. (see strategies of the familly).

Providers stressed that they were used to the care routines and rules in the nursing home, to the rehabilitation methods, and to providing (too much) care. They called this phenomenon 'institutionalization of providers', and stressed that this phenomenon constrains patient autonomy. Giving information and enhancing patient choice are strategies that might be used more than is the case now:

"Very often we do not explain why we do certain activities. I noticed that when a patient suddenly asked: "Why do I have to do this exercise?" (...) That was an eye opener! I think you should explain why things are done, and also leave a choice with the patient."

"I feel that you have to respect someone, for what he wants, for what his worries are. These may not always be the same as your own. Sometimes you may have to look for a compromise."

Providers acknowledge that they should give patients more information, and more room for self-determination than they do now.

\section{Strategies of the family}

Acting as go-between, and anticipating facilitate autonomy. Being paternalist or overprotective, and preventing constrain autonomy (see table 3, p.42)

Acting as go-between requires a deliberative balancing. 
Table 3. Facilitating and constraining factors for autonony, related to the family and the nursing home, as identified by care providers in nursing homes.

\begin{tabular}{|c|c|c|}
\hline Envirommental factors & Facilitating factors & Constraining factors \\
\hline Strategies of family & $\begin{array}{l}\text { acting as go berween } \\
\text { anticlpating }\end{array}$ & $\begin{array}{l}\text { boing paternalistoverprotective } \\
\text { preventing }\end{array}$ \\
\hline Nursing home & room for autonomy & $\begin{array}{l}\text { care routines } \\
\text { no privacy } \\
\text { unfamiliat enviromment } \\
\text { comparison with fellows } \\
\text { many providers }\end{array}$ \\
\hline
\end{tabular}

"It works well when (...) the decision-making isn't taken over by the family."

When consciously applied, acting as go-between might facilitate autonony, in particular if the patient has considerable speech impaiments.

"Because the family knows mother or father quite well, they, sooner than we can, recognize what the patient wants. And in this way you can promote his autonomy even more."

Anticipating families facilitate autonomy:

"And they really would like to see father or mother return home, or in any case, they show they care and ask: "How about being home again later?" And they want to support that situation."

These families positively prepare themselves for the future situation.

Paternalist or overprotective families constrain the stroke patient's autonomy, for example:

"When you have a patient who is doing well, physically and mentally, - but then there is a spouse who wants to control and doesn't give any room."

Preventing families also constrain autonomy.

"They would say quite quickly: "We don"t think it is possible for father or mother to come home again"." 
This approach limits patient autonomy in advance, because these families do not expect or will not expect any progress, which is demotivating for all parties involved.

\section{The nursing home}

The nursing home as temporary context for patients includes several features that influence patient autonomy: simply being in the nursing home, the presence of fellow patients, and a high number of providers (see table 3).

Being in the mursing home includes care routines, no privacy, and an unfamiliar emviromment.

"And then you end up in there and you have to live within that secluded environment and you're cut off from the outside world.(...) The daily routine of the nursing home.(..) You have to share bedroom, living room, bathroom."

Providers stressed that the admission into the nursing home constrains autonomy, but that, compared to a hospital, a nursing home provides more opportunities for autonomy.

"There is more room here, compared to the hospital. There are no [scheduled] visiting hours, the family can stay as long as they wish. They can watch TV together, they can do other activities together."

Fellow patients might facilitate each other's autonomy.

"When you have a lot of people working towards discharge, and a new stroke patient is admitted who starts his rehabilitation, you'll see the others helping him."

Fellow patients support each other, and talk to each other. In this way they get used to the situation faster, which facilitates their autonomy. On the other hand, the presence of fellow patients might constrain autonomy:

"If it takes somewhat longer than expected, and he sees other patients making more progress, he starts to compare himself to the other people. He becomes more introvert; depressed is a big word, but it seems like that because he is trying to cope."

Patients compare themselves with other patients. Seeing other patients making more progress might demotivate patients and constrain regaining autonomy.

A high number of providers might constrain autonomy because patients have to get to know all these unknown people and their different tasks in rehabilitation. A key person, who gives the patient information and discusses the 
rehabilitative process with the patient, might diminish the negative effect of many providers, as might do teamwork.

"What the patient is able to] is indicated at the ADL form near the sink. So it is clear for both the patient and the nursing aides, so everybody approaches in the same way."

\section{DISCUSSION}

In this study the core category 'Changing autonomy' has been developed. Changing autonomy identifies the process in which stroke patients regain their autonomy, and the factors affecting this process. Health professionals stressed the changes in patient autonomy during the rehabilitative process. On admission autonomy has been heavily diminished in comparison to autonomy pre-stroke; during rehabilitation patient autonomy increases step by step due to a learning process; at discharge autonomy further increases. Patient and environmental factors constrain or facilitate this process. Patient factors concern conditions and strategies of the patient, while environmental factors concem the approach and strategies of health professionals and families, and the nursing home as a context.

The results fitted with the concept actual autonomy as defined by Agich (1993). Actual autonomy is not a static concept, but a dynamic concept of autonomy, one that changes over time. Actual autonomy means that autonomy depends on a person's current development and environment. In fact, this sense of autonomy emphasizes the contextuality of autonomy: one can only realize one "s autonomy in relation with one's social and physical context. The results of our study indicated an increase of patient's actual autonomy during rehabilitation. "The environment sustained patient's actual autonomy as long as nocessary. Gradually, when actual autonomy increased, the enviromment became less supportive. The results suggested that the approach of providers started with a social concept of autonomy as framework, while later on an individual concept of autonomy accentuates their approach. A social concept of autonomy includes the support from health professionals and family (Proot et al., 1998). For example, decision-making and restoration of autonomy can be sustained by the enviromment. On the contrary, an individual concept protects the patient against interference by others and stresses the independence of the patient (Proot et al., 1998). This presumes the patient can live his or her life in a competent, individual way without others.

Three dimensions of autonony were revealed which need attention in the rehabilitative process: self-detemination, independence and self-care. Selfdetemination and independence as identified by health professionals are related to self-govermance in the bioethical literature. The concept of autonomy emphasizes the informed self-governance of the patient. In medical ethics autonomy is generally described as: to act voluntarily and consciously without 
any constraint. Informed consent, then, is fundamental in respect of patient autonomy (Beauchamp \& Childress, 1994). Self-determination appeared to be a dimension separate from independence because special attention is needed due to the often encountered communicative and cognitive disabilities of stroke patients, and to the process of their accepting boundaries and limitations (Deci, 1980). Self-care, the third dimension identified, is related to self-care as defined by Orem (1995) "The practice of activities that maturing or mature persons initiate and perform, within time frames, on their own behalf in the interests of maintaining life, healthful functioning, continuing personal development, and well-being" (p. 461). Self-care as identified in the present study includes both skills and activities of daily living necessary for functioning.

The study was limited to interviews with providers. They reflected on their work, and sometimes developed new (hypothetical) strategies. This entails that the strategies identified were not always (consciously) applied. Providers said that their work had so far been particularly focussed on the dimension self-care, which they felt was not appropriate. They expressed the need for guidelines concerning the approach regarding patient autonomy. In a study concerning the home care setting, Pool (1995) argued that goal-setting was strongly related to physical care, and less related to informational and psychosocial care, a situation which facilitated autonomy to a less than desirable degree. The results of our study, although in a different setting, tended in the same direction.

Teamwork might facilitate the providers' strategies regarding patient autonomy. The interviews showed that patient autonomy is often discussed during team meetings, but it appeared that providers used their own words to express their ideas. A shared language might improve discussions on the development of patient autonomy, and might increase teamwork in this respect. In addition, co-ordination of the process of changing autonomy, in which a team of providers is involved, appeared to be necessary. In most cases the nurse or nursing aide already co-ordinates daily care on the ward; therefore he or she might be the most appropriate person to take this role, which relates to the integrative function of the nurse (Kirkevold, 1997). This intagrative function includes both physical and social functioning of patients, and aims at patients integrating newly learned $\mathrm{ADL}$.

Regaining autonomy particularly depends on the providers" approach. Coordination of providers" strategies, teamwork and a shared language could sustain the providers' approach on the patients " changing autonomy, and might prevent 'providers institutionalization'. Providers' strategies are to be directed on all dimensions of autonomy. Giving information to patients and families on rehabilitation methods and the patients" progress might facilitate patient autonomy and support families" strategies. Co-operation with families enhances providers "knowledge of the patients" life history and character, which could be used to support patients" regaining autonomy. Nursing homes could try to provide more room for the patients' own customs and time frames.

Integrating all dimensions of autonomy in the rehabilitation approach, and teamwork on the process of changing autonomy are issues that need attention 
and warrant further investigation. Implementing the results in client-centered care, in care contracts and in exit interviews should be studied and encouraged. Dewelopment of multidisciplinary guidelines and courses regarding the approach of patient autonomy, and research into the effects of these interventions are reconmended to see whether the patients' autonomy better evolves. However, before guidelines and courses can be developed the experiences of stroke patients and their families during rehabilitation should be studied.

\section{REFERENCES}

Agich, G. J. (1993). Autonomy and longwerm care. Oxford: Oxford University Press.

Anderson, R. (1992). The aftermath of stroke. The experiences of patients and their families. Cambridge: Cambridge University Press.

Banja, J. D. (1993). Ethical issues in staff development. In C.J. Durgin, N.D. Schmidt, \& L.J. Fryer (Eds). Staff development and clinical intervention in brain injury (23-41). Maryland: Aspen.

Beauchamp, T. L. \& Childress, J. F. (1994). Principles of biomedicat ethics. Ox ford: Oxford University Press.

Bergnan, L., van der Meulen, J. H. P., Limburg, M., \& Habbema, J. D. F. (1995). Costs of medical carre after firstever stroke in the Netherlands. Stroke, 26, 1830-1836.

Caplan, L. R., \& Stein, R. W. (1986). Stroke, a clinical approach. Stoneham: Butterworth Publishers.

Deci, E. L. (1980). The psychology of self-determination. Lexington, Massachusetts: Lexington.

Denzin, N. K. (1989). The research act: a theoretical introduction to sociological methods. Englewood Cliffs: Prentice Hall.

Johnstone, M. (1987). The stroke patient: a team approach. Edinburgh: Churchill Livingstone.

Kirkevold, M. (1997). The role of nursing in the rehabilitation of acute stroke patients: towards a unified theoretical perspective. Advances in Nursing Science, 19(4), 55-64.

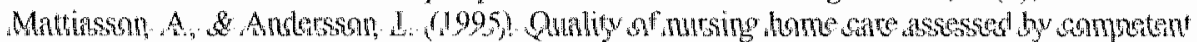
nursing home patients. In A. Mattiasson (Ed.), Auronomy in nursing hone sextirgss. Shady $5(1-14)$. Stockholm: Karolinskit Institute.

Mill, J. S. (1985). On liberty. Harmondswortly: Penguin Books. [First published 1859].

Miller, B. L. (1981). Autonomy \& the refusal of lifesaving treatment. Hasidngs Cenrer Report, $1 /(4), 22-28$.

Oren, D. E. (1995), Nursing: Concepts of practice. St. Louis: Mosby.

Pool. A. (1995). Auronomie, afhankelijheid en langdurige zorgyerlening. [Autonomy. dependence and long-term care]. Utrecht: Lemma.

Proot, IM. (1994). Protocol. autonomie en verantwoovdelijheid in de zorg woor CVAparièntex. [Protocol, autonony and responsibility in the care of stroke patients]. Masters thesis, Mastricht: Maastricht University.

Proot, 1.M., Crebolder, H. F. J. M., Huijer Abu-Saad, H., \& Ier Meulen, R. H. J. (1998) Autonomy in the rehabilitation of stroke patients in nursing homes: a concept analysis. Seandinavian Jounal of Caring Scrences, $12,139-145$.

Sim, J, \& Shapp, K. (1998). A critical appraisal of the role of triangulation in mursing research. International Jounal of Nursing Studies, 35, 23-31. 
Stonnington, $\mathbb{H} . \mathbb{H}$., \& Browne, $\mathbb{J}$. A. (1987), Team approach to management. In M. E. Brandstater \& J. V. Basmajian (Eds.), Stoke rehabilitation (199-207). Baltimore: Williams and Wilkins.

Strauss, A., \& Corbin, J. (1990). Basics of qualitative research groutded theory procedures and rechniques. Newbury Park: Sage.

Taes, C. G. J., van Campen, C., \& Kerkstra, A. (1996). Ervaren automomie en ervaren veiligheid bij somatische verpleeghutbewoners. [Experienced autonomy and experienced safety for somatic nursing home patients]. Kwaliteit en Zorg [Quality and Care], 4(2), 5262.

Taylor, C. (1991). The malase of modernity. Don Mills: Stoddart Publishing. (Republished as: The ethics of authenticity. (1992). Cambridge: Harvard University Press).

Tronto, J. C. (1994), Moral boundaries: a political arganent for an eihic of care. New York: Routlledge.

Van Campen, C., \& Kerkstra, A. (1995). Kwaliteit wan lever wan somatische verpleeghwispatiënten: Een begripswerheldering en overzicht van meetinstrumenten. [Qualify of life of somatic nursing home patients: A summary of concepts and measurement scales]. Utrecht: NIVEL.

Van der Wulp, J. C. (1986). Verstoring en verwerking in verpleeghuizen. [Impaiments and its resolution in nursing homes]. Nijkerk: Intro.

Wade, D. T. (1992). Stroke: Rehabilitation and long-term care. The Lancet, 39, 791-795. 



\title{
Facilitating and constraining factors on autonomy: the views of stroke patients on admission into nursing homes
}

\begin{abstract}
This article describes a model 'Changing autonomy" which was developed in a grounded theory study among stroke patients on admission into nursing homes for rehabilitation. Three dimensions of autonomy were identified: self-determination, independence and self-care. On admission patients" conditions (disabilities, multi-morbidity, emotional state, and feeling like a layperson) and patients' strategies (waiting and seeing, and acting as subordinate) constrain autonomy. Several environmenta] factors facilitate patient autonomy. The nursing home sustains patient autonomy by providing a hopeful atmosphere and room for autonomy. The health professionals facilitate autonomy by giving therapy, support and information, attentiveness and respect, patemalism and teamwork. Facilitating strategies of the family encompass emotional and instrumental support. Care routines, lack of privacy, an unfamiliar environment, waiting periods, boredom and lack of information were identified as constraining environmental factors. Developing guidelines and multidisciplinary courses regarding the approach to patient autonomy on admission is recommended.
\end{abstract}

Published as:

IM Proot, HFJM Crebolder, H Huijer Abu-Saad THGM Macor, RH ier Mculcn. (2000). Facilitating and constraining factors on autonomy: the views of stroke pattients on admission into nursing homes. Clinical Nursing Research, 9, 460-478. 


\section{INTRODUCTION}

Recovery from a stroke includes dealing with residual dysfunction (physical, sensory-perceptual, cognitive, and/or psychosocial) (Barton \& Sullivan Black, 1993). In the Netherlands, this process often takes place in a hospital, and subsequently in a rehabilitation center or nursing home (Bergman, van der Meulen, Limburg \& Habberna, 1995). Those stroke patients admitted temporarily into a nursing home for rehabilitation are mostly placed in a rehabilitation ward (short stay), where their rehabilitation is supported by a multidisciplinary team. An important aim of the rehabilitative process is the transition from dependence to independence (Wade, 1992) with a view to living independently after discharge. Most patients feel dependent and insecure due to considerable problems post-stroke on admission and are less autonomous than they were pre-stroke. Loor (1998) studied the quality of life of stroke patients 1 year and 2 years post-stroke. She concluded that the deterioration experienced in quality of life depends in particular on loss of autonomy, and that maintenance of autonomy should be the most important aim in the care of stroke patients. Facilitating the process of regaining autonomy is an important task for the health professionals working in a rehabilitation ward.

What elements does autonomy of stroke patients on admission encompass? A concept analysis on autonomy in relation to the rehabilitation of stroke patients showed that primary literature on this topic scarcely exists, but secondary literature does (Proot, Crebolder, Huijer Abu-Saad, \& ter Meulen, 1998). This analysis provided three important concepts derived from biomedical ethics, self-governance (Beauchamp \& Childress, 1994; Mill, 1985), selfrealization (Miller, 1981; Taylor, 1991) and actual autonony (Agich, 1993). The literature on nursing home care yielded the related concepts of privacy, authority and independence (Van Campen \& Kerkstra, 1995), and nursing litterature yiclded the concept of self-care (Orem, 1995). Analysis of these concepts revealed that these concepts can be divided into individual and social concepts of autonomy (Proot et al., 1998). The individual concepts of autonomy protect the patient against unwanted interference by others and place informed consent at the center. This presumes the patient can live his or her life in a competent, individual way, which is generally problematic on admission to the facility when the stroke patient is dependent on other people. At this time, a social concept of autonony might be appropriate, which stresses that autonomy also depends on a person's environment. The social concept includes the support from health professionals and informal caregivers, for example regarding decision-making and restoration of autonomy. The concept analysis shed light on the fact that the majority of studies regarding patient autonomy are primarily based on theoretical reflections and hardly on empirical evidence. The few empirical studies on patient autonomy focus on nursing home residents (long-stay) (Mattiasson \& Andersson, 1995; Taes, van Campen \& Kerkstra, 1996) and do 
not focus on stroke patients temporarily admitted to a nursing home for rehabilitation.

How could health professionals and family support stroke patients regaining autonomy on admission? There is little specific literature on this topic. Related to patients with other diagnoses than stroke, several authors stress that the environment could sustain the restoration of patient autonomy (Banja, 1993; Pool, 1995). Oren (1995) postulates the concept of dependent care, which describes the importance of support from family and friends when self-care is insufficient. Attentiveness and responsibility are important characteristics of the caregiver (professional and informal), necessary to identify patients" needs and to take action in resolving these needs (Tronto, 1994). More research is warranted to explore the stroke patients" experiences regarding their own autonomy and regarding the approach of health professionals to autonomy.

This article reports on interviews with stroke patients on admission. It is part of a large-scale research project regarding the autonomy of stroke patients rehabilitating in nursing homes. The long-term purposes of this project are twofold: First, to identify what areas need special attention regarding patient autonomy during different phases in the rehabilitative process and second, to make recommendations about how stroke patients can be prepared for their return home. Specifically, though, this article seeks to pinpoint which dimensions of autonomy are identified by stroke patients rehabilitating in nursing homes, and to determine which factors, in the stroke patients" perception, facilitate or constrain patient autonomy on admission.

\section{METHOD}

A qualitative research method was chosen because very little is known about the concept under study. Grounded theory (Strauss \& Corbin, 1990) was used to explore the stroke patients' experiences regarding autonomy on admission. This method starts from the descriptions of the respondents and not from concepts derived from the literature.

\section{Setting and sample}

The study was carried out on the rehabilitation wards of three nursing homes in the province of Limburg, the Netherlands. The project was approved by the ethics committees of the respective institutions. After approval, data were collected.

The researcher decided, in co-operation with a key person in each of the nursing homes, which persons could select the patients (head nurse, care coordinator, and/or doctor, hereafter "selectors"). Patients with a confirmed diagnosis of stroke who were admitted to one of the rehabilitation wards participating in this study were included if they were able to communicate Copinion of speech therapist, patients with aphasia were not excluded on 
Talyte 1. Demographic and clinical characteristics of the stroke patients.

Characteristics $\quad(\mathrm{N}=22)$

$\begin{array}{lc}\text { Civil state } & 4 \\ \text { - unmarried } & 6 \\ \text { - married } & 1 \\ \text { - divorced } & 11 \\ \text { - widowed } & \\ \text { Education level } & 16 \\ \text { - lower vocational or less } & 3 \\ \text { - intermediate wocational or general secondary } & 3 \\ \text { - higher vocational or university } & \\ & 11 \\ \text { Right-sided stroke } & 19 \\ \text { Multi-morbidity } & 22 \\ \text { Hospital admission } & 4(2-8) \\ \text { weeks (M, range) } & \end{array}$

- In particular diabetes mellitus, visual impairments, cardiowascular diseases and osteoarthritis.

principle), if they were Dutch and spoke their mother tongue, if the rehabilitation goal was to return to their own home or an elderly care facility, and if the selector(s) took the view that participating in the study was not a heavy burden for the patient. Patients were excluded if they had severe multi-morbidity (somatic, psychiatric and/or psycho-geriatric), which would interfere with study participation. Because a follow-up was planned, a large sample was invited for the study, allowing for dropouts. In the period November 1996 to May 1997 a total of 22 patients were telephoned and received a letter of invitation with information about the study and a written consent form. All patients invited consented. Interview arrangements were made. Twelve men and 10 women participated in the study, ranging in age from 50 to 85 years $(M=72)$. Table 1 gives demographic and clinical characteristics.

In total 58 interviews were held (not all patients participated in 3 interviews); 21 interviews on admission, 17 interviews during rehabilitation, and 20 interviews at discharge. All interviews with a particular patient were conducted by the same interviewer. This article reports on the interviews on admission.

\section{Data collection}

Twenty-one patients were interviewed 3.5 weeks ( $M$, range from 2 to 8 weeks) after admission to the mursing home. All interviews were held on the rehabilitation ward. Due to the patient's condition, the patient was offered the 
possibility of having an informal caregiver present during the interview. Thirteen patients consented and were asked which person was the infomal caregiver most involved. Thirteen informal caregivers were invited ( 3 spouses, 5 daughters, 2 sons, 1 sister, 1 cousin and 1 neighbor) and responded positively. The informal caregiver was instructed to support the pationt when needed but not to reply for the patient.

\section{Interview guide}

Experiences from a previous study (Proot, 1994), interviews with stroke patients discharged from nursing homes, and sensitizing concepts derived from literature (Proot et al, 1998) were used to develop an open-ended interview guide. This guide was reviewed by project group members and by selected experts, and accordingly revised. The order of the questions of the revised guide was changed a little after the first interview, which served as a pilot.

Autonomy was not defined for the respondents because an important goal of grounded theory is to understand the participants' world as they view it. Respondents were asked how they defined autonomy, and this definition was used during the interview. If the word autonomy was unknown, an equivalent was used to invite the patient to relate his or her experiences. In addition, patients were interviewed about their own autonomy ("Do you think that your autonomy (or the word used by the respondent) has decreased/increased since the stroke?"), about constraints and improvements of autonomy on admission ("What do you feel caused this decrease/increase in your autonomy (or the word used by the respondent)?"), and about the approach by health professionals and family with regard to autonomy. Patients were also asked about their own need to participate in decision making.

\section{Interview procedure}

The interviews were conducted by two trained interviewers. The interviewers introduced topics and used follow-up probes if necessary to encourage respondents to give more information or examples. The interviews were taperecorded (after consent) and transcribed with all identifying data removed. Fieldnotes were taken during and after each interview. One patient refused taperecording; in this case detailed field notes were made. The interviowers also reconded answers to questions conceming demographic variables and medical history.

\section{Data analysis}

Data collection and analysis proceeded simultaneously. After the first five interviews, analysis was started. The qualitative data were analyzed using the constant comparative method as described in grounded theory (Strauss \& Corbin, 1990). Interviews and field notes were coded. Themes related to autonomy of stroke patients on admission were grouped, compared and categorized. The computer program Kwalitan 4.0 was used to store and organize 
the qualitative data. Both descriptive coding and theoretical coding were used: descriptive coding to explote stroke patients" autonomy on admission and theoretical coding to develop a theory to clarify relationships between concepts and to facilitate the development of a theoretical framework. Saturation was reached atter analysis of 12 interviews. The other 9 interviews were used to validate the theory developed.

Data triangulation, investigator triangulation and methodological triangulation (Denzin, 1989) were used to broaden the analysis of the phenomenon of stroke patient's autonomy, and to secure content validity (Sim \& Sharp, 1998). Patients admitted to different nursing homes and with varying socio-demographic variables participated in the study (data triangulation); there were two interviewers, and peer debriefing during analysis was used (investigator triangulation). Apart from individual in-depth interviews, member checks were held (methodological triangulation).

\section{RESULTS}

\section{Changing autonomy}

The core category identified in the analysis is "Changing autonomy' and includes three dimensions of autonomy: self-determination, independence and self-care. The content of these dimensions as identified in the interviews with the stroke patients is as follows. Self-determination points at making choices and decisions about one's own life and health and also includes freedom of choice. Independence (physical, psychological and social) concerns planning and organizing one"s own life, including social contacts and role-taking; and refers to responsibility for one's own life and health care. Self-care includes skills (mobility, communication, cognition) and activities of daily living (ADL), that are necessary for functioning.

On admission most stroke patients experience that their autonomy has decreased in comparison to pre-stroke, in particular the dimension self-care because of disabilitics post-stroke.

"Most disappointing was that you were unable to do the smallest things. That you realize you just don't know how to do them... When you think about it, you know already: $\|$ can't do it, why bother to try.(...) Someone has to zip up yout fly when you sit on the toilet. It goes against the grain that we even cannot do that."

Although in the patients' perception independence and self-determination are decreased to a lesser degree than self-care, self-determination is particularly decreased regarding decisions about rehabilitation procedures because patients feel like a layperson. 
In addition to a decrease of autonomy, on admission patients also experience, in comparison to the situation shortly after the stroke, an increase of autonomy; in particular in the subcategories ADL and mobility of the dimension self-care.

"There is noticeable improvement, for instance being able to dress oneself, or wash without help."

"It [patient's leg] isn't quite functional yet, but I can walk again, and you need two legs to do that."

On admission some patients already start recreational activities:

"Sometimes a puzzle, but a small one, because that's all I can manage for now.(..) I like to do puzzles, always liked it."

Apart from disabilities post-stroke, there are many other factors influencing patient autonomy that can be divided into patient and environmental factors. Patient factors concern conditions and strategies of the patient. Environmental factors concern the nursing home as a context and the strategies of the health professionals and of the family.

\section{Patient factors}

\section{Conditions of the patient}

Patient conditions can be divided in conditions post-stroke (disabilities, multimorbidity, emotional state, feeling like a layperson) and conditions pre-stroke (life history, activity rate, multi-morbidity) (see table 2, p.56). Patients indicated that conditions post-stroke in particular constrain their autonomy and strategies. Conditions pre-stroke, conversely, sometimes facilitate the restoration of autonomy. For example, life history partly determines the way the patient deals with the new situation and the way he or she plays a role in the rehabilitation process.

Awareness of a decrease of autonomy leads patients to compare their situation with life beforehand, and inevitably confronts patients with loss (e.g. loss of self-realization, loss of identity). The fact that patients experience loss (and do not run away from it), however, indicates that they start to cope with the situation.

"I like to whistle... I used to work with horses. Behind those horses, in the field, up and down, you whistled all you wanted. I miss those things right now. They are gone forever." 
Table 2. Fachitating and constraining patient factors regarding autonomy, as experienced by stroke patients on adrmission into nursing homes.

Patient factors

Facilitating factors

Constraining factors
Conditions of patient

- pre-stroke

post-stroke

Strattegies of pationi"

life history
activity rate
(no conditions identified)

responsibility/mitiative resisting boredom seeking information criticism life history activity rate multi-norbidity

disabilities post-stroke multi-morbidity emotional state feeling like a layperson waiting and seeing acting as subordinate

- Fewer strategies than pre-stroke: patient conditions make some strategies unfeasible.

Disabilities post-stroke constrain self-care, and might vary:

"One day everything goes well, and then the next day nothing works out. It changes from day to day. A kind of yo-yo effect."

As a result of all the changes, patients feel insecure on admission, describe themselves as laypersons and the health professionals as experts, and find it difficult to judge the work of the health professionals:

"In a short time they have helped me to get this far. The only thing I think now is let's continue in their way. Because my opinion is very unimportant."

"I don"t know. I never really had to do anything with that.. I don"t know what they can do."

Patients try to trust the competence of the health professionalls but feel uncertain all times.

\section{Strategies of the patient}

On admission, patients have fewer strategies than pre-stroke because conditions make some strategies unfeasible (see table 2). Most patients have a passive role in rehabilitation: They wait and see and "act as subordinate" (as they call it 
themselves). Some patients have a modestly active role: They take responsibility and initiative (own effort, anticipating, problem solving), resist boredom, and yet less often, seek information and criticize the health protessionals.

On admission, waiting and seeing is often a strategy:

"We are waiting patiently. It is the only thing we can do."

Some patients, however, take responsibility and initiative, for example, show own effort, or anticipate the future when they will be more competent:

"There was an urge, I thave to do that by myself, I have to do it. I have to make sure I get better."

"I don"t know how independent I will become eventually ... When I can do a few more things I may become more motivated."

On admission patients feel it is difficult to have any measure of control over their own treatment, because they feel like a layperson but also because of the environment. Areas where patients could participate in decisionmaking - for example, the extent and schedules of therapy, and meals - are not always negotiated by health professionals.

Because of the patients" own conditions and because of the enviromment, they have fewer possibilities to spend time, to exercise within activities, or for self-realization. Some patients try to resist boredom:

"They wake you early in the morning, and you wash and dress. Then you go to the living room. And you sit. Well, I like to take the elevator down, and sit there and smoke a cigarette. Then I take the elevator back up again. And so another half hour passes."

Patients feel that therapy and supervised exercises in the ward facilitate regaining self-care, but they experience a lack of therapy and supervision, for example when their therapist is ill, or during weekends. In the patients" view, this problem can be solved but patients find it difficult to judge:

"I feel that with more assistance, one would improve at a quicker rate.(..) I can't judge if they hire enough staff, or if they could hire more, if the budget is enough."

\section{Environmental factors}

\section{Context of the patient}

The context of the patients participating in this study is the mursing home. 
Table 3. Facilitating and constraining environmental factors regarding autonomy, as experienced by stroke patients on admission into nursing homes.

\begin{tabular}{|c|c|c|}
\hline Envirommental factors & Facilitating factors & Constraining factors \\
\hline Nursing home & $\begin{array}{l}\text { health professionals } \\
\text { therapy } \\
\text { hopeful atmosphere } \\
\text { room for autonomy } \\
\text { suppont from fellow patients }\end{array}$ & $\begin{array}{l}\text { unfamiliar environment } \\
\text { care routines } \\
\text { lack of privacy } \\
\text { "hotel" function } \\
\text { waiting periods }\end{array}$ \\
\hline $\begin{array}{l}\text { Strategies of health } \\
\text { professionals }\end{array}$ & $\begin{array}{l}\text { supporttherapy } \\
\text { assessing } \mathrm{ADL} \\
\text { attentiveness/respect } \\
\text { patenalism } \\
\text { information } \\
\text { teamwork }\end{array}$ & $\begin{array}{l}\text { care routines } \\
\text { lack of information }\end{array}$ \\
\hline Strategies of family & $\begin{array}{l}\text { emotional support } \\
\text { instrumental support }\end{array}$ & (no strategies identified) \\
\hline
\end{tabular}

Important subcategories of patient's context are being in the nursing home, a high number of health professionals and the presence of fellow patients (see table 3).

In the patients" perception, being in a nursing home, in comparison with being in one's own home, means several changes that constrain autonomy: an unfamiliar environment, care routines, less room for own habits (for example sanitary habits) and lack of privacy. In comparison to the hospital, however, patients in the nursing home experience more therapy, a hopeful atmosphere and more opportunities for autonomy (three dimensions):

"You have nore freedom here. You can wear your streetchothes... in the hospital you wear pyjamas.(..) Here I am allowed to make a sandwich, in the hospital you couldn "t do anything."

"You're always in the same place, of course, when you are in the hospital. But when I have visitors here, I can go outside with them for a walk. You are entirely free to do that."

Nevertheless, the nursing home "seems like a hotel" (meals, bed making, etc.), which is more or less necessary because of post-stroke disabilities but offers fewer possibilities to spend time autonomously: 
"I did everything by myself, always. Cooking meals and everything. And now I do almost nothing by myself. Actually, I don"t need to cook here, they provide the meals."

"I started smoking out of boredom. I say all people here get the LTB syndrome, stands for Lazy, Tired, Bored. In the 4 weeks that I've been here, l"ve smoked about 200 cigars."

The presence of fellow patients as a part of patient's context leads to waiting periods, for example for taking showers, which constrain autonomy:

"You always have to wait here. There are too many people, you can't just take a quick shower, it's just impossible."

In the patients" perception, fellow patients also support each others autonomy:

"When he [fellow patient] wakes up at night and sees me lying there with my legs uncovered, or something. Also with meals, with pouring coffee. We help each other."

\section{Strategies of the health professional}

The presence of the health professionals is an important facilitating factor for autonomy. Facilitating strategies of the health professionals for autonomy are giving suppont, assessing ADL, attentiveness and respect, paternalism (deciding for the patient), giving information, and teamwork (see table 3). In particular lack of information and care routines constrain autonomy. The expertise and character of the health professionals determine the strategies available and the way strategies are applied. Time constraints, as context factor of the health professionals, leave less room for an individually attuned approach.

Giving support is of extreme importance on admission, and facilitates patient attionomy:

"All you had to do when you needed something was ring the bell and they would come right away. I am able to pull on ny pants but onlly to a certain point. I still need help with that and 1 always get it."

To give support only if necessary, the occupational therapist and the nurses assess what the patient can do independently:

"When they notice that you can wash and dress quite well, then they make you responsible for those tasks." 
An attentive approach facilitates autonomy. The health professionals watch patients and, for example, try to prevent falls, because fractures delay the rehabilitative process.

"They make sure you won't do stupid things, starting to walk too soon, or something like that."

But sometimes, when used too pointedly, attentiveness constrains autonomy:

"I feel I have to hurry up, when they watch me. Only because they are watching. I would get the job done, even if it takes a little bit more time."

Patients experience that paternalism is necessary, for example, when the therapist made the decision to start with ADL, which afterward appeared to be the right decision:

"I must admit that when she [occupational therapist] started last week [ADL], I told her a few times: "Girl, leave it, I don't want to learn how to manage my shirt and pants". I really had the idea it was a lost cause. But this morning I noticed that it actually goes well."

Some patients, however, have other experiences:

"Once I said: "Maybe I can stand if I hold on to those grab bars beside the toilet". And this week a nurse told me that was not allowed. If I had been home in this condition (...) I would try it, holding on to something. [Interviewer: Why do you think it is not allowed?] Because they think it is not good for me. That's what they have been taught. They receive an education in these matters. And they learn how things need to be done."

Deciding for patients and prohibiting actions are related to the rehabilitation method used; for example, neuro developmental treatment (NDT). Short-term autonomy is constrained in favor of facilitating long-term autonomy. It could be questioned whether patients get enough information why health professionals put them through a regimen. Although patients feel paternalism is necessary, not all patients follow the rules:

"I want to walk more, by myself... I'm not allowed to go to the bathroom by myself. But I go by myself if they are there or not.(...) [The patient has fallen one time] That nurse said: "But you are not allowed to!" She was not angry, but reprimanded me."

Information about treatment plans and a respectful attitude of the health professionals facilitate autonomy. The attitude is not always respectful, however: 
"So you go to the washroom. Says the nurse: "You have just been!" I say: "Well, I have to go again." "But you just went" they say then. And I find that a nuisance."

Care routines lead to long waiting periods and constrain autonony:

"Sometimes in the morning, or when they bring the meals, there are a lot of them [health professionals] and then, when we have to go to the bathroom, they are gone. They are nowhere to be found, maybe they are eating, I don't know, they need to do that too. But you know, if you can't find the nurses, you have to ring the bell.(..) And when they finally come, there are two, three or four people who urgently have to use the bathroom. And you have to wait sometimes for half an hour."

\section{Strategies of the family}

The presence of the family in the nursing home is very important for patient autonomy on admission. Conditions of the family that determine their strategies are age (advanced in years, morbidity), quality of the relationship between family and patient (post-stroke and pre-stroke), time (busy with work, own family), distance (between the nursing home and the family's home base) and seeing improvement.

Strategies of the family focus on giving emotional and instrumental support (see table 3, p.58). On admission emotional support is particularly important regarding patient autonomy:

"They [the children] come and visit regularly. So we can discuss everything."

"I don't see much of the grandchildren, but last Sunday her youngest daughter, 22, came to visit grandpa."

Furthermore, instrumental support is a considerable facilitating factor for autonomy, for example, regarding care of premises, plants and pets, shopping, delivering mail, and laundry:

"They [the children] come... My daughter does everything for me that I can't do for myself anymore. The laundry."

\section{DISCUSSION}

This grounded theory study among stroke patients on admission into nursing homes has identified the core category 'Changing autonomy', including three dimensions of autonomy: self-determination, independence and self-care. 
Patient and environmental factors influencing patient autonomy on admission were found. In a study among health professionals in nursing homes, the same core category was independently identified (Proot, Hujer Abu-Saad, van Oorsouw \& Stevens, submitted). The present study showed that on admission the development of patient autonomy depends for a great deal on the environment and supported the idea that a social concept of autonomy (that stresses that autonomy also depends on a person's environment) might be appropriate on admission. This result corresponds with the results from a qualitative study among stroke patients retrospectively interviewed about their admission to hospital; patients valued feeling cared about by experienced health professionals (Pound, Bury, Compentz \& Ebrahim, 1995). A positive contribution of the families' support to patients' autonomy was also showed by the present study. The crucial role of the family in recovery from stroke has been described before (Anderson, 1992; Nolan \& Nolan, 1998) but not related to patient autonomy. Due to the fragility of the stroke patients in the present study, some interviews took place more than 4 weeks after admission. It is questionable whether these patients' answers concerned the situation on admission. If these patients could have been interviewed earlier, however, the results might have supported a social concept of autonomy even more. Although 9 patients were interviewed alone, the absence of an informal caregiver during the interview did not yield incomplete information.

The present study revealed that on admission a lack of information constrains patients' autonomy. Anderson (1992) also found that stroke patients experience a lack of information and relates this result to a lack of systematic effort to inform patients. He pleads for better education and training for health professionals. Several features of the nursing home (for example, an unfamiliar environment, care routines, 'hotel' function) appeared to constrain the stroke patients' autonomy. Mattiasson \& Andersson (1995) interviewed 60 chronically ill but competent nursing home residents about quality of mursing home care. Quality of nursing home care was operationalized as the discrepancy between individual priorities (i.e. degree of perceived personal autonomy) and institutional possibilities. Residents appreciated developing and maintaining social contacts more than influencing daily routines, which illustrates that residents" priorities differ from the priorities of stroke patients on admission in the present study, who experienced care routines as a constraining factor for autonomy.

\section{Implications for practice}

On admission, the development of patient autonomy heavily depends on the environment, which entails that facilitating environmental factors should be maintained, and constraining environmental factors should be changed or minimized. Regarding the health professionals' strategies, support and supervision are to be provided, balanced, and tailor made, which requires attentiveness. Health professionals should give patients more information 
regarding the methods used. Despite the organizational difficulty, nursing homes could try to minimize care routines for stroke patients in rehabilitation wards and consider seriously the opportunity for patients to help with household work in the ward to prevent boredom. Long waiting periods might be shortened by a different way of organizing the breaks for personnel, and by providing sufficient aids in the toilets and sufficient bathrooms.

\section{Recommendations}

Informing patients and their families, supporting the patients decisions, developing self-management skills of patients, and counseling the patients" families are issues that need attention and warrant further investigation. Additional study should also cover the education and training of health professionals about the problems and needs of patients and families with regard to autonomy on admission as well as the provision of support and counseling for health professionals to help them deal with issues regarding the stroke patients" autonomy on admission. The development of multidisciplinary guidelines, based on the results, regarding the approach of patient autonomy on admission, and research into the effects of these guidelines is recommended to see if with these interventions the patients" autonomy will better evolve. More research is warranted to explore the experiences of stroke patients during rehabilitation and at discharge.

\section{REFERENCES}

Agich, G. J. (1.993). Autonomy and long-term ca*e. Oxford: Oxford Universily Press.

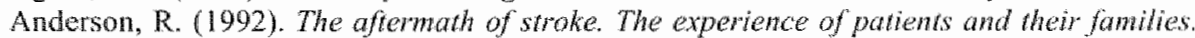
Cambridge: Cambridge University Press.

Banja, J. D. (1993). Ethical issues in staff development. In C. J. Durgin, N. D. Schmid, \& L. J. Fryer (Eds.), Staff development and clinical intervention in brain inhury (23-41). Maryland: Aspen.

Barton, L. A., \& Sullivan Black, K. (1993). Learning treatment strategies applicd to stroke rehabilitation. In Gordon, W. A. (Ed.), Advances in stroke rehabilitation. Boston: Andover Medical Publishers.

Beauchamp, T. L., \& Childtess, I. F. (1994). Principles of biomedical ethic. Ox ford: Ox ford University Press.

Bergman, L., van der Meulen, J. H. P., Limburg, M., \& Habbema, J. D. F. (1995). Costs of medical care after firstwever stroke in the Netherlands. Stroke. 26, 1830 1836.

Denzim, N. K. (1989). The research act: a theoretical introduction to sochological methods. Englewood Cliffs, Prentice Hall.

Loor, H. I. (1998). Kwaliteit wan leven: CVA-patienten maken de balans op. [Quality of life: stroke patients" views]. Tijdschrift woor Gerontologie en Geriatsie [Journal for Gerontology and Geriatrics], 29,52-58.

Mattiasson, A., \& Andersson L. (1995). Quality of nursing home care assessed by competenf nursing home patients. In Mattiasson A. (Ed.), Autonomy in numsing home setings: Study 5 (1-14). Stockholm: Karolinska Institute.

Mul, J. S. (1985). On liberty. Harmondsworth: Penguin Books. [First published 1859]. 
Miller, B. L. (1981). Autonony \& the refussal of lifesaving treatment. Hastings Center Report. $1 /(4), 22-28$.

Nolan M., \& Nolan J. (1998). Stroke 1: a paradigm case in nursing rehabilitation. British Journal of Nursing. 7, 316-322.

Orem, D. E. (1995). Nursing: concepts of practice. St. Louis: Mosby.

Pool, A. (1995). Automomie, afhankelijkheid en langdurige zorgverlening. [Autonony, dependence and long-term care]. Urrecht: Lemma.

Pound, P., Bury, M., Gompertz, P., \& Ebrahim, S. (1995). Stroke patients" views on their admission to hospital. British Medical Joumal, $3 /, 18-22$.

Proot, 1. M. (1994). Protocol, attonomie en verantwoordelijkheid in de zorg woon CVAparienten. [Protocol autonomy and responsibility in the care of stroke patients]. Masters thesis. Maastricht: Maastricht University.

Proot, I.M. Crebolder, H. F. J. M., Hujer Abu-Saad, H., \& ter Meulen, R. H. J. (1998). Autonomy in the rehabilitation of stroke patients in nursing homes: a concept analysis. Scandinawian Joumal of Caring Scicnces, 12, 139-145.

Proot, I. M., Huijer Abu-Saad, H., Oorsouw, van, G. G. J. \& Stevens, J. J. A. M. Autonomy in stroke rehabilitation: the perceptions of health professionals in nursing homes. Submitted for publication in Nursing Eihics.

Sim, J., \& Sharp, K. (1998). A critical appraisal of the role of triangulation in nursing research. International Joumal of Nursing Sudies, 35, 23-31.

Strauss, A., \& Corbin, J. (1990). Basics of qualitative research: grounded theory procedures and techniques. Newbury Park, NY: Sage.

Taes C. G. J., wan Campen C., \& Kerkstra A. (1996), Ervaren autonomie en ervaren veiligheid bij somatische verpleeghuisbewoners. [Experienced autonomy and experienced safety for somatic nursing home residents]. Kwaliteit en Zorg [Quallity and Care], 4, 52-62.

Taylor, C. (1991). The malaise of modernity. Don Mills: Stoddart Publishing. (Republished as: The ethics of athenticity. (1992). Cambridge: Harward University Press).

Tronto, J. C. (1994). Moral boundaries: a political argument for an ethic of cane. New York: Roulledge.

Van Campen, C., \& Kerkstra, A. (1995). Kwaliteir wan leven van somatische verpleeghnispatienten. Een begripsverheldering en overzicht wan meerinsmumenten. QQuality of life of somatic mursing home patients. A summary of concepts and measurement scales], Utrecht: NIVEL.

Wade, D. T. (1992). Stroke: rehabilitation and long-term care. The Lancet. 339. 791-795. 


\title{
Chapter 5
}

\section{Patient autonomy during rehabilitation: the experiences of stroke patients in nursing homes}

\begin{abstract}
This article describes the results of a grounded theory study among stroke patients $(N=17$, aged 50-85) in rehabilitation wards in nursing homes. Patient autonomy (dimensions: self-determination, independence and self-care) increases during rehabilitation due to patient factors (conditions and strategies of patient) and environmental factors (nursing home and strategies of health professionals and family). During rehabilitation patients are in a state of transition regarding autonomy: patients need support to enhance autonomy, gradually regain autonomy, and thereby need less support. Although facillitating environmental factors were discovered, patients also experienced constraining factors regarding patient autonomy. Health professionals should give more attention to self-determination and independence; the nursing home should offer stroke patients more opportunities to do familiar activities autonomously.
\end{abstract}

Reprinted from:

International Joumal of Nursing Studies, 37, IM Proot. H Hujer Abu-Sagd, WP de EschJanssen, HFJM Crebolder, RHJ ter Meulen, Patient autonomy during rehabilitation: the experiences of stroke patients in nursing homes, 267-76, $\odot 2000$, with permission from Elsevier Science. 


\section{INTRODUCTION}

Patients who survive a stroke (or cerebrovascular accident) have to deal with the new situation of disability and handicap, a process that is often supported by rehabilitation in hospital, rehabilitation center or nursing home. In the Netherlands, stroke patients temporarily admitted to nursing homes are mostly placed in so-called rehabilitation wards. An important aim of the rehabilitative process is the transition from dependence to independence (Wade, 1992). Whereas on admission the stroke patient is hardly autonomous, after discharge he or she has to live independently and autonomously. How could health professionals and family support the patient in regaining his or her autonomy?

A concept analysis on autonomy in relation to the rehabilitation of stroke patients showed that primary literature scarcely exists, but secondary literature does (Proot, Crebolder, Huijer Abu-Saad, \& ter Meulen, 1998). Biomedical ethics provided at least three important concepts related to autonomy and rehabilitation of stroke patients: self-governance (Beauchamp \& Childress, 1994; Mill, 1985), self-realization (Miller, 1981; Taylor, 1991) and actual autonomy (Agich, 1993). The literature on rehabilitation practices and nursing home care provided related concepts which describe the aims of rehabilitation and the support of the environment in reaching these aims: self-care, self-care limitations and dependent care (Orem, 1995), restoration of patient autonomy (Banja, 1993; Pool, 1995), privacy, authority and independence (van Campen \& Kerkstra, 1995), and attentiveness and responsibility (van der Wulp, 1986; Tronto, 1994). Analysis of these concepts revealed that these concepts can be divided in individual and social concepts of autonomy (Proot et al., 1998). An individual concept protects the patient against unwanted interference by others, and places informed consent at the center. This presumes the patient can live his or her life in a competent, individual way, which is in any case problematic in the first months post-stroke because of dependency on other people. A social concept includes the support from the health professionals and the informal caregivers, e.g. regarding decision-making and restoration of autonomy, which seems to link better with the needs in the first phase of the rehabilitation than an individual concept does. The concept analysis shed light on the fact that the majority of studies regarding patient autonomy are primarily based on theoretical reflections, and not on empirical evidence. Moreover, empiricallybased studies on patient autonomy (Mattiasson \& Andersson, 1995; Taes et al., 1996) deal almost exclusively with residents of nursing homes, and do not concern stroke patients temporarily admitted to a nursing home for rehabilitation.

In a grounded theory study among health professionals in nursing homes the core category found out was "Changing autonomy" which identifies the process in which the stroke patients regain their autonomy (Proot, Huijer Abu-Saad, van Oorsouw \& Stevens, 2000a). Health professionals identified three dimensions of 
autonomy: self-determination, independence and self-care. Self-determination refers to freely making choices and decisions about one's own life and health. Independence (physical, psychological and social) concerns planning and organizing one's own life, including social contacts and roles, and responsibility for one's own life and health care. Self-care includes skills (mobility, communication, cognition) and activities of daily living (ADL), necessary for functioning.

Interviews held on admission with stroke patients in rehabilitation wards of nursing homes revealed the same core category (changing autonomy) as found in the health professionals study, and supported a social concept of autonomy (Proot, Crebolder, Huijer Abu-Saad, Macor, \& ter Meulen, 2000b). On admission physical and emotional conditions strongly constrain patient autonomy, and the patient has fewer strategies than pre-stroke. The health professionals facilitate regaining patient autonomy by giving support and information, deciding for the patient (paternalism), assessing ADL, attentiveness and respect. The family facilitates autonomy by providing emotional and instrumental support. Interviews with stroke patients rehabilitating in nursing homes might reveal which concept of autonomy is suitable during rehabilitation.

This article reports on interviews with stroke patients during rehabilitation. These interviews are part of a large-scale research project regarding the autonomy of stroke patients temporarily admitted to nursing homes. The longterm purposes of this project are twofold: firstly, to identify what areas need special attention regarding patient autonomy during different phases in the rehabilitative process; secondly, to make recommendations how stroke patients can be best prepared for their return home regarding their own autonomy. Specifically, though, this article seeks to determine which facilitating or constraining factors regarding patient autonomy during rehabilitation are identified by stroke patients in rehabilitation wards in nursing homes.

\section{METHOD}

Grounded theory (Strauss \& Corbin, 1990) was used to explore patient autonomy during rehabilitation, for two reasons. First, the concept under study has been little studied, and second, the final recommendations of the project have to be used by health professionals. Grounded theory is an appropriate method to uncover a phenomenon, and has the advantage that the theory to be generated fits in with practice (Strauss \& Corbin, 1990). Through theoretical sampling, data sources are selected.

\section{Setting and sample}

The study was carried out in the rehabilitation wards of 3 nursing homes in the province of Limburg, the Netherlands. After approval was received from the appropriate ethics committees, data were collected. 
Table 1. Demographic characteristics of the stroke patients.

Characteristics

Women

Age (years: $M$, range)

Civil state

- unmarried

- married

- divoreed

- widowed

Educational lewel

- lower vocational or less

- intermediate vocational or general secondary

- higher vocational or university

$(\mathbb{N}=17)$

7

$72.5(50-85)$

4

4

9

12

3

2

Twenty-two stroke patients were approached (Proot et al., 2000b). Consecutive patients with a confirmed diagnosis of stroke who were admitted to one of the rehabilitation wards participating in the study were included if they were able to communicate, if they were Dutch and spoke their mother tongue, if the rehabilitation goal was to return to their own home or an old people's home, and if participating in the study was not a heavy burden for the patient. Patients were excluded if they had severe multi-morbidity (somatic, psychiatric and/or psychogeriatric) which would interfere with participation in the study. Participation was contingent on informed consent. The protocol for selection and sampling has been described in detail elsewhere (Proot et al., 2000b). In total, 58 patient interviews were held; 21 interviews on admission, 17 interviews during rehabilitation, and 20 interviews at discharge. All interviews with a particular patient were conducted by the same interviewer. This article reports on the interviews during rehabilitation. All 17 stroke patients invited consented. Of the 22 patients participating in the study, one patient died and 4 patients were discharged quickly (with three of them interviews at discharge were held).

Table I shows demographic characteristics of the patients participating: 10 men and 7 women, ranging in age between $50-85$ years $(M=72.5)$.

\section{Data collection}

\section{Interview guide}

Experiences from a previous study (Proot, 1994), interviews with stroke patients discharged from nursing homes, and sensitizing concepts derived from literature (Proot et al., 1998) were used to develop an open-ended interview guide. This guide was reviewed by project group members and by selected experts, and 
accordingly revised. A pilot interview was held, leading to no changes being made.

Autonomy was not defined for the patients because an important goal of grounded theory is to understand the interviewees' world as they understand it. In the admission interviews patients were asked how they defined aulonomy (if patients did not know the word autonomy an equivalent was used to invite patients to tell about their experiences). This definition was also used in the rehabilitation interview, which concemed questions on changes in autonomy ("Do you think that your autonomy (or the word used by the respondent) has decreased/increased in the last three weeks?'), on constraints and improvements of autonomy ("What do you feel led to a decrease/increase in your autonomy?"), and on the approach by health professionals and family with regard to aum tonomy. Refusal of treatment, complaints about treatment, and the patient's own need for sharing decisions were also questioned.

\section{Procedure}

Interviews were held 8 weeks ( $M$, range from 6-1 I weeks) after admission in the rehabilitation ward (when the patient was habituated to health professionals and care routines, and when the patient started to see own improvement), and lasted for about 45 minutes (range 25-60 minutes). Due to communicative impairments, the patient was offered the possibility to have a 'spokesperson' present during the interview, but no patient used a spokesperson. The interviews were conducted by two trained interviewers, who introduced topics and used follow-up probes if necessary to encourage patients to give more information or examples. The interviews were tape-recorded (after consent) and transcribed with all identifying data removed. Field notes were kept during and after each interview. The result was about 255 pages of text.

\section{Data analysis}

The qualitative data were analyzed using the constant comparative method as described in grounded theory (Strauss \& Corbin, 1990). The computer program Kwalitan 4.0 was used to store and organize the qualitative data. Interviews and field notes were coded. Themes related to autonomy of stroke patients were grouped, compared and categorized.

Both descriptive coding and theoretical coding were used: descriptive coding to explore the phenomenon, and theoretical coding to develop a theory in order to clarify relationships between concepts and to facilitate the development of a theoretical framework. Saturation was reached after analysis of 9 interviews. Eight interviews were used to test the theory developed.

\section{Validity}

Data triangulation, investigator triangulation and methodological triangulation (Denzin, 1989) were used to broaden the analysis of the phenomenon of stroke patient's autonomy, and to secure content validity (Sim \& Sharp, 1998). Patients 
admitted to different nursing homes and with varying socio-demographic variables participated in the study (data triangulation); two interviewers, and peer debriefing during analysis were used (investigator triangulation); apart from individual in-depth interviews, member checks were held (methodological triangulation).

\section{RESULTS}

Patient autonomy changes during rehabilitation, a process subsumed in the core category 'Changing autonomy' (dimensions self-determination, independence and self-care). In this section the core category and the factors influencing the core category during rehabilitation are described and illustrated by selected interview scenes (where the core category as a whole is meant, the word 'autonomy' is used; where a particular dimension is meant, this dimension is used).

\section{Changing autonomy}

During rehabilitation patient autonomy is increased in comparison to admission, particularly the dimension self-care:

"They don't have to help me. I get out of bed by myself, step into my slippers which are beside my bed, and off I go to the bathroom." (p04b,p.2)

"I am not so dependent anymore.(..) Activities I couldn't or wouldn"t do because I was not motivated, or because I didn't feel well, I do now by myself. But mainly because I was unable to do them. For instance, it was difficult to pass a dish or to reach for something during a meal. That is much better now. And my walking is improving. I'm not scared to take the elevator. Most times someone is with us." (p12b,p.4)

The patient needs less support, but the need for support may vary:

"Sometimes the pants are a problem, especially when they are tight. If I wear looser fitting pants I'm able to go to the bathroom by myself."(p 13b,p.6)

During rehabilitation some patients experience a status quo (leveling out in their rate or degree of progress) regarding the dimension self-care:

[Autonomy is]"Not less. Maybe the speed of progress is less. Improvement is slower, you can't do everything by yourself yet. They want to teach you how to be independent, but it isn't happening. Walking isn't independent. I need a therapist. But that isn't really independent."(pllb,p.2) 
Some patients experience a difference between what they want to do and what they are able to do, which may lead to sadness or irritation:

"I used to be right-handed; now I have to do it left-handedly. "That's difficult. I would love to be able to shave myself with soap. I have tried it once, in the hospital, but I started to bleed like a pig. I'm scared to try again, but miss. doing it. [Interviewer: Do you shave electric now?] I have to now. But I'm used to shave with soap and a knife, long time ago.(...) Ever since l we been married, I have used those double blades. That worked fine, but you know, I can't do that now and I feel bad about that."(p/3b,p.7/8)

Patient autonomy changes during rehabilitation due to patient and environmental factors. Patient factors concern conditions and strategies of the patient. Environmental factors encompass the nursing home, and the strategies of health professionals and family.

\section{Patient factors}

\section{Conditions of the patient}

Two patient conditions facilitate patient autonomy during rehabilitation: improving abilities and increasing self-confidence (being aware of ow progress, getting accustomed to health professionals and care routines, comprehension of therapy targets, increasing expertise) (see table 2, p.72). Residual disabilities post-stroke, multi-morbidity and insecurity constrain patient autonomy.

Improving abilities facilitate the dimension self-care, whereas residual disabilities post-stroke and multi-morbidity constrain self-care:

[Memory]"Increases. I used to get stuck, but now I remember more." (p $\mid 2 b, p .5)$

"It [the right arm』 won"t work. Sometimes I think that it serves worse." (p $136, p .5)$

Patients are aware of an increase in self-care, and are proud of their own progress. Moreover, they are habituated (e.g. they know health professionals, allocation of tasks and care routines), and experience increasing expertise. These alterations lead to an increase in self-confidence. Nevertheless, patients feel insecure and feel like laypersons concerning rehabilitation methods:

"If I have to go to the bathroom now and again one hour later, they say" "Your have just been." A while ago I said: "But nurse, how do you know when I have to pee?" Maybe a bit forward, but you know, they tell you to tell them, to come up for yourself."(pl 1 b, p.6) 
Table 2. Facilitating and constraining patient factors regarding autonomy during rehabiliation, as experienced by stroke patients.

\begin{tabular}{lll} 
Paticnt factors & Facilitating factors & Constraining factors \\
\hline Condutions of patient & improwing abilities & $\begin{array}{l}\text { residual disabilities } \\
\text { multi-morbidity } \\
\text { insecurity }\end{array}$ \\
Strategies of patient & $\begin{array}{l}\text { responsibilityinitiative } \\
\text { using self-care skills } \\
\text { instructing the family } \\
\text { shared decision-making }\end{array}$ & (no strategies mentioned) \\
\hline
\end{tabular}

"I assume that the staff of the nursing home know how you should do everything. That's none of my business. I don't exactly know how things are done. They are trained, and know what is correct [regarding rehabilitation methods].[Interviewer: Did you discuss it with the staff?] No, I haven't done that yet. Everytime I think: the way you guys do it, is good enough for me." $(p|| b, p, 10)$

\section{Strategies of the patient}

The following strategies facilitate autonomy: taking responsibility and initiative (co-operation, anticipating, problem solving, taking stock of the situation, own effort, refusal), using self-care skills, instructing the family, and shared decisionmaking (see table 2).

Patients take responsibility and initiative, and sometimes learn that their selfcare skills are not always sufficient:

"I usually say: "Let me be (...), let me do what I think is right." They [health professionals] will let me know when I do it wrong, and they don't have to do anything when I do it right." (p21 b,p.11)

"That's when I fell. I went to bed by myself, it was $8.45 \mathrm{p} . \mathrm{m}$. Those nurses can't be everywhere at the same time I thought. So I went to bed by myself, wheeled the wheelchair up to my bed. That worked OK another time."(p06b,p.6)

Patients co-operate with the health professionals, anticipate the care routines and solve problems:

"When I go to bed, I'll tell the girls: "I'll call you" or "Why don't you come back in half an hour", and proceed to drop my clothes on the floor as I 
undress. I am unable to keep my balance and hang my clothes at the same time. They'll tidy it up. And then I crawl under my blankets." (p 13b,p.5)

Patients take stock of the situation and indicate their priorities in learning. Learning self-care skills requires their own effort:

"I will take that paper when P. is finished with it. I want to study it. Then I"Il take my shoes off, and practise as I see it in the picture."(p04b,p. I 1)

During rehabilitation patients inform and instruct the family, and sometimes refuse health professionals" proposals or decline support:

"When my daughter offered to help me with my dress, I told her: "You have to do the bad arm first, then the good one, and then over my head". But she couldn't do it, and I told her: "You're not cut out to be a nurse"."(p04b,p.8)

"Standing by myself at the sink. To wash myself, top to bottom, and getting dressed. And then she [caregiver] wants to steady me - but I. say" "You don't need to do that, I won"t fall, I know"."(p07b,p.10).

Although decision-making about their own treatment is difficult for most patients, they valued shared decision-making, e.g. about destination and moment of discharge, recreation, meals, therapy schedules, care routines, and aids. Shared decision-making might be improved by information, deliberation and evaluation, for example, by the presence of the patient at team meetings:

"That I'm allowed to be present, at my own team-conference."(p19b,p.27)

\section{Environmental factors}

\section{Context of the patient}

The nursing home as temporary context of the patient both facilitates and constrains autonomy (see table $3, p .74$ ). The presence of healti professionals and fellow patients facilitates autonomy, as does spending time performing familiar activities. In comparison with hospital, patients experience a personal atmosphere and receive more physiotherapy, occupational therapy and speech therapy which also facilitate autonomy. However, care routines, no privacy, time constraints, and lack of familiar activities to perform limit autonomy. The context has been described in detail elsewhere (Proot et al., 2000b). The subcategory familiar activities plays a particular role during rehabilitation and is discussed here.

Spending time autonomously is important for patients during rehabilitation, because patients possess more skills than on admission. In addition, for some patients therapy has decreased, or even fimished, which leads to more "free 
Trable 3. Facilitating and constraming environmental factors regarding autonomy during rehabilitation, as experienced by stroke patients.

\begin{tabular}{|c|c|c|}
\hline Environmental factors & Facilitating factors & Constraining factors \\
\hline Nursing home & $\begin{array}{l}\text { healh professionals } \\
\text { fellow patients } \\
\text { familiar activities } \\
\text { personal atmosphere }\end{array}$ & $\begin{array}{l}\text { care routines } \\
\text { no privacy } \\
\text { lack of familiat activitics } \\
\text { time constraints }\end{array}$ \\
\hline $\begin{array}{l}\text { Sirategies of health } \\
\text { professionats }\end{array}$ & $\begin{array}{l}\text { attentiveness/respect } \\
\text { support/therapy } \\
\text { paternalism (treatment) } \\
\text { information } \\
\text { evaluation } \\
\text { deliberation }\end{array}$ & $\begin{array}{l}\text { paternalism (other) } \\
\text { lack of information } \\
\text { lack of evaluation } \\
\text { lack of deliberation }\end{array}$ \\
\hline Strategies of family & $\begin{array}{l}\text { emotional support } \\
\text { instrumental support }\end{array}$ & being overprotective \\
\hline
\end{tabular}

* paternalism regarding treatment decisions

b paternalism regarding other decisions than treatment

time'. Lack of familiar activities to devote time to constrains autonomy, because the patient is less motivated to learn and to train in skills and activities, and because opportunities to express individuality are missing.

"Maybe you'll start to participate with the crafts, and that doesn't interest me. Thar's good for when you have more grandchildren. They can play with those things." (p04b,p.8)

\section{Strategies of the health professionals}

A consistent approach by all team members greatly facilitates patient autonomy. Attentiveness and respect, giving support and therapy (supervision, instructions, aids), paternalism (deciding for the patient) regarding treatment, information, giving evaluation, and deliberation facilitate autonomy. Lack of information, evaluation and deliberation, and paternalism (regarding other aspects than treatment) constrains autonomy (see table 3 ). Health professionals' conditions affect their strategies negatively (time constraints and illness) or positively (expertise and commitment).

Attentiveness is necessary to determine whether and when support is needed, and what sort of support. If carefully used, waiting periods stimulate autonomy during rehabilitation, except waiting periods for toiletting: 
"Then they [caregivers] go to someone else, and then I think, why don't you give it a try. And then I do it all by myself, then I want to do it by myself." (p04b,p. 14)

"In the beginning I had some difficulty with that [waiting periods]. And I said: "You girls have to take into account that it is not my fault either, that I have to pee. My doctor tells me to drink lots. I do, and then I have to pee more." (...) I am already punished enough by this disease. They have laken much of your freedom."(p 10b, p.4/5)

Giving less support helps patients discover their own possibilities and take responsibility:

"Last week Friday, the physiotherapist said (..): "Why don't you go by yourself?". So I went for a walk, alone. I walked too long, one hour. I was quite tired in the evening." (p07b,p.3)

Proffering therapy, e.g. assessing patient's need for aids or adaptations at home after discharge, and giving instructions, facilitates the dimension self-care:

"With walking, they say, you have to lift your feet up, lift them up more, don't drag them. Also how to climb stairs, for when I go home."(p $12 b, p .5)$

A respectful approach is important with regard to the dimension selfdetermination, which includes, for example, apologizing:

"Without me noticing it, she mixed some powdered medication in my coffee.(...) "I don"t like that. So now I get other medication and half a glass of water. I hate medication in my coffee, it makes it tasteless." Later on she came and offered her excuses." $(p 07 b, p, 8)$

Health professionals decide for patients (paternalism) regarding their rehabilitation, which facilitates the patients" long-tem autonomy. The health professionals assign to patients tasks for which they need to be motivated, because patients do not always see the aim. Health professionals use the discharge enviromment to molivate the patient.

"We [patients] are inclined to say too quickly:" That is silly, why do I have to do that childish stuff. To sit at a table and work with small blocks". (...) But later on $\mathbb{I}$ find that the activity was much more difficult than I initially thought." (p $10 \mathrm{~b}, \mathrm{p} .13)$

"Then they [caregivers] say: "When you're home, you still have to be able to do that"."(p04b,p.11) 
Patients mostly value paternalism regarding treatment decisions, but they need information, evaluation and deliberation. However, they do not appreciate patemalism with regard to other decisions, for example, regarding toilet times and leisure activities.

"I would like to get more therapy. I would like to get better as fast as possible. But what is the best way? (...) The other day we had had a busy day with walking etc., but I had to pay for it the next day. The head of the department said: "It"s possible that we not exercise too much too quickly, that we don't force it"." (p10b,p.15)

"When I"m done in occupational therapy, she takes me to the craftroom, to have a look around. (...) Then she says: "Do you want to do a craft?", but I answer: "Please take me back upstairs". She would like me to stay in the craftroom." (p04b,p.8/9)

A number of patients experience lack of information, deliberation and evaluation about treatment plans and discharge planning which constrains the dimensions independence and self-determination:

"When they told me: "It is written down here, that you have to take care of yourself". I said: "Nobody has ever told me that, but I appreciate it", I can see that I have to." (p $136, p .5)$

"I"m not sure how long you can stay here for rehabilitation."(p l l b,p.5)

\section{Strategies of the family}

During rehabilitation facilitating strategies of the family concern in particular emotiona support (e.g. frequently visiting, distracting, advising and stimulating the patient, and giving feedback). In addition, instrumental support is given (e.g. supporting during home-visit, transporting, regarding care of premises, plants and pets, shopping, delivering mail and laundry) (see table 3, p.74). Families' conditions affect their strategies negatively (fear -that something failed- and having a job) or positively (having a driver's license, a reliable car, and expertise). Long distance between families" whereabouts (families' context) and the nursing home constrains families" strategies.

The family stimulates the patient and arranges home visits. Home visits connect patients with life pre-stroke, and facilitate autonomy.

"Last week my daughter asked me: "When can you come and visit me?". I said: "That's impossible with that wheelchair". And she said: "I'll ask about it". She picked me up on Sunday and took me back in the evening and everything went alright." $(p \mid 1 b, p, 7)$ 
However, patients sometimes experience being overprotected, which may constrain autonomy:

"Between us, when I'm busy at home, and I need something then she [spouse] is right there to help. That is not so good. She means well, but takes over too quickly."(p 13b,p.8)

\section{DISCUSSION}

This study indicated that the stroke patient's autonomy increases during rehabilitation due to patient and environmental factors. Patient factors concern conditions and strategies of stroke patients. Improving abilities and increasing self-confidence facilitate patient autonomy, but residual disabilities post-stroke, multi-morbidity, and insecurity are constraining. Patient's strategies facilitate autonomy: taking responsibility and initiative, using self-care skills, instructing the family, and shared decision-making. Envirommental factors concern the nursing home and the strategies of the health professionals and the family. The nursing home as temporary context of the patient facilitates autonomy by the presence of health professionals and follow patients, and by famillar activities to spend time doing. In comparison with hospital, patients experience a personal atmosphere and receive more physiotherapy, occupational therapy and speech therapy which also facilitate autonomy. However, care routines, no privacy, time constraints, and lack of familiar activities to spend time on constrain autonomy. If tailored to patient's conditions and strategies, and if all team members approach the patient in a consistent way, the following strategies of health professionals support regaining autonomy: attentiveness and respect, giving support and therapy, paternalism regarding treatment, information, giving evaluation, and deliberation. However, lack of information, evaluation and deliberation, and paternalism regarding other aspects than treatment, such as toilet times and leisure activities constrain autonomy. Surprisingly, patients indicate that waiting periods, if carefully used, stimulate autonony, excepr waiting periods for toiletting. Facilitating strategies of the family concern particularly emotional support, but also instrumental support. Being overprotective constrains autonomy.

During rehabilitation patients are in a state of transition regarding autonomy. Autonomy is changing: on the one hand, patients need environmental support, and patemalism (regarding treatment) to enhance autonomy (a social concept of autonomy, Proot et al, 1998); on the other, patients gradually develop responsibility and self-care skills, and need less environmental support, indicating that they regain autonomy (between a sociall and indiwidual concept of autonomy, Proot el al., 1998). These results relate to the concept 'actual autonomy' (Agich, 1993) which entails that autonomy is not a static concept, but one that changes over time. Expressions of autonomy show not only who the person is, but also who the person is becoming. The results of the present study 
showed that healh professionals take on a paternalist attitude, which involves deciding for patients regarding their rehabilitation in view of restoring the patients' autonomy in the long-term. In bioethical literature, individual concepts of autonomy dominate, e.g. self-governance. Self-governance is generally described as acting voluntarily and consciously without any constraint (Beauchamp \& Childress, 1994). In general, paternalism nuns counter to an. indiwidual concept of autonomy. As long as patients are capable to decide for themselves, patemalism can not be morally justified (Musschenga, 1987). However, several authors have discussed the problematic status of autonomy in the context of rehabilitation (Caplan, 1988; $\operatorname{Sim}, 1998$ ). Caplan, for example, argued that in the context of rehabilitation autonomy as the only principle would sometimes be inappropriate, in particular when patients have undergone a sudden and unexpected course of severe impairment. According to Caplan, in these cases it is required that patemalistic actions be viewed to some extent as morally justified. However, only if health professionals can justify such actions in view of enhancing or restoring autonomy, ignoring or overriding patient choices is allowed (Caplan, 1988). Meier and Purtilo (1994) suggested alternating between beneficence and autonomy. They stated that if patients prefer experienced health professionals to make the decisions regarding their treatment, autonomy as leading principle falls short and beneficence is more appropriate.

The results showed that health professionals gave enough attention to the dimension self-care, but should stimulate and enable the dimensions selfdetermination and independence more than they do now. Health professionals stated that when patients regain autonomy, gradually an individual concept of autonomy might be more appropriate, but realized that they do not give enough attention to this process (Proot et al., 2000a). Banja (1993) observes that health professionals working with patients suffering from brain injury often interpreted independence as only physical non-dependence. Health professionals should be attentive to the patients' attempts to reclaim their dignity, assertiveness, and sense of control, and not regard them as instances of non-compliance when they seem to contradict or oppose the treatment plan (Banja, 1993). Wegener (1996) proposed a model based on unterdependence and deliberation. In this model the interaction between patient and health professional is marked by deliberation: the process of reflection, choice and discussion serves to balance the patient's initial lack of choice.

Spending time autonomously appeared to be more important during rehabilitation compared to admission: a number of patients experienced lack of familiar activities in therapy, in recreation and on the ward. Lack of familiar activities constrains autonomy for at least two reasons. First, patients are less motivated to learn and to train in skills and activities. During rehabilitation. patients have to become what Ada, Canning \& Westwood (1990) called active learners". Active learning involves that patients have the opportunity to practise skills and tasks on their own as much as possible, in order to gain carryover from therapy to everyday situations (Ada et al., 1990). Nurses or practical nurses 
have an integrative function in daily care on the ward, and can help stroke patients integrate newly learned activities of daily living (Kirkevold, 1997). Second, familiar activities enhance patients" self-realization. Self-realization, an autonomy concept derived from biomedical ethics, includes the way one shapes and lives one's own life and expresses individuality (Miller, 1981; Taylor, 1991). During rehabillitation both active learning and self-realization are important with regard to being prepared for autonomous living at home after discharge.

The patients in this study valued families' support regarding autonomy: in particular emotional support, but also instrumental support facilitate autonomy. However, in the interviews remarks were made about families being overprotective during home visits. Glass \& Maddox (1992) examined the impact of social support on the recovery from stroke. In a longitudinal study among 44 stroke patients during and after hospital admission a high level of emotional support appeared to be an important facilitating factor for recovery from stroke. Findings indicate that with emotional support "more is better'. In contrast, for instrumental support 'moderation in all things' may be a better rule of thumb.

\section{Implications of the study}

In sum, several envirommental factors might be modified to improve patient autonomy during rehabilitation. Health professionals should be attentive to the stroke patient's actual autonomy (self-determination, independence and selfcare) and avoid patemalism regarding other aspects than treatment. Giving information, deliberation and evaluation regarding treatment are important to stimulate patient's responsibility and initiative, and give room for shared decision-making. Although patients instruct their families during rehabilitation, the health professionals should be attentive about families' insecurity regarding what support they should give, and about families being overprotective. If this is the case, health professionals should instruct the patient and the family together, in order to prevent a decrease of newly leamed autonomy. Health professionals" expertise and commitment appeared to influence their strategies positively. These conditions might be improved through multidisciplinary guidelines and courses regarding the approach of patient autonomy. The results of the present study could be used to develop such guidelines and courses, which might also enthance a team approach with regard to patient autonomy. The nursing home as organization should seek for opportunities to proffer patients a varriety of activities to spend time doing in order to stimulate and increase autonomy. Although difficult to organize, the opportunity for patients to help with household work in the ward should be considered seriously. Therapy activities should be tailored as much as possible to the individual patient, or enough information should be given why a particular therapy activity is chosen.

Patient autonomy during rehabilitation appeared to differ from autonomy on admission, a result that gives ground to expect that autonomy at discharge from the nursing home will also differ from autonomy during rehabilitation. More 
research is warranted into the experiences of stroke patients regarding autonomy during the last weeks in the nursing hone, to explore patient's needs at discharge, and to improve patients" preparation for their return home.

\section{REFERENCES}

Ada, L., Canning, C., \& Westwood, P. (1990). The patient as an active leamer. In L. Ada, \& C. Canning (Eds.), Key issues in netrological physiotherapy (99-124). Oxford: Butcrworth Heinemann.

Agich, G.J. (1993). Autonomy and long-term care. Oxford: Oxford University Press.

Banja, J. D. (1993). Ethical issues in staff development. In C.J. Durgin, N.D. Schmidt, \& L.I. Fryer (Eds.), Staff development and clinical interwention in brain injury (23-41). Maryland: Aspen.

Beauchamp, T. L., \& Childress, J. F. (1994). Principles of biomedical ethics. Oxford: Oxford University Press.

Campen, van, C., \& Kerkstra, A. (1995). Kwaliteit van leven wan somatische werpleghuispatiënten. Een begripsverheldering en overzicht van meetinstrumenten. [Quality of life of somatic nursing home patients. A summary of concepts and measurement scales]. Utrechi: NIVEL.

Caplan, A.L. (1988). Informed consent and provider-patient relationships in rehabilitation medicine. Archives of Physical Medicine and Rehabilitation, 69, 312-317.

Denzin. N.K. (1989). The research act: a theoretical introduction to sociological methods. Englewood Cliffs: Prentice Hall.

Glass, T.A., \& Maddox, G.L. (1992). The quality and quantity of social support: stroke recovery as psycho-social transition. Social Science and Medicine, 34, 1249-1261.

Kirkevold, M. (1997). The role of nursing in the rehabilitation of acute stroke patients: towards a unified theoretical perspective. Advances in Nursing Sciences, 19(4), 55-64.

Mattiasson, A., \& Andersson, L. (1995). Quality of nursing home care assessed by competent nursing home patients. In A. Mattiasson (Ed.), Autonomy in nursing home settings. Study $5(1-14)$. Stockholm: Karolinska Institute.

Mejer, R.H., \& Purtilo, R.B. (1994). Ethical issues and the patient-provider relationship.

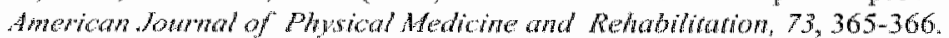

Mill, J.S. (1985). On Wberry. Harmondsworth: Penguin Books. [First published 1859].

Milter, B.L. (1981). Autonomy \& the refusal of lifesaving treatment. Hastings Center Repont. 1/(4), 22-28.

Musschenga, A.W. (1987). Kwatiteir van leven: criterim vor medisch handelen? [Quality of life: a nom in medical ethics?]. Baam: Ambo.

Orem, D.E. (1995). Nursing: concepts of practice. St. Louis: Mosby.

Pool, A. (1995). Autonomie, afhankelijkheid en langdurige zorgverlening. [Autonony, dependence and long-term care]. Utrecht: Lemma.

Proot, I.M. (1994). Protocol, autonowie en werantwoordelijheid in de zorg voor CFApatienten. [Protocol, autonomy and responsibility in the care of stroke patients]. Masters thesis. Maastrich: Maastricht University.

Proot, I.M., Crebolder, H. F, J. M., Huijer Abu-Saad, H., \& ter Meulen, R. H. J. (1998). Autonomy in the rehabilitation of stroke patients in nursing homes: a concept analysis. Seandinavian Joumal of Caring Sciences, $12,139-145$.

Proot, I.M., Hujjer Abu-Saad, H, Oorsouw, van, G.G.ll. \& Stevens, J.J.A.M. (2000a). Autonomy in stroke rehabilitation: the perceptions of health professionals in nursing homes. Submitted for publication in Nursing Ethics. 
Proot, I.M., Crebolder, H.F.M., Huijer Abu-Sad, H., Macor, T.H.G.M., \& ter Meulen, R.H.J. (2000b). Facilitating and constraining factors on autonomy: the views of stroke patients on admission into nursing homes. Clinical Nursing Research, 9.460-478.

Sim, J. (1998). Respect for autonomy: issues in neurological rehabilitation. Chinical Rehabilitation, $12,3-10$.

$\operatorname{Sim}$, J., \& Sharp, K. (1998). A critical appraisal of the role of triangulation in nursing research. International Joumal of Nursing Snudies, 35, 23-31.

Strauss, A., Corbin, J. (1990). Basics of qualitative research: grounded theory procedures and lechniques. Newbury Park: Sage.

Taes, C.G.J, van Campen, C., \& Kerkstra, A. (1996). Ervaren autonomie en ervaren weiligheid bij somatische verpleeghuisbewoners. [Experienced autonony and experienced safety for somatic nursing home patients]. Kwaliteit en Zorgr [Quality and Care], 4, 52-62.

Taylor, C. (1991). The malaise of modernity. Don Mills: Stoddart Publishing. (Republished as: The ethics of awhenicity. (1992). Cambridge: Harvard Uniwersity Press).

Tronto J.C. (1994). Moral boundaries: a political argument for an ethic of care. New York: Routledge.

Wade, D.T. (1992). Stroke: rehabilitation and long-term care. The Lancet, 339. 791-795.

Wegener, S. T. (1996). The rehabilitation ethic and ethics. Rehabilitation Psychology, 41, 517.

Wulp, van der, J.C. (1986). Werstoring en verwevking in verpleeghuizen. [Impairments and its resolution in nursing homes]. Nijkerk: Intro. 



\section{Chapter 6}

\section{Stroke patients' needs and experiences regarding autonomy at discharge from nursing home}

\section{ABSTRACT}

In this qualitative study stroke patients rehabilitating in nursing homes experienced an increase in their autonomy (particularly in self-determination, independence and self-care) in the last weeks before discharge. The change in autonomy was found to be related to regained abilities and self-confidence, and to patients' strategies (e.g. taking initiative, being assertive). The attitude of health professionals and family, and the nursing home could influence patient autonomy. Overprotection, paternalism, care routines and an inconsistent approach constrain autonomy. Conversely, attentiveness, tailored interventions and a respectful dialogue facilitate autonomy, like moderate instrumental and emotional support by the family. Nursing homes can enhance autonomy by minimizing care routines and by providing room for doing activities independently and privately. Attention to patient autonomy may improve patients' active participation in rehabilitation, quality of life, and autonomous living after discharge. Multidisciplinary guidelines based on the results may increase attention to the stroke patients' autonomy and stimulate a team approach.

Reprinted Trom:

Paient Education and Counseling, 4I, IM Proot, HFJM Crebolder, H Huijer Abu-Saad, THGM Macor, RHJ ter Meuten, Stroke patients' needs and experiences regarding autonony at discharge from nursing home, 275-283, $\odot$ 2000, with penmission from Elsevier Science. 


\section{INTRODUCTION}

In the Netherlands older stroke patients with considerable residual disability, who need further rehabilitation after hospitalization are frequently admitted to nursing homes (1). On so-called rehabilitation wards they are treated by a multidisciplinary team (nurses, doctors, physiotherapists, occupational therapists, speech therapists and social workers) $(2,3)$. On admission the patients' autonomy will often be decreased: Not only the patients' physical abilities are diminished but their life plans are also suddenly interrupted. Patient, family and professionals work together to regain lost abilities, and to adapt to residual disabilities. These efforts are made taking into consideration the requirements of the discharge environment (own home or an old people's home) where the patient has to live more or less autonomously, that is, in respect of the transition from dependence to independence (4). In the last weeks before discharge final preparations are made to ensure a smooth and successful transition. However, after discharge problems often occur. 'Samen Verder' ['Continuing Together'], a Dutch organization of stroke patients and spouses, refers to this situation as the 'black hole', a phenomenon which occurs when stroke patients return to their homes and do not know how to live their lives. These concerns have raised a number of questions with regard to the role of health professionals and family in facilitating the stroke patient's autonomy at discharge.

Concerning the rehabilitation of patients suffering from brain injury, Banja stated that, although patient autonomy is affected when rehabilitation starts, during the rehabilitative process patients become more and more responsible for their actions and decisions, and that the health professionals have to relinquish the protective orientation they may have assumed initially toward the client (5). In a study looking at the perceptions of health professionals working in nursing homes with regard to the stroke patients" autonomy, three dimensions of changing autonomy were identified: Self-determination, independence and selfcare (6). Self-determination refers to freely making choices and decisions about one's own life and health (e.g. how to spend one's own time, choice of therapist). Independence (physical, psychological and social) concerns planning and organizing one's own life, including social contacts and roles, and responsibility for one's own life and health care. Self-care includes skills (mobility, communication, cognition) and activities of daily living (ADL), necessary for functioning. The health professionals appeared to focus particularly on the dimension self-care, which they felt was not enough to prepare patients for autonomous living (6). In a study looking at the perceptions of stroke patients with regard to their autonomy similar results were identified (7). During rehabilitation stroke patients regain their autonomy due to patient-related factors and to factors related to nursing home, health professionals and family (8). On admission patients need support to enhance autonomy, and as they gradually regain their autonomy, they need less support from the environment. This is in 
line with the concept of actual autonomy, which defines autonomy not as a static concept, but as one that changes over time and which depends on a person's current development and environment (9).

This article reports on interviews with stroke patients at discharge from nursing homes. These interviews are part of a large-scale research project regarding the autonomy of stroke patients rehabilitating in nursing homes. The long-term purposes of this project are twofold: Firstly, to identify the areas that need special attention regarding patient autonomy during different phases in the rehabilitative process; secondly, to make recommendations how stroke patients can be best prepared for their return home regarding their own autonomy. Specifically, though, this article seeks to determine which facilitating or constraining factors regarding patient autonomy at discharge are identified by stroke patients in nursing homes.

\section{METHOD}

\section{Grounded theory}

Grounded theory (10) was used to explore patient autonomy at discharge, for two reasons. First, the concept in question has been little studied, and second, the final recommendations of the project have to be used by health professionals. Grounded theory is an appropriate method to uncover a phenomenon, and has the advantage that the theory to be generated fits in with practice (10). Through theoretical sampling, data sources are selected.

\section{Sample}

The study was carried out on the rehabilitation wards of three nursing homes in the province of Limburg, the Netherlands. The project was approved by the ethics committees of the respective institutions. After approval, data were collected. The researcher decided, in co-operation with a key person in each of the nursing homes, which persons could select the patients (head nurse, care coordinator, and/or doctor). Patients with a confirmed diagnosis of stroke who were admitted to one of the rehabilitation wards participating in the study were included if they were able to communicate (opinion of speech therapist), if they were Dutch and spoke their mother tongue, if the rehabilitation goal was to return to their own home or an old people's home, and if participating in the study was not a heavy burden for the patient. Patients were excluded if they had severe multi-morbidity (somatic, psychiatric and/or psycho-geriatric) which would interfere with participating in the study. In total 22 patients were telephoned and received a letter of invitation with information about the study, and a written consent form. All patients invited consented. In total 58 patient interviews were held; 21 interviews on admission, 17 interviews during 
rehabiltation. and 20 interviews at discharge. All interviews with a particular patient were conducted by the same interviewer. This article reports on the interviews at discharge.

Twelve man and eight women participated, ranging in age between 50 to 85 years $(M=72.4)$. Four patients were unmarried, six patients were married, one patient was divorced and nine patients were widowed. Fourteen patients had a low level of education (lower vocational education or less), three had a medium level (intermediate vocational or general secondary education) and three pationts had a high level (higher vocational education or university). Eleven patients were planned to be discharged to their own homes, seven patients to an old people"s home, one patient was planned to be discharged to a home for the handicapped and one patient to a residential ward in the nursing home.

\section{Data collection}

Experiences from a previous study (11), intervicws with stroke patients discharged from nursing homes, and sensitizing concepts derived from literature (12) were used to develop an open-ended interview guide. This guide was reviewed by project group nembers and by selected experts, and revised accordingly. A pilot interview was held, leading to no changes being made.

Autonomy was not defined for the patients because an important goal of grounded theory is to understand the participants' world as they understand it. In the interviews on admission respondents were asked how they define autonomy, and the word they used was also used in the interview at discharge. Patients were interviewed about their own autonomy ("Do you think that your autonomy" (or the word used by the respondent) has decreased/increased in the last three weeks?"), about constraints and improvements of autonomy at discharge ("What clo you feel led to a decrease/increase in your autonomy?'), and about the approach by health professionals and family regarding autonomy. Refusal of treatment, complaints about treament, and the patient's own need for participation in decision-making were also asked about.

Intervicws were held just before the moment of discharge $(M=14$ weeks after admission in the rehabilitation ward, range 4-25 weeks). Patients waiting for adaptations to their own home or for a place in an old people"s home were interviewed when rehabilitation was terminated. Interviews lasted for about 45 minutes (range 35-65 minutes). Due to communicative impairments, the patient was offered the possibility to have a "spokesperson" present during the interview, but no patient used a spokesperson. The interviews were conducted by two trained interviewers, who introduced topics and used follow-up probes to encourage pationts to give more information or examples. The interviews were tape-recorded (after consent) and transeribed with all identifying data removed. Field notes were kept during and after each interview. The result was about 334 pages of text. 


\section{Data analysis}

The qualitative data were analyzed using the constant comparative method as described by Strauss \& Corbin (10). The computer program Kwalitan 4.0 was used to store and organize the qualitative data. Interviews and field notes were coded. Themes related to autonomy of stroke patients were grouped, compared and categorized. Both descriptive coding and theoretical coding were used: Descriptive coding to explore the phenomenon, and theoretical coding to clarify relationships between concepts and to facilitate the development of a theoretical framework. Saturation was reached after analysis of ten interviews; ten interviews were used to validate the theory developed.

Data triangulation, investigator triangulation and methodological triangulation (13) were used to broaden the analysis of the phenomenon of the stroke patient's autonomy, and to secure content validity (14). Patients admitted to different nursing homes and with varying socio-demographic variables participated in the study (data triangulation); there were two interviewers, and peer debriefing during analysis was used (investigator triangulation); apart from individual in-depth interviews, member checks were held (methodological triangulation). "Member checks" means that group meetings were organized with the patients who participated in the study, where the results of the analysis were discussed.

\section{RESULTS}

Patient autonomy changes at discharge, a process subsumed in the core category 'Changing autonomy' (dimensions self-determination, independence and selfcare). In this section the core category and the factors influencing the core category at discharge are described and illustrated by selected interview scenes. (Where all three dimensions are meant, the word 'autonomy' is used; where one of the three dimensions is meant, this particular dimension is used.)

\section{Changing autonomy}

At discharge patient autonomy was found to increase in comparison to autonomy during rehabilitation. The patient needs less support.

"For myself I think everything is going well. I get up and wash myself - they don't need to help me. Same in the evening(...) 1 just go to bed by myself."(pl6c,p.4)

"I stand up more [for myself], yes that"s right(...) I never did that before in my life, I always looked at others."(p18c,p.4) 
Some patients experience a "status quo" (leveling out in their rate of progress) regarding the dimension self-care:

"Right now I feel we"ve reached a quiet phase, nothing much happens [little progress](...). Maybe that's good, it gives you time to mentally adjust to your handicap, to learn to live with it.(..) When you're here, you're actually normal when you have a handicap, but when you're home you feel that you shouldn't be handicapped." $(p 20 \mathrm{c}, \mathrm{p} .1)$

At discharge patient autonomy is influenced by patient and environmental factors. Patient factors concern conditions and strategies of the patient. Environmental factors concern the approach and strategies of the health professionals and the family, and the nursing home as a context.

\section{Patient factors}

At discharge the change in autonomy was found to be related particullarly to patients' improved conditions (regained abilities and self-confidence), and to patients" strategies (taking initiative and responsibility, being assertive, putting things into perspective and sharing decision-making) (see table 1). On the other hand, stroke patients experienced that sometimes the growth of their autonomy is limited by their own conditions (residual disabilities post-stroke, multimorbidity and insecurity).

\section{Conditions of the patient}

Regained abilities facilitate autonomy, although functioning may vary due to residual disabilities post-stroke or multi-morbidity:

"Especially when walking around in a bookstore, doing something interesting or meaningful. Before, I was looking down constantly so I wouldn't trip over the floor-tiles, that was then most important. When I'm entering a bookstore now, I"m looking around to see if $I$ can find something interesting." $(p 20 c, p .5)$

"I'm walking better in the morning than in the evening." (p17c,p.14)

Habituation to own functioning and to the care routines, expertise and being proud of increased autonomy facilitate patients' self-confidence and autonomy, whereas insecurity (due to fear of falling, feeling like a layperson, and leaving the nursing home) constrains autonomy. 
Table 1. Facilitating and constraining patient factors regarding autonomy at disclarge, as experienced by stroke patients.

\begin{tabular}{lll} 
Patient factors & Facilitating factors & Constraining factors \\
\hline Conditions of patient & regained abilities & $\begin{array}{l}\text { residual disability post-stroke } \\
\text { multi-morbidity } \\
\text { insecurity }\end{array}$ \\
Strategles of patient & $\begin{array}{l}\text { taking responsibility/nitiative } \\
\text { being assertive } \\
\text { putting things in perspective } \\
\text { sharing decision-making }\end{array}$ \\
&
\end{tabular}

"Just imagine, when I'm not able to be by myself at home, we have to think of doing something else."(p17c,p.12)

\section{Strategies of the patient}

Patients take initiative and responsibility: they anticipate, for example, home visits and the moment of discharge:

"So I said to the physiotherapist: "I want to know where I'm at, what are your plans? How much longer do I need to be here?" Previously, I had decided not to interfere with my discharge planning, because I thought they would know better, I am no expert." (p20c,p.12)

Patients realize which new problems could appear in the future, organize aids at home, prepare for moving. Some patients leave all practical things regarding discharge to their families. Patients, now habituated to their own functioning, are assertive and set their own limits. They give feeclback to the health professionals (non-verbal or verbal) and sometimes make complaints (for example about fellow patients* smoking, meals and wake-up time):

"When it was too much, when I had to rest, I told them I needed a break." (p18c,p.13)

Patients put their own situation in perspective. They compare their own progress with feilow patients and give information to each other:

[Interviewer: Who did propose that you could go home on Sunday?] [I did] "I heard that from patients who have been here awhile." $(p / 2 c, p .8)$ 
Sharing decision-making would be possible about discharge destination and moment of discharge, therapy schedules, shower schedules and room arrangements. Some patients value shared decision-making about their own treatment, but other patients draw the line here, although they stress that information and cleliberation are necessary:

"I. think it goes too far when patients take part in the decision-making process.(...) That they [health professionals] consult you for something, ok. Certain things like that resting. I think they should have asked me first." (p22c,p.9)

The strategies identified facilitate in particular the dimensions independence and self-determination.

\section{Environmental factors}

Facilitating environmental factors for autonomy include strategies used by the health professionals and the family (see table 2). Strategies of the health professionals include therapy and supervision, attentiveness and respect, and information, evaluation and deliberation. Facilitating strategies used by the family mainly concern instrumental support; in addition emotional support is given. Furthermore, at discharge the presence of fellow patients in the nursing home positively influences patient autonomy (see patient factors). However, some strategies used by the health professionals appeared to constrain autonomy, notably lack of preparation at discharge, lack of attentiveness, respect, information, and evaluation, paternalism (deciding for the patient), and lack of a team approach. Some strategies used by the family, being overprotective and paternalist, were also found to limit patient autonomy. Moreover, in the nursing home, care routines, lack of familiar activities to perform, lack of privacy, and lack of aids were found to impinge on autonomy.

\section{Strategies of the health professionals}

In the last weeks before discharge therapy and supervision might lead to important progress in autonomy, because the patient, in view of the requirements of the discharge environment (living in old people's home, living alone, handicapped partner), is highly motivated.

[The other day] "I had another therapist, who let me walk with a normal cane (...) and everytime he tried to trip me up. I said: "What are you doing?" And he said: "I want to know how your reflexes are". If I would fall or something like that." (p13c,p.3) 
Table 2. Facilitating and constraining envirommental factors regarding autonomy at discharge, as experienced by stroke patients.

\begin{tabular}{|c|c|c|}
\hline Environmental factors & Facilitating factors & Constraining fuctors \\
\hline $\begin{array}{l}\text { Strategies of health } \\
\text { professionals }\end{array}$ & $\begin{array}{l}\text { therapy/supervision } \\
\text { attentiveness/respect } \\
\text { information } \\
\text { evaluation } \\
\text { deliberation } \\
\text { - }\end{array}$ & $\begin{array}{l}\text { lack of preparation at discharge } \\
\text { lack of attentiventesstrespect } \\
\text { lack of infommation } \\
\text { lack of evaluation } \\
\text { paternalism } \\
\text { lack of tean approach }\end{array}$ \\
\hline Strategies of family & $\begin{array}{l}\text { instrumental support } \\
\text { emotional support }\end{array}$ & $\begin{array}{l}\text { overprotection } \\
\text { patemalism }\end{array}$ \\
\hline Nursing home & $\begin{array}{l}\text { fellow patients } \\
-\end{array}$ & $\begin{array}{l}\text { care routines } \\
\text { lack of familiar activities } \\
\text { lack of privacy } \\
\text { lack of aids }\end{array}$ \\
\hline
\end{tabular}

Attentiveness is very important to see which supervision patients need, and to stimulate self-confidence. Patients experience a change in approach in comparison to admission:

[In the beginning]"'They were there for you, physically and emotionally as well. Now they tend to say: "You can do that". I experience that as positive.(...) For instance when you are watehing TV in the evening in the dining room; in the beginning they made sure you were not sitting all alone, and now they come and keep you company, but more to talk about themselves, and to share a drink." (p20c,p.11)

Patients do not always know the reason for a changed approach. In the patients' view the health professionals' expectations are sometimes too hight, which patients experience as a lack of attentiveness:

"They don't stay with you, I wish they would as it increases your selfconfidence and everything works better. "I am in another room, call me when you are ready"."(p19c,p.6)

Some patients experience a lack of preparation at discharge:

[Preparation at discharge?] "Not so far. Or it's coming. I think they'll give me a couple of letters for my doctor."(p16c,p.6) 
Lack of respect, information and evaluation, and paternalism constrain autonomy (in particular self-determination and independence). Some patients are not assertive because of fear of reprisal (for example delay of discharge).

"When they come at 6:45 am, I say: "Nurse, I'm not getting up yet, I did not sleep well and I'm tired. Just let me stay in bed a little bit longer" and if you get the wrong one "Come on, get up, you have to get washed"." (p19c,p.24)

Lack of a team approach is highly constraining for autonomy, because it may be confusing and may diminish self-confidence:

"I'm going by myself again; when I ask them about it they say: "You can go by yourself". And yesterday $\mathrm{X}$ said: "You are not allowed to go by yourself, you have to call us". I said: "I'm not sure what to do anymore". "I'll tell you when you can go by yourself" she said."(p19c,p.9/10)

In the patients' perception, time constraints and hierarchy affect the strategies of the health professionals negatively, which in turn constrains patient autonomy. Patients indicate that time constraints prevent deliberation:

"We don't have a lot of time here. They need to have time for a conference, also at a moment I don't have therapy." (p22c,p.9)

\section{Strategies of the family}

Instrumental support, such as support during home-visits, transport, caring for the home, plants and pets, shopping, delivering mail, laundry, support regarding financial procedures, preparing the discharge environment (rebuilding the patient's own home, designing the new room in an old people's home), facilitates patient autonomy (see table 2, p.91). Instrumental support during longer home-visits is important to help the patient habituate to the new situation:

"I've been home for a long weekend, I left on Saturday night and returned on Monday. My daughter came, and she did all the cooking and the chores, that was very convenient. She sleeps in her own home."(p17c,p.7)

Additional emotional support concerns in particular frequently visiting, and organizing activities in the patients' line. Being overprotective and paternalist constrains autonomy:

"They [kids] said: "You can't go upstairs anymore". "I would not know why not", "Well that's become impossible" they said, but l'd like to try that for myself." (p 14c,p. 10)

In the patients' perception, illness of a family member affect families' strategies negatively, whereas families' expertise affects their strategies positively: 
"Right now she [daughter] has to look after her husband., who is ill, so she is unable to come and visit me."(p03c,p.10)

[Regarding going on holiday with the kids]" The male nurse also said: "Sure, if all are nurses they can all help".'(p $11 \mathrm{c}, \mathrm{p} .8)$

\section{Context of the nursing home}

When the patients" needs for their own habits and planning increase, care routines constrain autonomy (see table 2, p.91):

"Sometimes you have to wait 15 minutes for tea, toast, and you are not allowed to start [breakfast] before 8:30, that is annoying. You are thirsty, and no tea or coffee on the table.(...) You've been up for some time already. It takes awhile when you have to wash yourself independently. "(p/9c,p.25)

Autonomy is also constrained by a lack of familiar activities to perform and by a lack of privacy, for example with regard to recreational activities. Patients sometimes wait till they are back home before doing these activities:

"They come around and ask you to join the exercise program, or crafts, but I'm not going downstairs to throw a ball. That"s a bit childish, if you ask me.(...) [Interviewer: And fancywork?] I do that at home. I knit when I'm home. I can't find a private space here, where I can go and sit."(p /6c,p.9/10)

Broken or insufficient aids, particularly in toilet rooms, impede patients' autonomy.

\section{DISCUSSION}

This study revealed that at discharge the health professionals can facilitate patients' autonomy and active participation by attentiveness, tailored interventions and respectful dialogue while opposite strategies appeared to constrain autonomy. Attentiveness as important factor for tailoring strategies has been described before $(15,16)$. Unsworth (17) examined the perceptions of older stroke patients concerning discharge decisions made during rehabilitation in hospital, and concluded that involving patients in the decision-making process is needed to facilitate the discharge process. In the present study patients appeared to provide each other with support and information, which might have diminished their insecurity, and facilitated their autonomy. Positive effects of being together with other stroke patients have been found before (18). Regarding social support Glass and Maddox (19) followed 44 stroke patients for six montlos following the first stroke and found that with emotional social support "more is better', but for instrumental social support 'moderation in all things' seems 
beneficial for optimal recovery from stroke. In the present study a 'surplus' of emotional support (overprotection) was found to constrain patients' autonomy at discharge. With regard to instrumental support Norris et al. (20) found in a study among geriatric stroke patients that patients reporting a greater variety of problems conceming the receipt of instrumental support from their family also reported a decline in self-care after discharge from hospital. Concerning the mursing home, care routines, lack of familiar activities and lack of privacy appeared, in our study, to hinder patients from getting used to the activities they will have to do after discharge, which may impede a gradual transition from the nursing home to the discharge environment. Conversely, if an environment challenges stroke patients' initiative and responsibility, and stimulates patients to practise everyday tasks, this might improve the outcome of rehabilitation (21).

The results did not indicate that clinical or demographic characteristics determine the content of autonomy, the strategies or the experiences with regard to autonomy. In comparison with data from the national Nursing Home Registration System SIVIS of the Dutch center for health care information (22), the stroke patients in this study were younger and there were more men. Probably this is due to the fact that only patients of rehabilitation wards participated in the study.

\section{PRACTICAL IMPLICATIONS}

One of the purposes of the large-scale research project, of which the present study is part, is to make recommendations how stroke patients can be best prepared for their retum home regarding their own autonomy. There were at least two reasons behind this purpose. First, 'Samen Verder' [Continuing Together'], a Dutch organization of stroke patients and spouses, mentioned what is called "the black hole", a phenomenon which occurs when stroke patients return to their homes and do not know how to continue their lives. Second, more people than simply the stroke patient are involved with the stroke, a phenomenon conceptualized as the "social prevalence" of a disease (23). The crucial role of social support, particularly by the family, in recovery from stroke, makes stroke a family affair $(24,25,26$ ). In the long term social support may be too heavy a burden. At three years after stroke, patients" partners experienced feelings among others that they bore a heavy responsibility and that the patient relied on their care only (27). Attention to patient autonomy and active participation during admission in the nursing home may improve the patients' quality of life and may decrease their problems after discharge and diminish families' burden.

At discharge the aim of rehabilitation, which is (in other words) the transition from dependence to independence, seems to be achieved. Particularly selfdetermination and independence need more attention from health professionals than they give now. A respectfull dialogue, for example, speaking with patients 
about future aims and treatment plans, and asking consent about these ains and plans, stimulates active participation in rehabilitation, and facilitates the patients' dealing with their own abilities and disabilities. Room for the patients" own activities, responsibility and customs is important for the situation after discharge when patients have to plan and organize their own lives, to choose how to spend the day, to initiate social contacts, etc. Despite the organizational difficulty, nursing homes could try to minimize care routines for stroke patients at discharge, and to provide room for patients to do activities autonomously and privately. Because the discharge environment appeared to be an important stimulus for patient autonomy, home visits should be encouraged. Regarding patients planned to be discharged to an old people's home, it is advisable to provide the opportunity of spending the weekend in a single unit in the nursing home or in the old people's home with support similar to the situation after discharge. Ensuring that the necessary aids or adaptations in the discharge environment are ready at discharge will facilitate patient autonomy. Finally, attention to family"s role in rehabilitation is necessary to avoid overprotection and paternalism. Families need some guidance in tailoring their support, because a 'surplus' of social support was found to limit autonomy at discharge. Therefore, focussing education and counseling not only on patients, but also on patients' families is recommended.

Empowering the patient and the family to deal with the consequences of stroke, improving self-management skills of patients, teaching and guiding the family how to deal with the situation at home, providing continuity of care to patient and family through skilled and specialized after-care in the home situation are issues that need attention and warrant further investigation. Additional study should also cover the education and training of health professionals about the problems and needs of patients and families in the transition phase with regard to autonomy, as well as the provision of support and counseling for health professionals to help them deal with issues regarding the stroke patients' autonomy in the transition phase. The development of multidisciplinary guidelines based on the results, and research into the effects of these guidelines is recommended to see if interventions improve patients" autonomy. Such a study should also include the situation after discharge from nursing home, to see whether a 'black hole' situation occurs or not.

\section{REFERENCES}

1. Bergman $L$, van der Meulen JHP, Limburg M, \& Habbema JDF. Costs of medical care after first-ever stroke in the Netherlands. Stroke 1995;26:1830-6.

2. Caplan LR, Stein RW. Stroke, a clinical approach. Stoneham: Butterworth Publishers, 1986.

3. Johnstone M. The stroke patient: a team approach. Edinburgh: Churchill Livingstone, 1987

4. Wade DT. Stroke: rehabilitation and long-tern care. Lancet 1992;339;791-5. 
5. Banja JD. Eithicall bsues in staff development. In: Durgin CJ, Schmidt ND, Fryer LJ, eds. Staff development and clinical intervention in brain injury. Maryland: Aspen, 1993:23-41.

6. Proot M, Huijer Abu-Saad H, van Oorsouw GGJ, Stevens JJAM. Autonomy in stroke tehabilitation: the perceptions of thealth professionals in nursing homes. Submitted for publication, in Nursing Ethics.

7. Proot IM, Crebolder HFJM, Huijer Abu-Saad H, Macor THGM, ter Meullen RHII. Facilitating and constraining factors on autonomy: the views of stroke patients on admission into nursing homes. Clin Nurs Res 2000;9:460 78 .

8. Proot $\mathbb{M}$, Hujer Abu-Saad H, de Esch-Janssen WP, Crebolder HFJM, ter Meulen RHJ. Patient atutonomy during rehabilitation: the experiences of stroke patients in nursing homes. Int I Nurs Stud 2000;37:267-76.

9. Agrich GJ. Autonomy and long-term care. Oxford: Oxford University Press, 1993.

10. Strauss $A$, Corbin J. Basics of qualitative research: grounded theory procedures and techniques. Newbury Park: Sage, 1990.

11. Prool IM. Protocol, autonomie en verantwoordelijkheid in de zorg woor CVA-patiënten. [Protocol, autonomy and responsibility in the care of stroke patients]. Masters thesis. Maastricht: Maastricht University, 1994.

12. Proot IM, Crebolder HFJM, Huijer Abu-Saad H, ter Meulen RHI. Autonomy in the rehabilitation of stroke patients in nursing homes: a concept analysis. Scand J Caring Sci $1998: 12: 139-45$

13. Denzin NK. The research act: a theoretical introduction to sociological methods. Englewood Clifs: Prentice Hall, 1989.

14. Sim J, Sharp K A critical appraisal of the role of triangulation in nursing research. Int Nurs Stud 1998;35:23-31.

15. Van der Wulp JC. Verstoring en verwerking in verplecghuizen. [lmpairments and its resolution in nursing homes]. Nijkerk: Intro, 1986.

16. Tronto JC. Moral boundaries: a political argument for an ethic of care. New York: Routledge, 1994.

17. Unsworth C. Clients' perceptions of discharge housing decisions after stroke rehabilitation. AJOT 1996;50:207-16.

18. Lewinter M, Mikkelsen S. Patients" experience of rehabilitation after stroke. Disabil Rehabil 1995;17:3-9.

19. Glass TA, Maddox GL. The quality and quantity of social support: stroke recovery as psycho-social transition. Soc Sci Med 1992;34:1249-61.

20. Norris VK, Parris Stephens MA, Kinney JM. The impact of family interactions on recovery from stroke: help or hindrance? Gerontologist 1990;30:535-42

21. Ada $L$, Caming $C$, Westwood $P$. The pationt as an active learner. In: Ada $L$, Camning $C$, eds. Koy issues in nceurological physiotherapy. Oxford: Butterworth Heinemann, 1990:99. 124.

22. Ribbe MW, Frijters DHM, van Mens JTh. Kenmerken van verpleeghuispatiënten bij ecrste opmame: leeftijd, geslacht en morbiditeit. [Characterisitics of nursing home patients al lirst admission: age, sex and morbidity.] NTVG 1993:137:2544-8.

23. Knotnerus JA, Metsemakers J, Höppener $P$, Limonard $C$. Chronic illness in the community and the concept of 'social prevalence', Fam Prac 1992;9:15-21.

24. Anderson, R. The aftermath of stroke. The experience of patients and their families. Cambridge: Cambridge University Press, 1992.

25. Evans RL, Connis RT, Bishop DS, Hendricks RD, Haselkom JK. Stroke: a family dilemma. Disabil Rehabil $1994 ; 16: 110-8$.

26. Nolan M, Nolan I. Stroke I: a paradigm case in nursing rehabilitation. Br I Nurs 1998;7:316-22.

27. Seholte op Reimer WJM. de Haan RJ, Rijnders PT, Limburg M, van den Bos GAM. The burden of caregiving in partners of long-term stroke survivors. Stroke 1998;29:1605-11. 


\title{
Chapter 7
}

\section{Changing autonomy. Facilitating stroke patients' autonomy in the different phases of rehabilitation}

\begin{abstract}
In a qualitative longitudinal study into the experiences of stroke patients rehabilitating in nursing homes, a changing approach regarding patients' changing autonomy was found to be helpful for the restoration of patients' autonomy. Two patterns in health professionals' approach appeared to be facilitating: 1) from full support on admission through moderate support and superwision, to reduced supervision at discharge; and 2) from paternalism on admission through partial patemalism (only regarding treatment) to shared decision-making at discharge. The approach experienced by the patients in this study did not always appear to match the desired approach regarding autonomy. In patients" perception support and supervision were reduced in time, but patemalism was often continued too long. Additionally, patients experienced a lack of information. Tailoring interventions to patients progress in autonomy, gradually reducing support and paternalism, and giving information, will stimulate patients" active participation in rehabilitation and in decision-making, and will improve patients" preparation for autonomous living after discharge.
\end{abstract}

Submitted as:

IM Proot, RHJ ter Meulen, H Hujer Abu-Saad, HFJM Crebolder. Changing autonomy. Facilitating stroke patients' autonomy in the different phases of rehabilitation. 


\section{INTRODUCTION}

Patients who survive a stroke might have considerable residual disability which often requires further rehabilitation after discharge from hospital. In the Netherlands both in-patient and out-patient care are given to fulfil these needs. Patients needing in-patient rehabilitation are often admitted to a rehabilitation center or nursing home $(1)$, where a multidisciplinary team $(2,3,4)$ helps patients regain as much as possible their role fulfillment and autonomous living, the most important aim of stroke rehabilitation (5). A multidisciplinary approach is warranted because stroke patients needing further rehabilitation mostly have severe and multiple impairments, which require multidisciplinary, intensive and specialized care (1). However, despite rehabilitation efforts, when stroke patients return to their homes, considerable problems occur, according to observations of 'Samen Verder' ['Continuing Together'], a Dutch organization of stroke patients and spouses. For example, patients are unable to make plans and to take initiative and responsibility in daily life, and caregivers who support the patients at home experience a heavy burden, because they feel extremely responsible (6). Many stroke patients remain dependent to varying degrees, and it is questionable whether rehabilitation meets the needs of stroke patients themselves. Several authors have stressed that hardly any research has been undertaken into the experiences of the stroke patients who have had to undergo rehabilitation programs $(7,8)$. In a retrospective study among stroke patients one year and two years post-stroke, experienced deterioration of quality of life appeared to depend in particular on loss of autonomy (9). Patients were asked to value their quality of life on a scale from $1-10$, and to give reasons for their choice. Fifty-five percent of these patients spontaneously mentioned autonomy as the most important determinant of quality of life. The maintenance of autonomy as a particularly important aim in the care of stroke patients is stressed, because in the patients' perception loss of autonomy will negatively influence quality of life (9).

In a large-scale research project regarding the autonomy of stroke patients rehabilitating in nursing homes, health professionals and stroke patients were interviewed $(10-13)$. The long-term purposes of this project are twofold: Firstly, to identify the areas that need special attention regarding patient autonomy during different phases in the rehabilitative process; Secondly, to make recommendations how stroke patients can be best prepared for their return home regarding their own autonomy. Three dimensions of changing autonomy were identified which need attention during rehabilitation: self-determination, independence and self-care $(10,11)$. Self-determination refers to freely making choices and decisions about one"s own life and health (for example, how to spend one's own time, choice of therapist). Independence (physical, psychological and social) concerns planning and organizing one's own life, including social contacts and roles, and responsibility for one's own life and 
health care. Self-care includes skills (mobility, communication, cognition) and activities of daily living (ADL), necessary for functioning.

This article reports on a longitudinal study into the stroke patients" experiences regarding the health professionals' approach towards autonomy. This study is part of the large-scale research project already mentioned. Specifically, though, this article sheds more light, from the patients" perspective, on the approaches used by health professionals to facilitate the restoration of the stroke patients" autonomy in the different phases of the rehabilitative process.

\section{METHOD}

\section{Data collection and sample}

The data for this longitudinal study were gathered in the rehabilitation wards of three nursing homes in the province of Limburg, the Netherlands, after approval was received from the ethics committees of the nursing homes involved.

Twenty-two stroke patients were approached (11). Patients with a confirmed diagnosis of stroke who were admitted to one of the rehabilitation wards participating in the study were included if they were able to communicate, if they were Dutch and spoke their mother tongue, if the rehabilitation goal was to return to their own home or an old people's home, and if participating in the study was not a heavy burden for the patient. Patients were excluded if they had severe multi-morbidity (somatic, psychiatric and/or psycho-geriatric) which would interfere with participation in the study. Participation was contingent on informed consent. The protocol for selection and sampling has been described in detail elsewhere (11). In principle patients were invited three times for an interview: on admission, during rehabilitation and at discharge. All patients invited consented. Two patients who only participated in the interview on admission (one due to death, the other because of rapid discharge) were not included in the longitudinal study. In total 56 interviews were conducted with 12 men and 8 women, ranging in age between $50-85$ years $(M=72.4)$. Four patients were unmarried, 6 patients were married, 1 patient was divorced and 9 patients. were widowed.

\section{Interview guides}

Open-ended interview guides were developed based on experiences from a previous study (14), interviews with stroke patients discharged from nursing homes, and sensitizing concepts derived from literature (15). These guides were rewiewed by project group members and by selected experts, and revised accordingly. Pilot interviews were held, leading to a slight change in the order of the questions in the admission interview, and to no changes in the rehabilitation and the discharge interviews. 
In the interviews the respondents" own definition(s) of autonomy were used. Patients were interviewed about constraints and improvements of autonomy and about the approach by health professionals regarding autonomy ("Are health professionals in the nursing home able to stimulate or support your autonomy (or the word used by the respondent)?").

\section{Procedure}

The interviews were conducted by two trained interviewers, who introduced topics and used probing questions if necessary to encourage patients to give more information or examples. All interviews with a particular patient were conducted by the same interviewer. The interviews were tape-recorded (after consent) and transcribed with all identifying data removed. Field notes were kept during and after each interview. Due to the patient's condition the possibility of having an informal caregiver present during the admission interview was suggested to the patient (12 informal caregivers were invited after consent of the patient). In the rehabilitation and the discharge interviews the possibility of having a 'spokesperson' during the interview was suggested, but no patient used a 'spokesperson'.

\section{Data analysis}

\section{Procedure}

Separate analysis of each rehabilitation phase (11-13) had been conducted using the constant comparative method as described in grounded theory (16). For this paper the constant comparative method was used to uncover which patterns in health professionals" approach during rehabilitation facilitate stroke patients" autonomy throughout the rehabilitative process as a whole, and 'to capture whether and how change occurs' (17).

\section{Validity}

Data triangulation, investigator triangulation and methodological triangulation (18) were used to broaden the analysis of the health professionals' approach to stroke patients' autonomy, and to secure content validity (19). Patients admitted to different nursing homes, with varying socio-demographic variables participated in the study (data triangulation); there were two interviewers, and peer debriefing during analysis was used (investigator triangulation); apart from individual in-depth interviews, member checks were held (methodological triangulation).

\section{RESULTS}

This section reports on the approach of the health professionals regarding the stroke patients' changing autonomy. For each phase (admission, rehabilitation 
and discharge) patients' autonomy is described briefly (for detailed descriptions see Proot et al. 11-13) followed by the approach of the health professionals as experienced by patients.

\section{On admission}

On admission most stroke patients experience in particular a decrease in the dimension self-care in comparison to pre-stroke.

"Most disappointing was that you were unable to do the smallest things. That you realize you just don't know how to do them... When you think about it, you know alleady: "I can't do it, why bother to try". (...) Someone has to zip up your fly when you sit on the toilet. It goes against the grain that we even cannot do that." (ploa,p.5)

Patients have limited possibilities to spend time, not only because of thein own conditions, but also due to being in the nursing home. In addition, patients feel insecure, and see themselves as laypersons, and the health professionals as experts regarding rehabilitation procedures, which decreases independence and self-determination. To have any measure of control over their own treatment is difficult. Patients often take a passive role in rehabilitation: they wait and see, and act as 'subotdinate' (as they call it).

"We are waiting patiently. It is the only thing we can do." (p19a,p.10)

\section{Health professionals: support and paternalism}

On admission patients experience more therapy, a hopeful atmosphere and more opportunities for autonomy compared to the hospital.

"You have more freedom here. You can wear your streetclothes ... in the hospital you wear pyjamas. (...) Here 1 am allowed to make a sandwich, in the hospital you couldn"t do anything. Everything is done for you. But they mean well." (p13a,p.9)

In the nursing home health professionals assess patients" self-care abilities in order to give support only if necessary:

"When they notice that you can wash and dress quite well, then they make you responsible for those tasks." (p12a,p.5)

In all, on admission health professionals" support often is needed regarding self-care, and patients experience support as facilitating autonomy: 
"All you had to do when you needed something was ring the bell and they would come right-away. I am able to pull on my pants, but only to a certain point. I still need help with that, and I always get it." (p!7a,p.13)

Patients feel that paternalism is necessary, that the health professionals decide for them how to rehabilitate:

"I must admit that when she [occupational therapist] started last week [ADL], I told her a few times: "Girl, leave it, I don't want to learn how to manage my shirt and pants ..." I really had the idea it was a lost cause. But this morning I noticed that it actually goes well" (p20a,p. 10)

Sometimes health professionals prohibit actions patients would like to do:

"I want to walk more, by myself ... I'm not allowed to go to the bathroom by myself. But go by myself if they are there or not. (...)[The patient has fallen one time.] That nurse said: "But you are not allowed to!" She was not angry, but reprimanded me." (p/3a,p.12)

Deciding for patients and prohibiting actions are related to the rehabilitation method used, for example, Neuro Developmental Treatment (NDT). Questions arise whether patients get enough information why health professionals put them through a particular regimen. Although patients feel paternalism is necessary with respect to some aspects, there are areas where patients could participate in decision-making, for example, about the extent of therapy, the schedules of therapy, and meals.

\section{During rehabilitation}

During rehabilitation patients need less support than on admission. In particular the dimension self-care increases due to improving abilities and an increase in confidence.

"I am not so dependent anymore. (...) Activities I couldn't or wouldn't do because I was not motivated, or because I didn't feel well, I do now by myself. But mainly because I was unable to do them. For instance, it was difficult to pass a dish or to reach for something during a meal. That is much better now. And my walking is improving. I'm not scared to take the elevator. Most times someone is with us." (p12b,p.4)

However, the need for support may vary, and residual disabilities post-stroke, multi-morbidity and insecurity partly constrain self-care. Some patients experience a status quo (leveling out in their rate or degree of progress) tegarding self-care, and some patients are confronted with things they are not able to do which may lead to sadness or irritation. Patients take a moderately 
active role in rehabilitation and show growing independence and selfdetermination:

"When I'm done in occupational therapy, she takes me to the craftroom, to have a look around. (...) Then she says: "Do you want to do a craft?", but 1 answer: "Please take me back upstairs". She would like me to stay in the craftroom." (p04b,p.8/9)

Patients take initiative and responsibility, instruct their families and participate in decision-making.

\section{Health professionals: support/supervision and partial paternalism}

During rehabilitation health professionals give instructions and assess the patient's need for aids or adaptations at home after discharge, which facilitates self-care:"

"With walking, they say, you have to lift your feet up, lift them up more, don't drag them. Also how to climb stairs, for when I go home." (p.12b,p.5)

Activities which the patient partly masters are trained further supervised by nurses. If carefully used, waiting periods stimulate self-care and independence, except waiting periods for toiletting:

"Then they [caregivers] go to someone else, and then I think, why don't you give it a try. And then $\mathbb{I}$ do it all by myself, then 1 want to do it by myself." (p04b,p. 14)

"In the beginning I had some difficulty with that [waiting periods]. And I said: "You girls have to take into account that it is not my fault either, that I have to pee. My doctor tells me to drink lots. I do, and then I have to pee more." (...) I am arready punished enough by this disease. They have taken much of your freedom." (pl0b,p.4/5)

The therapists (physiotherapist, occupational therapist and speech therapist) assign tasks to patients for which they need to be motivated, because patients do not always see the aim, and because the lasks confront patients with their disabilities. Health professionals anticipate future consequences; for example, they use the discharge enviromment to motivate patients.

"We [patients] are inclined to say too quickly: "That is silly, why do I have to do that childish stuff. To sit at a table and work with small blocks"s, (...$)$ But later on 1 find that the activity was much more difficult than I initially thought." (p10b,p.13) 
"Then they [caregivers] say: "When you're home, you still have to be able to do that"." (poub,p.』1)

Patients mostly value paternalism regarding treatment decisions, but need information, evaluation and deliberation about it. Information about treatment plans and discharge planning is sometimes lacking in the view of patients, which constrains shared decision-making, independence and self-determination. Patients do not appreciate paternalism with regard to other decisions, for example, regarding recreational activities and toilet times:

"If I have to go to the bathroom now and again one hour later, they say: "Your have just been." A while ago I said: "But nurse, how do you know when I have to pee?" "( 1 1 1 b, p.6)

\section{At discharge}

At discharge patient autonomy increases due to regained abilities and confidence. Sometimes a status quo regarding self-care is reached.

"For myself I think everything is going well. I get up and wash myself - they don't need to help me. Same in the evening (...), most people need some assistance, but $\mathbb{I}$... I just go to bed by myself." (p16c,p.4)

Patients take initiative and responsibility, are assertive, put things in perspective and participate in decision-making.

"I stand up more [for myself], yes that"s right (...) I never did that before in my life, I always looked at others (...). And I'm going to change that too." (pl 8c,p.4)

Some patients value shared decision-making about their own treatment, but other patients draw the line here, although they stress that information and deliberation are necessary. Residual disabilities post-stroke, multi-morbidity, and insecurity (about the future) sometimes lower the level of autonomy that is reached

\section{Health professionals: reduced supervision and shared decision-making}

Just before discharge, instructions and supervision might lead to important progress in autonomy, because the patient, in view of the requirements of the discharge environment, is highly motivated. Activities are trained under supervision in order to attain as much independence as possible, while the supervision is reduced more and more. Support on request is available, but the amount of support is tuned to the support needed after discharge. Patients experience that they receive less support than earlier on admission: 
[In the beginning]"You'd only had to say the word. They helped you right away, physically, they were there for you, emotionally as well. Now they tend to say: "You can do that". I experience that as positive.(...) For instance when you are watching TV in the evening in the dining room; in the beginning they made sure you were not sitting all alone, and now they come and keep you company, but more to talk about themselves, and to share a drink." (p20c,p.11)

However, patients do not always know the reason why supervision is reduced, which may constrain autonomy:

"They don't stay with you, I wish they would as it increases your self-confidence and everything works better. "I am in another room, call me when you are ready"." (p $190, p .6)$

Patients take their own responsibility, just as they will do after discharge. Nevertheless, the interviews hardly show examples of shared decision-making, but do show examples of paternalism, which may constrain antonomy:

"When they come at 6:45 am, I say: "Nurse, I"m not getting up yet, I did not sleep well and I'm tired. Just let me stay in bed a little bit longer" and if you get the wrong one "Come on, get up, you have to get washed"." (p 19c,p.24)

"I can't remember such things [therapy schedules]. I would have to write it all down.' [Interviewer: Do you write it down?] 'No, I don't do that, since they come and get me. They write it in the agenda and clseck it, so I don't really have to write it down myself." ( $18 \mathrm{c}, \mathrm{p} .3)$

A lack of team approach may diminish patient's self-confidence and antonomy. It is important that heath professionals discuss with each orther about the approach to patient autonomy to ensure that they are on the same wavelength:

"I"m going by myself again; when I ask them about it, they say: "You can go by yourself". And yesterday $X$ said: "You are not allowed to go by yourself, you have to call us". I said: "I'm not sure what to do anymore". "I"Il tell you when you can go by yourself," she said." (p/9c,p 9/10)

\section{DISCUSSION}

The stroke patients" autonomy changes during rehabilitation. The recovery of autonomy was found to follow more or less the same pattern in all stroke patients participating in this study (see table $1, \mathrm{p} .107$ ). While atutonomy 
increases, patients ${ }^{3}$ role in rehabilitation develops from a passive role to an active role.

Autonomy appeared not to be present "a priori" in stroke patients admitted to nursing homes for rehabilitation. From the patients' perspective, a changing approach used by health professionals was found to be helpful for the restoration of autonomy. The desired approach to changing autonomy includes two patterns:

1. From full support through moderate support and supervision, to reduced supervision;

2. From paternalism through partial paternalism to shared decision-making.

On admission support and paternalism (deciding for the patient) facilitate patient atonomy (see table 1). Nevertheless, it is important to support patients and to decide on their behalf only when needed, to give information about decisions and to stimulate patients' participation in decisions wherever possible. During rehabilitation moderate support and supervision and partial paternalism (only regarding treatment) facilitate patient autonomy. Leaving decisions on other aspects than treatment to patients themselves is necessary, for example, regarding recreational activities and toilet times. Giving information and deliberation about treatment plans and patient's progress stimulate the patients" participation in decisions. At discharge patient autonomy is facilitated by giving information and sharing decision-making, including regarding treatment. Support and supervision need to be limited to a degree comparable to the situation after discharge. It is stressed that the pace of improvement (and the length of each phase) differs among patients.

Although initially support and paternalism may be expected to constrain autonomy, in the patients" perception support and paternalism facilitate (the restoration of their autonomy, particularly on admission and also during rehabilitation. These results run counter to the dominating concepts of autonomy in bioethical literature, autonomy as self-governance $(20)$, and autonomy as self-realization (21). Self-governance is generally described as acting voluntarily and consciously without any constraint (20). Self-realization also includes the way one shapes and lives one's own life and expresses individuality $(21,22)$. Self-govemance and self-realization represent an individual concept of autonomy (15), which stresses the independence and authenticity of the individual person, protects the individual against unwanted interference by others, and places informed consent at the center. Regarding stroke patients in the first phase of rehabilitation such an individual concept is problematic, because stroke patients are (partly) clependent on health professionals and family, meet unexpected barriers with regard to their self-realization, and have to integrate impaiments and disabilities into a new "post-stroke identity". Another concept from bioethical literature, actual autonomy (23), seems to be more suitable in the first phase of rehabilitation. Actual autonomy means that autonomy depends on a person's current development and environment, including environmental support (23), and represents a social concept of autonomy (15). The results of the present study stress that a social concept of 
Table 1. Facilitating patient autonomy: the desired health professionals" approach and the experienced approach in the different phases of rehabilitation, as reveated from interviews with stroke patients (differences between desired and experienced approach in ifalics).

\section{REHABILITATION PHASES}

Admission Rehabilitation Discharge

Patient:

- autonomy decreased

gradual increase

increased

- role in rehabilitation

passive

moderate active

active

Health professionals:

- desired approach

full support

assessment

support/supervision

reduced supervision

information

training/instructions

information

final instructions

paternalism

partial" patemalism

information

sharing decisions"

- experienced approach full support

assessment

support/supervision

reduced supervision

lack of information

training/instructions

lack of inforsnation

paternalism

excess patemalism

final instructions

lack of information

excess paternalism

* regarding treatment

autonomy could be a key principle for health professionals' approach towards the stroke patient's autonomy, particularly in the first phase of rehabilitation. In the final part of rehabilitation, however, when patients show a reasonable progress in autonomy, a social concept of autonomy is no longer adequate for the restoration of their autonomy.

In the patients' experience support and supervision were reduced in time, but paternalism was often continued too long (see table 1), which constrains their autonomy. These results are related to the observations of Banja (24), who found, studying health professionals working with patients suffering from brain injury, that health professionals are inclined to interpret independence as only physical non-dependence, which may influence the restoration of autonomy. He recommends a changing approach wherein health professionals relinquish the protective approach they may have assumed initially toward the client.

In the present study patients experienced a lack of information during the rehabilitative process, for example, regarding the reduction of support, which they identified as constraining for autonomy. A study among health prow fessionals revealed comparable results (10). Health professionals noticed that they give too little information to patients and leave very little room for patient. choices. Anderson (8) also found that stroke patients experience a lack of 
information, and relates this result to a lack of systematic effort to inform patients. He pleads for better education and training for healch professionals, so that they can become more sensitive to the patients' changing needs during rehabilitation (8).

As far as is known, there are no empirical studies into the experiences of rehabilitating patients with diagnoses other than stroke regarding the health professionals" approach to autonomy. Yet several authors have discussed the problematic status of autonomy and informed consent in the context of rehabilitation $(25,26)$.

\section{Implications of the study}

Health professionalls working on rehabilitation wards in nursing homes should tailor their interventions to the stroke patients" changing autonomy. Multidisciplinary guidelines based on the results of this study might sustain thealth professionals in identifying patients' progress in autonomy and in gradually reducing both support and paternalism. In the rehabilitation phase, when patients are accommodated, they are able to decide for themselves, except regarding treatment and rehabilitation procedures. Leaving room for the patients" planning and deciding stimulates autonomy then, for example, regarding wake-up time, toilet time, and spending the day. Step by step also sharing decision-making with regard to treatment becomes possible, for example, regarding which activities need to be trained and to what extent, and regaiding the discharge environment and necessary aids. If health professionals continue deciding for the patient, patients might be less prepared to autonomous living after discharge at home or in an old people's home. Giving information (including progress evaluation) and deliberation on, for example, treatment plans and discharge decisions is a prerequisite for patients ${ }^{3}$ active participation in rehabilitation and in sharing decision-making.

Giving attention to patient autonomy in clinical care, developing multidisciplinary guidelines based on the results, and educating and training health protessionals on how to stimulate patient autonomy in the different phases of rehabilitation are aspects warranting further study. It may be expected that the rehabilitative process might proceed more efficiently if patient autonomy is consciously taken into account. This might, with regard to stroke patients, lead to a shorter length of stay in the nursing home, and diminish the risk of re-admission in the mursing home, and thus to better cost-effectiveness. However, additional research is necessary to investigate these expectations thoroughly.

\section{REFERENCES}

1. Dutch Institute for Health Care Improvement CBO. Richtlijn Beroerte. [Stroke guideline]. Utrecht: CBO, 2000. 
2. Capian LR, Stein RW. Stroke, a clinical approach. Stoncham: Butterworth Pablishers, 1986.

3. Johnstone $M$. The stroke patient: a team approach. Edinburgl: Churchill Livingstone, 1987.

4. Stonnington $\mathrm{HH}$, Browne JA. Team approach to management. In: Brandstater $\mathrm{ME}$, Basmajian JV, eds. Stroke rehabilitation. Baltimore: Williams and Wilkins, 1987:199-207.

5. Wade DT. Stroke: rehabilitation and long-term care Lancet 1992;339:791-5.

6. Scholte op Reimer WJM, de Haan RJ, Rijnders PT, Limburg $M_{3}$, van den Bos CAM. The burden of caregiving in partners of long-term stroke survivors. Stroke 1998;29:1605-11.

7. Lewinter M, Mikkelsen S. Patients' experience of rehabilitation after stroke. Disabil Rehabil 1995;17:3-9.

8. Anderson R. The aftermath of stroke. The experience of patients and their families. Cambridge: Cambridge University Press, 1992.

9. Loor HI. Kwaliteit van leven: cva-patiënten maken de balans op. [Quality of life: stroke patients' views]. Gerontol Geriatr 1998;29:52-8.

10. Proot IM, Huijer Abu-Saad H, wan Oorsouw GGJ, Stevens, JJAM. Autonomy in stroke rehabilitation: the perceptions of health professionals in nursing homes. Submitted for publication in Nursing Ethics.

11. Proot IM, Crebolder HFJM, Huijer Abu-Saad H, Macor THGM, ter Meulen RHJ. Facilitating and constraining factors on autonomy: the views of stroke patients on admission into nursing homes. Clin Nurs Res 2000:9:460-78.

12. Proot IM, Huijer Abu-Saad H., De Esch-Janssen WP, Crebolder HFJM, ter Meulen RHIJ. Patient autonomy during rehabilitation: the experiences of stroke patients in nursing homes. Int J Nurs Stud 2000;37:267-76.

13. Proot IM, Crebolder HFJM, Huijer Abu-Saad H, Macor THGM, ter Meulen RHJ. Stroke patients" needs and experiences regarding autonomy at discharge from nursing home. Pat Educ Couns 2000;41:275-83.

14. Proot IM. Protocol, autonomie en verantwoordelijkheid in de zorg voor CVA-patiënten. [Protocol, autonomy and responsibility in the care of stroke patients]. Masters thesis. Maastricht: Maastricht University, 1994.

15. Proot IM, Crebolder HFJM, Hujier Abu-Saad H, ter Meulen RHJ. Autonony in the rehabilitation of stroke patients in nursing homes: a concept analysis. Scand J Caring Sci $1998 ; 12: 139-45$.

16. Strauss $\mathrm{A}$, Corbin I. Basics of qualitative researeh: grounded theory procedures and techniques. Newbury Park: Sage, 1990.

17. Sandelowski M. Time and qualitative research. Res Nurs Healih 1999;22:79-87.

18. Denzin NK. The research act: a theoretical introduction to sociological methods. Englewood Ciifs: Prentice Hall, 1989.

19. Sim J, Sharp K. A critical appraisal of the role of triangulation in nursing research. int J Nurs Stud 1998; 35:23-31.

20. Beauchamp TL, Childress JF. Principles of biomedical ethics. Oxford: Oxford University Press, 1994.

21. Berlin I. Two concepts of liberiy. Four essays on liberty. Oxford: Oxford Universily Press, 1969.

22. Miller BL. Autonomy \& the refusal of lifesaving treatment. Hastings Cent Rep 1981:111(4):22-28.

23. Agich G.j. Autonomy and long-term care. Oxford: Ox ford University Press, 1993.

24. Banja JD. Ethicall issues in staff development. In: Durgin CJ, Schmidt ND, Fryer LJ, eds. Staff development and clinical intervention in brain injury. Maryland: Aspen, 1993:23 41.

25. Caplan AL. Informed consent and provider-patient relationships in rehabilitation medicine. Arch Phys Med Rehabill 1988;69:312-7. 
1101 Chapher 7

26. Sim J. Respect for atonomy: issues in neurological rehabilitation. Clin Rehab $1998: 12: 3-10$ 


\section{Chapter 8}

\section{Empirical research in bioethics}

\section{INTRODUCTION}

This chapter discusses the results of the present study in the context of theoretical discussions in bioethics. The empirical study has focussed on the use of the concept of autonomy in practice. More specifically, the rehabilitation of stroke patients in nursing homes, and the way patient autonomy was dealt with within the provider-patient relationship were explored. The first part of the chapter discusses the state of the art regarding empirical research in bioethics. Contributions and limitations of empirical research in bioethics mentioned in the bioethical literature are dealt with. The second part discusses the contribution of the empirical study to the field of bioethics in long-term care and rehabilitation, and reflects on the method used. Last, some conclusions with regard to empirical studies in bioethics are drawn and recommendations are advanced.

\section{EMPIRICAL RESEARCH IN THE BIOETHICAL LITERATURE}

\section{Introduction}

The term 'bioethics' refers to ethics with regard to medicine and health care. 'Ethics is a generic term for various ways of understanding and examining the moral life. Some approaches to ethics are normative (that is, they present standards of right or good action), others are descriptive (that is, they report what people believe and how they act), and still others analyze the concepts and methods of ethics (melaethics)" (Beauchamp \& Childress, 1994, p. 4). Generally, 'bioethics' is not defined (Ten Have, ter Meulen \& van Leeuwen, 1998); it has been described as 'systematically studying ethical questions in and around health care' (De Wachter \& de Beaufort, 1986, p. 20). Bioethics has been a strongly developing field since the 1970s. During the 1970s, articles in medical ethics concerned either theoretical discussions of ethical concepts or case studies (Arnold \& Forrow, 1993). During the late 1980s when academic physicians became more and more interested in medical ethics, articles based on empirical methods of social scientists and especially of clinical epidemiologists. started to appear (Arnold \& Forrow, 1993). This development has continued. Recently, an annotated bibliography on empirical research on informed consent was published, including the titles of 377 articles (Sugarman, McCrory, Powell, Krasny, Adams, Ball \& Cassell, 1999). 
Before 1993 the purpose and rationale of empirical ethics were hardly discussed in the bioethical literature (Arnold \& Forrow, 1993), and in the late 1990s this kind of work still received little explicit acknowledgement (Hope, 1999; Zussman, 2000). For example, textbooks and standard writings see medical ethics as almost exclusively a branch of philosophy. Hope questions the reasons for this situation: 1) empirical work takes medical ethics away from its true intellectual base in philosophy; 2) empirical work is a worthwhile activity, but is not medical ethics; 3) empirical work is a next step in the development of medical ethics. In defense of the last position, Hope argues that medical ethics has reached a stage where empirical research could enrich philosophical medical ethics. Traditionally, medical ethics has been influenced by empirical issues, for example, through the experiences of health professionals. Cases derived from daily practice have been consciously described, discussed and philosophically analyzed. These experiences and facts, however, have rarely been collected systematically (Hope, 1999). Alternative approaches to bioethics emphasize an increased attention to context and variability. 'Theory, rather than being an overarching conceptual scheme from which predictive variables are derived, is developed from the ground up. The categories researchers use to organize their observations, are not derived from theory and predefined, but are found instead embedded in the situations themselves and the participants' orientations and understandings' (Douglas-Steele \& Hundert, 1996, p. 114). Findings such as these are not meant to give predictive certainty, but give insight into the ways participants make sense of and understand what is going on. Such studies in bioethics are as yet in their infancy (Douglas-Steele \& Hundert, 1996).

An important discussion arising in the late 1990 s concerns the question whether the knowledge revealed by empirical studies can be incorporated in bioethical theory. The moral relevance of empirical data is a theme of dispute, for example, the integration of knowledge based on analysis of empirical data in moral discourse, and the relationship between different domains of ethics, such as description, clarification and normation are discussed (Pellegrino, 1995). Ten Have \& Lelie (1998) stressed that ethics research needs to go beyond description and should develop a normative theory of the practice studied, using a hermeneutic ethical approach. In what sense, however, can a hermeneutic approach be normative, and transcend the level of individual experiences? According to Ten Have \& Lelie, normative hermeneutic ethics has to study and explain the results of empirical studies, thereby developing alternative views, and looking further than the dominant moral knowledge. From the perspective of hermeneutic ethics, normativity means that alternative actions in a particular situation will be discussed and reflected on, which will enrich the understanding of that situation. (Ten Have \& Lelie, 1998). In the Netherlands, recently a study has been started concerning two methods that might be used to integrate empirically based knowledge in moral discourse: philosophical hermeneutics and reflective equilibrium. This multidisciplinary study is being carried out by several cooperating universities (Widdershoven, 1998). 


\section{Contributions of empirical research in bioethics}

The bioethical literature mentions a number of possible contributions of empirical studies to bioethics. These contributions concern the content and scope of empirical studies in bioethics. According to the bioethical literature, the following aims can be addressed using empirical methods in ethics, i) to uncover theoretical points that are unworkable in practice; 2) to evaluate health professionals' ability to operationalize ethical principles; 3) to develop hypotheses for theoretical moral reasoning.

First, moral philosophy (theoretically developed and applied to clinical problems) often does not fit the experience of those who have spent time in clinical settings (Hoffmaster, 1992). Bioethical analysis could be corrected (or validated) by empirical research methods: for example, empirical results on euthanasia decisions in hospitals questioned whether theories on self-determination fit the real-life situations in hospitals and nursing homes (De Beaufort \& Trappenburg, 1999). With empirical ethics moral theories can be conceived that are more responsive to the empirical dimensions of the problems under study (Hoffmaster, 1992). Using empirical research methods, facts and values can be interlocked, and descriptive and normative concepts can be compared (Jennings, 1989). In this way theoretical points can be uncovered that are unworkable in practice, and theoretical justifications might sometimes even be undermined (Pearlman, Miles \& Arnold, 1993). For example, in a study on surviving cardiopulmonary resuscitation, the results may have led to theoretical questions with regard to the role and limitations of patient autonomy in decision making (Pearlman et al., 1993).

Second, using empirical research methods, health professionals' ability to operationalize ethical principles could be evaluated (Pearlman et al., 1993). For example, studies on health providers' implementing do-not-resuscitate (DNR) orders showed that it was difficult for providers to realize the ethical goals expected by philosophers (Pearlman et al. 1993). According to Pellegrino (1995), reacting to an article about quantitatively empirical work on the moral propriety and policy implications of euthanasia and assisted suicicle, descriptive ethics can explore how people actually behave in moral situations. Clarification, the analytical-metaethical domain of ethics, can explain which ethical or moral concepts and language people use, and what status they accord moral knowledge: for example, which ethical concepts are expressed in health care practices and professional codes.

Third, systematic research into the empirical base of bioethics might lead to new issues and focuses, or might lead to (re)discovering unappreciated ethical issues (Pearlman et al., 1993) particularly if perspectives of patients and families are studied (Hope, 1999). New ideas or concepts with respect to the ethical aspects of health care can be derived from empirical studies (De Beaufort \& Trappenburg, 1999). In addition, new hypotheses (that is, not derived from existing bioethical knowledge) can be developed which can give rise to theoretical moral reasoning and study (Hope, 1999). 
In addition to strengths of empirical studies in bioethics, limitations are also mentioned in the bioethical literature.

\section{Limitations of empirical research in bioethics}

Empirical studies in bicethics have so far used quantitative research methods more often than qualitative methods. This entails that the limitations of empirical studies discussed in the bioethical literature particularly focus on quantitative studies. These limitations concern 1) the content and scope of empirical ethics; 2) the method used; 3) the expertise of the researcher.

Many current empirical studies focus on what is documented and readily measurable, and not on (complex) processes (Pearlman et al., 1993). For example, outcomes of care are easier to measure than the way ethical principles are used in practice. Conclusions based on empirical data should have a relation with the type of data gathered (Brody, 1993). If the research question concerns non-consequentialist issues, (quantitative) empirical data will largely be irrelevant. Description of what concepts and languages are used in practice, and by whom and why (clarification) cannot resolve conflicts about these concepts and languages used, and cannot provide normative guidelines (Pellegrino, 1995). Normation asks something more, namely a thoroughly philosophical reasoning, to set out what ought to be done. Or, according to Kant, 'Sollen' (what ought to be done) cannot be based on 'Sein' (what is done) (Van Peursen, 1994).

In the biocthical literature, several limitations of the methods used in cmpirical ethical studies are mentioned. First, quantitative research methods, such as the methodologies of epidemiology and decision analysis, are more often used in bioethical studies than the qualitative methods of anthropology or sociology (Arnold \& Forrow, 1993). While yiclding some important insights for the field of bioethics, quantitative methods have achieved a limited depth of understanding, and have led to the study of especially a particular type of research question. There must be a relation between the research question, the method used, and the data (Brody, 1993): in other words, the methods used must be appropriate for answering the research question, similar to other fields of scientific research. A longitudinal and qualitative approach, for example, is favored over when changes in leading opinions are examined (De Beaufort \& Trappenburg, 1999). Second, attention to the preferences of patients and family members is often lacking, as already mentioned in relation to empirical studies on euthanasia and assisted suicide (Emanuel, 1995). If empirical studies do not concern the patients' preferences and practices, an important source of knowledge is neglected. Third, the use of hypothetical vignettes (as is often employed) raises serious concerns, because this method measures intentions and attitudes, and does not measure practice (Pearlman et al., 1993). The conclusions to be drawn should be carefully interpreted, and have a limited scope. In general the use of a wide variety of empirical methods (including qualitative research methods) is needed, dependent on the questions under study (Arnold \& Forrow, 1993). 
Researchers involved in empirical ethical studies need to have ethical knowledge (Pearlman et al., 1993; Brody, 1993). An understanding of theoretical ethical issues is vital to design research on ethical issues, and to interpret the significance and limitations of the data. Researchers need to have this ethical knowledge, or need to co-operate with ethical experts. On the other hand, investigating ethical issues empirically deserves knowledge and expertise about empirical research methods (Zussman, 2000). For future empirical studies in bioethics, multidisciplinary co-operation between ethicists and social science researchers is recommended (Hofland, 1988; Jennings, 1989; Musschenga \& van der Steen, 1999). This will facilitate both bioethical reasoning and the use of adequate empirical methods.

\section{THE PRESENT STUDY ON STROKE, AUTONOMY AND REHABILITATION}

\section{Introduction}

In this section, the contribution of the present study to bioethics in long-term care and rehabilitation is discussed. The first part of this section is structured around the three aims which can be addressed, according to the literature, using empirical methods in ethics: 1) to uncover theoretical points that are unworkable in practice; 2) to evaluate health professionals" ability to operationalize ethical principles; 3) to develop hypotheses for theoretical moral reasoning. The last part of this section discusses the method of the study related to the limitations mentioned in the bioethical literature. (Note that other methodological strengths. and limitations of the study are discussed in chapter 9).

\section{Contributions of the study in the context of bioethics}

\section{Uncovering theoretical points that are unworkable in practice}

The results of the empirical study are compared to several theoretical concepts revealed in a concept analysis on autonomy in relation with the rehabilitation of stroke patients in nursing homes (see chapter 2). These concepts, however, did not function as a starting point for the empirical study. In the empirical study, theory was inductively built using the principles and procedures of grounded theory.

Dimensions of autonomy. The empirical study revealed three dimensions of autonomy, which are at stake in the rehabilitation of stroke patients: self-care, independence and selfudetermination. Self-care includes skills (mobility, communication, cognition) and activities of daily living, necessary for functioning. Independence (physical, psychological and social) concems planning and organizing one's own life, including social contacts and role- 
taking and refers to responsibility for one's own life and health care. Selfdetermination, the third dimension identified, points at making choices and decisions about one's own life and health; and includes also freedom of choice.

The dimemsion self-care is related to the concept of self-care used in literature about nursing and rehabilitation: "The practice of activities that maturing or nature persons initiate and perform, within time frames, on their own behalf in the interests of maintaining life, healthful functioning, continuing personal development, and well-being' (Orem, 1995, p. 461). The empirical results give ground for the link between theoretical concepts of autonomy and self-care in the setting of stroke rehabilitation, a link that was already made in the concept analysis (see chapter 2 ).

The dimensions independence and self-determination are both related to the concept of self-governance in the literature: to act voluntarily and consciously without any constraint (Beauchamp \& Childress, 1994). In the empirical study self-determination appeared to be a dimension separate from independence. Self-determination needs particular attention from the providers, because stroke patients often encounter communicative and cognitive disabilities, and find themselves in a process of accepting their handicaps (Deci, 1980), which may heavily influence the patients" self-determination.

The dimensions of autonomy identified in the empirical study are distinguished from each other for analytical and practical purposes, but they cannot be totally separated. In order to make clear what your choices are (selfdetermination) you need, for example, communicative and sensory-motor skills (self-care), and you have to take initiative, which requires a certain level of physical, psychological and social independence.

The empirical results showed not only that in the practice of stroke rehabilitation different aspects of autonomy should be distinguished, but also that these aspects are not automatically present in stroke patients. On the contrary, in some patients and in some rehabilitative phases, one or more aspects are absent (see chapters 4-6). These results relate to the concept of actual autonomy (Agich, 1993), which means that autonomy depends on a person's current development and environment, including environmental support. The study indicated that the order of regaining autonomy aspects in stroke patients is as follows (according to the patients' values): first self-care, second independence and self-determination. The patients" autonomy changes during rehabilitation. During early rehabilitation patients experience that self-care, and in the same time self-determination and independence (e.g. waiting for assistance), are limited. They experience a "dependency conflict" (Van der Wulp, 1986), a gap between their will and their physical abilities. Regaining and improving self-care is most important for patients then. Gradually, however, patients develop self-care skills and responsibility, needing less environmental support and more independence.

A social concept of autonomy. The empirical study indicated support and paternalism to be facilitating for the patients' autonomy and its restoration, 
particularly on admission and also during rehabilitation (chapters 4 and 5). These results run counter to the theoretical concepts self-governance (Beauchamp \& Childress, 1994) and self-realization (Miller, 1981), representing individual concepts of autonomy (see chapter 2). An individual concept of autonomy stresses the independence and authenticity of the individual person, protects the individual against unwanted interference by others, and gives informed consent a central place. The empirical results underline that the theoretical concept actual autonomy (Agich, 1993), representing a social concept of autonomy (see chapter 2), provides a more appropriate ethical framework for early relabilitation than an individual concept does. The results also showed that, when the patients' autonomy improves, a social concept of autonomy may be no longer sufficient as framework for the health professionals' practice. Patients become less dependent on other people, gradually develop responsibility and self-care skills, and want to make choices by themselves. At discharge patient autonomy is facilitated, for example, by giving information and sharing decision-making. In that phase a "surplus' of support or paternalism constrains patient autonomy (chapter 6). Actual autonomy stresses that the patient's autonomy depends on the person's current development and environment. This implies that as the rehabilitation advances, providers should also bear in mind the individual concepts of autonomy, in order to tailor their interventions to the patients' needs, and in order to develop the patients' actual autonomy further, which is an important aim of the rehabilitation process.

Conclusion. The empirical results showed what autonony encompasses in a particular setting, and provided a detailed description of aspects of autonomy, and of the process of regaining autonomy. It appeared that the prevailing theoretical concepts of autonony partly fall short in the setting studied, in particular during early rehabilitation.

\section{Evaluating health professionals' ability to operationallize ethical principles}

This study evaluated the way health professionals operationalize the concept of patient autonomy, from the point of view of both the health professionals and the stroke patients.

Lacking attention. In the interviews health professionals said that their work had so far been particularly focussed on the dimension self-care, which they felt was not appropriate. They stated that as patients regain autonomy, gradually independence and self-determination should be concentrated on, but they realized that they do not give enough attention to these aspects (chapter 3). This result relates to the experiences of stroke patients participaring in the study. During rehabilitation, patients experience lack of information, lack of evaluation and a lack of deliberation. In addition, they experience paternalism (providers deciding for them) regarding other aspects than treament, such as toilet times and leisure 
activities, which constrams their autonomy. At discharge, some strategies used by the health professionals appeared to constrain autonomy too, notably lack of preparation for the situation after discharge, lack of attentiveness, lack of respect, lack of information and lack of evaluation. Patients also experienced patemalism, and lack of a team approach to be limiting their autonomy. In short, health professionals gave enough attention to the dimension self-care, but, in the patients" perception, they should stimulate and facilitate the dimensions self-determination and independence more than they do now.

Shared language? In nursing homes, rehabilitation professionals work together in a team. In the interviews with providers, it appeared that patient autonomy is often discussed during team meetings. However, each provider used his or her own words to express ideas about the patients" autonomy. It is questionable whether they understand each other fully when discussing the patients" autonomy. A shared language (i.e. distinguishing different dimensions of autonomy and agreeing some terminology to discuss autonomy) might improve discussions on the development of patient autonomy, and might increase teamwork in this respect. Co-ordination of providers' strategies, teamwork and a shared language could sustain the providers" approach on the patients" autonomy. Providers stressed that they were used to the care routines and rules in the nursing home, to the rehabilitation methods, and to providing (too much) care. They called this phenomenon "institutionalization of providers", and stressed that this phenomenon constrains patient autonomy. Providers expressed the need for guidelines concerning the approach regarding patient autonomy.

Conclusion. The study revealed that health professionals operationalized autonomy particularly as self-care in their daily work, which means that they had a limited interpretation of patient autonomy. A shared language to discuss the patient"s autonomy was lacking.

\section{Developing hypotheses for theoretical moral reasoning}

The empirical study identified several questions related to patient autonomy in the context of rehabilitation and long-term care. These questions might function as a starting point for theoretical moral reasoning.

Changing autonony and partiall paternalism. Stroke patients admitted to a rehabilitation ward of a nursing home are in a state of transition regarding autonomy. Patients are between the acute care phase (of the hospital) and the long-term care phase (of the nursing home). Patient autonomy changes during stroke rehabilitation, a process subsumed in the core category "Changing atrtonomy' developed in the empirical study. Changing autonomy emphasizes the process of regaining autonomy, and patient and environmental factors influencing this process (see figure 1). 

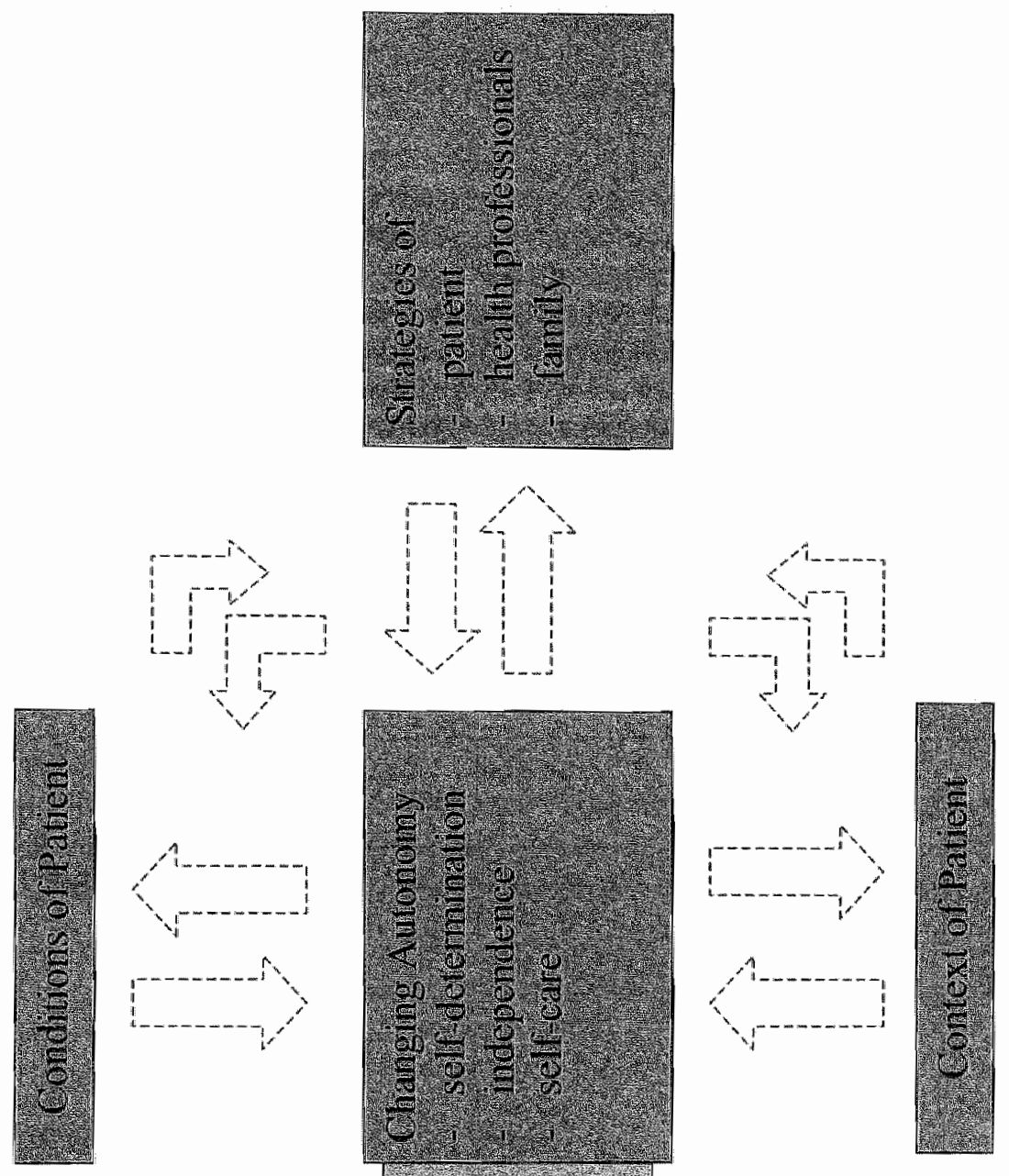
From the patients" perspective, a changing approach used by health professionals was found to be helpful for the restoration of autonomy (see chapter 7). The approach to changing autonomy desired by patients includes two patterns, 1) from full support through moderate support and supervision, to limited supervision; 2) from patemalism through partial paternalism to shared decision-making. Support includes instrumental and emotional support, and relates in particular to the dimensions self-care and independence. Paternalism concerns choices and decision-making, and therefore has to do particularly with the dimensions self-determination and independence. The empirical results showed that a supporting and paternalist approach can play a positive role towards the patients ${ }^{3}$ autonomy, particularly on early rehabilitation.

Several authors have discussed the problematic status of autonomy and informed consent in the context of rehabilitation (Sim, 1998) and long-term care (Agich, 1993). Respect for autonomy as guiding principle falls short for some patients at some times during their care, in particular when patients have undergone a sudden and unexpected course of severe impairment (Caplan, 1988). The question is, however, to what extent and under what conditions patemalistic actions can be viewed as morally justified, and under what conditions overriding patients" preferences is allowed (Caplan, 1988; Gorovitz, 1995). Such actions can be morally justified in view of enhancing or restoring autonomy (in the meaning of autonomy as decision-making) (Caplan, 1988), or in view of the ethical principle of beneficence (Gorovitz, 1995).

Empirical research into the experiences and preferences of stroke patients themselves has not been reported until now. The present study showed that paternalistic behavior to some extent appeared to be desired by the stroke patients. Nevertheless, to what extent and regarding what content patients experienced patemalistic actions to be facilitating for their autonomy varies in the course of rehabilitation. The concept 'partial paternalism' (to the best of our knowledge not described in bioethical literature) was identified. This concept expresses that the stroke patients in the present study did not strive for an 'cither-or" situation (either all decisions made by themselves or all decisions made by the health professionals). They need a 'both-and' situation (both some decisions made by themselves, and other decisions made by the health professionals) to restore their autonony. These results might suggest that patients consciously delegate certain decisions to the providers, which is indeed the case in the present study. The results, however, also showed situations of patients being happy retrospectively with providers deciding for them. At the moment the decisions were taken, however, patients did not agree and did not consciously delegate decisions. From the providers' perspective these paternalistic actions might be morally justified in view of enhancing or restoring the patients' autonomy in the long-tem. Providers know from their experiences with other stroke patients rehabilitating that patients need time to adjust to their impaiments and to learn which possibilities there are to adyust to the new situation (Caplan, 1988). 
Questions for theoretical moral reasoning. These results provided several questions regarding the concept of patient autonomy that could be a starting point for theoretical moral reasoning and future research. For example:

- Does the concept of "changing autonomy" provide a sufficient framework for the rehabilitation of stroke patients?

- Which implications does the concept of 'changing autonomy' have with regard to the principle of respect for autonomy?

- Does the concept of "partial paternalism" make sense in rehabilitation and long-term care, and if so, what does this imply for the principle of respect for autonomy?

- Are there serious threats for autonomy if the concept of "partial paternatism" is implemented, and if so, which precautions should be taken?

Conclusion. In the study two new concepts were developed, namely 'changing autonomy' and 'partial paternalism'. The consequences of these (tentative) concepts should be further studied. Several questions for theoretical moral reasoning in this respect were provided.

\section{Limitations of the study in the context of bioethics}

In contrast with many other empirical ethical studies where quantitative research strategies have been used, the present study explored the phenomenon of patient autonomy in a particular setting using a qualitative method (grounded theory, Strauss \& Corbin, 1990). The study did not focus on what is documented and readily measurable (a limitation often mentioned in regard with quantitative studies), but tried to assess patient autonomy related to the rehabilitation of stroke patients in nursing homes. Another limitation related to the scope and content of empirical ethics is that descriptive studies on what concepts and languages are used in practice, and by whom and why (clarification), cannot resolve conflicts about these concepts and language used, and cannot provide nommative guidelines. The aim of the present study was to develop a framework for providers concerning the approach towards the stroke patients autonomy during rehabilitation. In addition to description (what is at stake, and how), such a framework specifes different positive (and possibly negative) approaches (see chapters 3-7), which represents a normative component in this study. When used in practice, such a framework steers the approach to autonomy, although it does not provide one solution to a given problem, but on the contrary stimulates health professionals to reflect on their everyday practice. A qualitative study like the present study includes several phases in which the results are connected to the (bioethical) literature. These phases require conscious reasoning about the concepts and factors identified in the study. A second study is necessary to develop guidelines based on the framework developed, which will allow scope to do justice to the normative aspect.

In the present study the limitations of method mentioned in the literature were (partly) overcome. A qualitative method (grounded theory, Strauss \& 
Corbin, 1990) was used to study an unexplored phenomenon, namely patient autonomy in a particular setting (see chapters 3-7). An important goal of grounded theory is to understand the participants' world as they view it. Indepth semi-structured interviews were held with stroke patients and health professionals of three nursing homes. In this way the perceptions of the stroke patients and the health professionals on patient autonomy, and on the dimensions and processes regarding patient autonomy could be analyzed and identified. Attention was paid particularly to the patients' experiences, needs and preferences in the different phases of the rehabilitative process (see chapters 4 7 ), and to the patients' processes of regaining autonomy. Only the last three questions of the interviews with the health professionals concerned hypothetical. vignettes.

An often heard limitation is that researchers involved in empirical ethical studies do not have satisfactory ethical knowledge, while this knowledge is vital to design research on ethical issues, and to interpret the significance and limitations of the data. In the project group involved in the present study both bioethical expertise and expertise in (empirical) social sciences was represented.

\section{DISCUSSION}

The present study illustrated that different research aims mentioned in the bioethical literature can be addressed by empirical ethical studies: 1) to uncover theoretical points that are unworkable in practice; 2) to evaluate health professionals' abillity to operationalize ethical principles; 3) to develop hypotheses for theoretical moral reasoning. First, the empirical results showed what autonomy encompasses in a particular setting, the context of stroke patients rehabilitating in nursing homes, and provided a detailed description of aspects of autonomy, and of the process of regaining autonomy. The prevailing theoretical concepts of autonomy, self-govemance and self-realization were shown partly to fall short in the setting studied, in particular during early rehabilitation. Second, the study revealed that health professionals operationalized autonomy particularly as self-care in their daily work, which means that they had a limited interpretation of patient autonomy. A shared language to discuss the patient's autonomy was lacking. Teaching and guiding providers on how to approach autonomy is warranted. The results of the study can be used to develop multidisciplinary guidelines and courses in this respect. Third, in the study two new concepts were developed, namely changing autonomy and partial paternalism. The consequences of these (tentative) concepts should be further studied. Several questions for future debate and research in this respect were provided.

The contributions of empirical ethics mentioned in the literature particularly focus on contributions to the bioethical knowledge domain. Empirical studies, however, might also contribute to quality of care, e.g. the attitude of health professionals towards patients. A framework for providers concerning the 
approach of the stroke patients' autonomy developed in the study steers the approach of autonomy and stimulates health professionals to reflect on their everyday practice. In this way the study not only provides knowledge on patient autonomy, but may also contribute to a better approach to stroke patients and their autonomy in the setting of rehabilitation in nursing homes.

The study showed that the limitations of empirical research mentioned in the bioethical literature might be partly overcome by adopting a qualitative method. The present qualitative study focussed on a complex, undocumented phenomenon, and appeared to be fruitful for exploring the perspectives of patients, family and health professionals on this phenomenon. The study included several phases in which consciously reasoning on the concepts and factors identified in the study, and connecting the results to the bioethical literature have taken place.

Empirical ethics is an important branch of bioethics. Many questions require answers on an empirical base. Much ethical reasoning is about consequences (or presumed consequences). Key assumptions about consequences need to be tested empirically, i.e. an issue such as informed consent raises empirical questions about what ways of informing help increase autonomy and what ways do not. Empirical ethics deserves and warrants more attention from ethicists and researchers in the field of bioethics than it has been given till now.

\section{Acknowledgement}

I express my thanks to Dr. Tony Hope, Ph.D., University of Oxford, for his helpful comments on an earlier draft of this chapter.

\section{REFERENCES}

Agich, G.J. (1993). Autonomy and longuterm cane. Oxford: Ox ford University Press.

Arnold, R.M., \& Forrow, L. (1993). Empirical research in medical ethics: an introduction. Theoretical Medicine, 14, 195-196.

Bequchamp, T.L., Childress, J.F. (1994), Principles of biomedical ethics. Oxford: Oxford University Press.

Brody, B.A. (1993). Assessing empirical research in bioethics. Theoretical Medicine. 14,211 . 219.

Caplan. A.L. (1988). Informed consent and provider-patient relationships in rehabilitation medicine. Archives of Physical Medicine and Rehabilitation, 69, 312-317.

De Beaufort, 1., \& Trappenburg, M. (1999). Het geeft te denken. Gezondheidsethick en sociale wetenschappen. [It makes one think. Bioethics and social sciences]. In K Vos, V. Timmerhuis (Eds.), Gedragswetenschappen in context. Essays aver beleidrelewende en wetenschappelijke widagingen $35 * 45)$. Den Haag: Sdu.

Deci, E. L. (1980). The psychology of self-determinotion. Lexington, Massachusetts: Lexington.

De Wachter, M.A.M., \& de Beaufort, I. (Eds.). (1986). Het Institutit noor Gezondheidsethick. [The Institute for Biocthics]. Amsterdam: Ploegsma.

Douglas-Steele, D., \& Hundert, E.M. (1996). Accounting for context: future directions in bioethics theory and research. Theoretical Medicine, 17, 101-119. 
Emanuel, E.J. (1995). Empirical studies on euthanasia and assisted suicide. The Journal of Clinical Enhics; $6,158-160$.

Gorovilz, S. (1995). Fundamental issues in health care. In S.E. McCrae, N. Mattison, J.L. Sturchlo, P. B. Catterall (Eds.). Health care. The patient's perspective. Proceedings of the Patient s Chavter Conference (40-47). Lake Lanier Islands.

Hoffmaster, B. (1992). Can cthnography save the life of medical ethics? Social Science and Medicine, 35, 1421-1431.

Hofland, B.F. (1988). Autonomy in long term care: backgronnd issues and a programmatic response. The Gerontologist, 28 , Suppl. June, 3-9.

Hope, T. (1999). Empirical medical ethics. Editorial Journat of Medical Ethics, 25, 219-220.

Jennings, B. (1989). Ethics ans ethnography in neonatal intensive care. In G. Weisz (Ed.) Sncial science perspectives on medical ethics. Philadelphia: University of Pennsylvania.

Miller, B.L. (1981). Autonomy \& the refusal of lifesaving treatment. Hastings Center Report. $1 /(4), 22-28$

Musschenga, A.W., \& van der Steen, W.J. (1999). Empirie in de ethiek en empirische ethiek. [Empiricism in ethics and emporical ethics]. K\&M Tijdschrift voor Enpirische Filosofie, $23,155-166$.

Orem, D.E. (1995). Nursing: concepts of practice. St. Louis: Mosby.

Pearlman, R.A., Miles, S.H., \& Anold, R.M. (1993). Contributions of empirical research to medical ethics. Theoretical Medicine. 14, 197-210.

Pellegrino, E.D. (1995). The limitation of empirical research in ethics. The Joumal of Clinical Enics, $6,|6|-162$.

Sim, J. (1998). Respect for autonomy: issues in neurological rehabilitation. Clinical Rehabilitation, 12,3-10.

Strauss, A. \& Corbin, J. (1990). Basics of qualirative research: grounded theory procedures and rechniques. Newbury Park: Sage.

Sugarman, J., McCrory, D. C., Powell, D., Krasny, A., Adams, B., Ball, E., \& Cassell, C. (1999). Hastings Center Report, 29(1), Special Supplement.

Ten Have, H.A.M.J., \& Lelie, A. (1998). Medical ethics research between theory and practice. Theoretical Madicine, 19, 263-276.

Ten Have, H.A.M.J., ter Meulen, R.H.J., \& van Leeuwen, E. (1998). Medische ethiek. [Medical ethics]. Houten: Bohn Stafleu Van Lochum.

Van der Wulp, J.C. (1986). Verstoring en werwerking in verpleeghtizen. [Impairments and its resolution in nursing homes]. Nijkerk: Intro.

Van Peursen, C.A. (1994). Na het postmodernisme. Van metafysica tof flosofisch sureralisme. [After postmodernism. From metaphysics to philosophical surrealism]. Kumpen: Kok Agora.

Widdershoven, G. (1998). NWO-Projectworstel Theorie en methodologie van empirischethisch onderzoek". [NWO (Netherlands Organization of Scienlific Research) research proposal. Theory and methodology of empirical-ethical research]. Unpublished.

Zussman, R. (2000). The contributions of sociology to medical ethics. Hastings Center Report, $30(1), 7-11$. 


\section{Chapter 9}

\section{General discussion}

\section{INTRODUCTION}

In this chapter the main results of the study will be discussed. Methodological issues will be considered. Theoretical and methodological strengths and limitations in the context of bioethics have been discussed in chapter 8 . In the present chapter other methodological strengths and limitations of the study are discussed. Finally, implications for clinical practice, for education and training, for policies in nursing home care, and for further research will be discussed.

\section{MAIN RESULTS OF THE STUDY}

The research project on which this thesis is based concerned the phenomenon of the stroke patients' autonomy in the setting of rehabilitation wards in nursing homes. The project started with the following global research question:

In which way can providers contribute to the maintenance and/or recovery of the stroke patient's autonomy during rehabilitation post-stroke?

Patients who survive a stroke (or cerebrovascular accident) experience problems post-stroke: impairments, disabilities, and handicaps (Anderson, 1992). They have to deal with the new situation, a process that is often supported by rehabilitation in hospital, rehabilitation center or nursing home. In the Netherlands, stroke patients temporarily admitted to nursing homes are mostly placed in so-called rehabilitation wards. In most cases patient autonomy will be decreased post-stroke; not only are the physical capabilities of the patient diminished, but also the patient's life plans are suddenly interrupted as a result of the stroke. To be autonomous means not only to be independent of others, but to act according to your own standards and ideals as well. Yet what precisely is meant by patient autonomy? What are the theoretical underpinnings of this concept? And what is the role of caregivers regarding patient autonomy?

These questions were investigated in a concept analysis of the phenomenon of autonomy in relation to the rehabilitation of stroke patients (cliapter 2). A literature survey through several data bases on medical and psychological literature yielded scarcely any literature concerning autonomy and the rehabilitation of stroke patients. Secondary literature, however, was found about patient autonomy and related concepts in rehabilitation practices and residential long-term care. Most studies regarding patient autonomy appeared to be 
primarily based on theoreticall reflections. The few existing empirical studies concerned residential long-term care. The analysis of the literature showed that there are individual and social concepts of autonomy. An individual concept, for example, self-governance (Beauchamp \& Childress, 1994) stresses independence and authenticity, while a social concept such as actual autonomy (Agich, 1993) includes support by the environment. The literature indicated the importance of the social environment (formal and informal caregivers) for the restoration of autonomy, which suggests that a social concept of autonomy makes more sense in the rehabilitation of stroke patients than does an individual concept. Whether a social concept of autonomy is suitable for all phases of the rehabilitation is a question that remains unanswered. Considering these results it was concluded that patient autonomy in stroke rehabilitation warranted further investigation.

The project sheds more light on the stroke patients' changing autonomy during rehabilitation, and on the approaches used by health professionals regarding the restoration of patient autonomy in the different phases of the rehabilitative process. A qualitative research method was chosen because very little is known about the concept under study. The study was carried out on the rehabilitation wards of three nursing homes in the province of Limburg, the Netherlands. Twenty-two stroke patients and 27 health professionals working on the rehabilitation wards were interviewed. With regard to the patients' perceptions a longitudinal approach was chosen to see whether perceptions changed during the course of rehabilitation. Patients were interviewed three times during their admission in the nursing home: shortly after admission, during rehabilitation, and just before discharge. In the context of a qualitative study, the number of patients $(\mathrm{N}=22)$ was relatively high due to the longitudinal design. Professionals were interviewed once. The results of the empirical studies are presented in the chapters 3-7.

\section{Providers}

In a study among providers (chapter 3 ) the core category 'Changing autonomy' was developed. This category identifies the process of stroke patients regaining their autonomy, and the factors affecting this process. These factors can be divided into patient and environmental factors. Patient factors concern conditions and strategies of the patient. Environmental factors concern the nursing home as a context, and the strategies of the health professionals and of the family (see figure 1).

Three dimensions of autonomy were identified, self-determination, independence and self-care. Self-determination points at making choices and decisions about one's own life and health, and includes freedom of choice. Independence (physical, psychological, and social) concerns planning and organizing one's own \ife, including social contacts and role-taking, and refers to responsibility for one's own life and health care. 

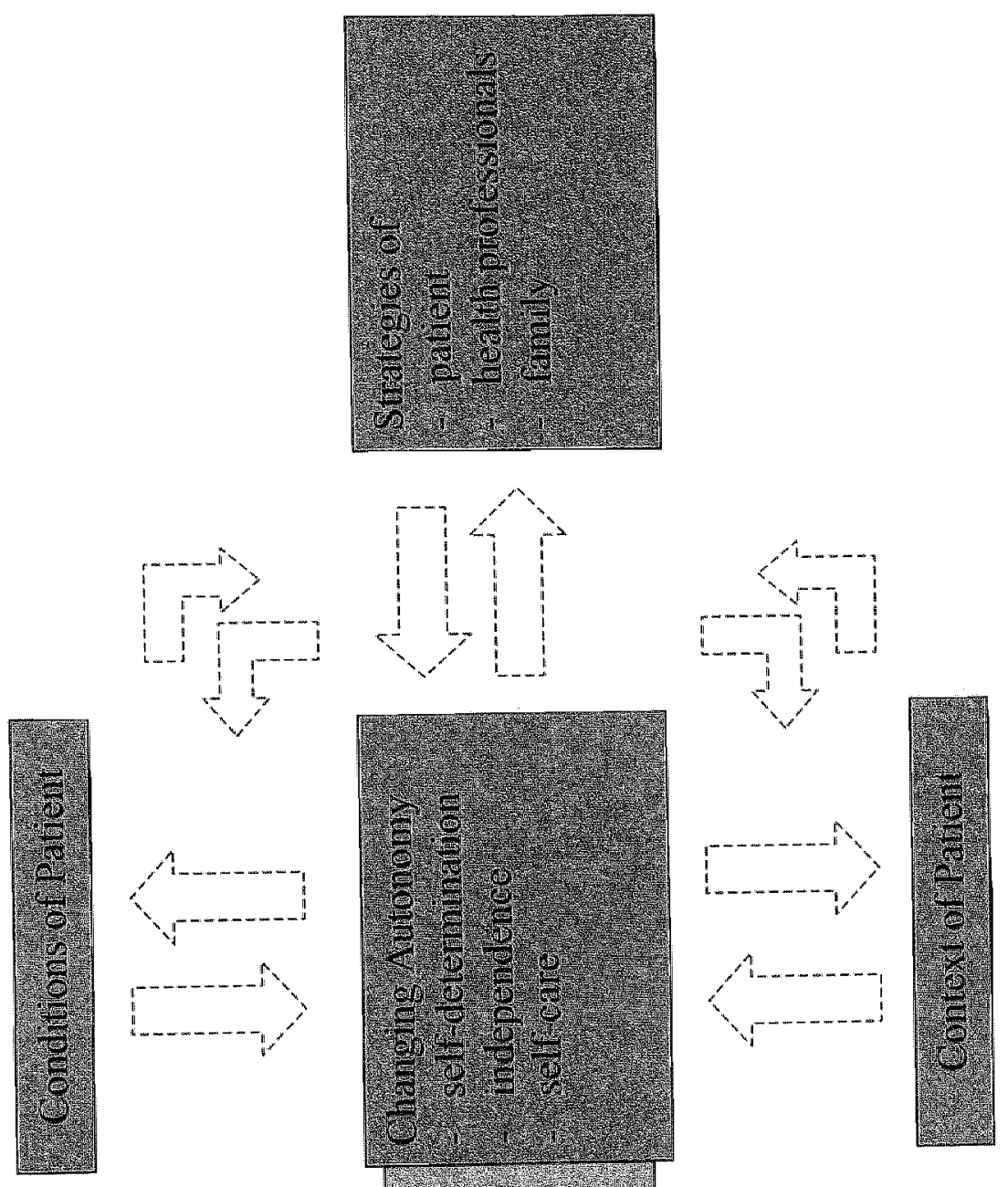

递

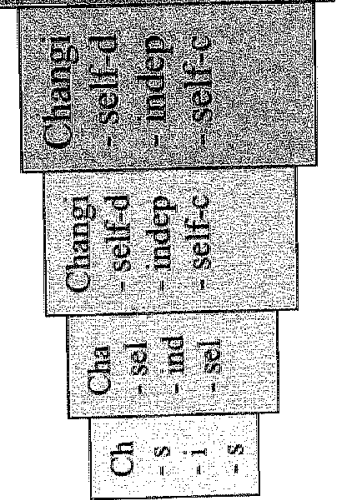


Self-care includes skills (mobility, communication, cognition) and activities of daily living, necessary for functioning. Self-determination and independence are related to self-governance in the bioethical literature (Beauchamp \& Childress, 1994). Self-determination appeared to be a dimension separate from independence because special attention is needed due to the often encountered communicative and cognitive disabilities of stroke patients, and to the process of their accepting boundaries and limitations (Deci, 1980). Self-care, the third dimension identified, is related to self-care as defined by Orem (1995).

Providers said that their work had so far been particularly focused on the dimension self-care, which they felt was not appropriate. Providers tended to hesitate about how to approach patient autonomy, and about which dimensions of autonomy need priority in the different phases of the rehabilitative process. In a study concerning the home care setting, Pool (1995) argued that the providers' goal-setting was strongly related to physical care, and less related to informational and psychosocial care. Banja (1993) observes that health professionals working with patients suffering from brain injury often interpreted. independence as only physical non-dependence.

\section{Stroke patients}

In the project several studies into the experiences of the stroke patients were undertaken (chapter 4-7). Independent from the study focussing on providers, the same core category, 'Changing autonomy', was identified in the stroke patients' study on admission including the same dimensions of autonomy: selfdetermination, independence and self-care (chapter 4). The interviews with patients in different phases of their rehabilitation provided important information about the process of regaining autonomy. In the different phases patient and environmental factors change and have a different effect on changing autonomy.

\section{On admission}

On admission patients" conditions (disabilities, multi-morbidity, emotional state, and feeling like a layperson) and patients' strategies (waiting and seeing, and acting as subordinate) constrain autonomy (the three dimensions). Several environmental factors facilitate patient autonomy. The nursing home sustains patient autonomy by providing a hopeful atmosphere and room for autonomy. The providers facilitate autonomy by giving therapy, support and information, by attentiveness and respect, by paternalism (deciding for patients) and by teamwork. The family gives emotional and instrumental support. These results correspond with the results from a qualitative study among stroke patients retrospectively interviewed about their admission to hospital; patients valued feeling cared about by experienced health professionals (Pound, Bury, Gompertz \& Ebrahim, 1995). The crucial role of the family in recovery from stroke has been described before (Anderson, 1992; Nolan \& Nolan, 1998), but not related to patient autonomy. In the present study constraining environmental factors for 
autonomy on admission are, care noutines, lack of privacy, an unfamiliar environment, waiting periods, "hotel" function and lack of information. Anderson (1992) also found that stroke patients experience a lack of information, and relates this result to a lack of systematic effort to inform patients. Mattiasson \& Andersson (1995) interviewed sixty chronically ill but competent nursing home residents about quality of nursing home care. They found that residents appreciated developing and maintaining social contacts more than influencing daily routines, which illustrates that residents" priorities differ from the priorities of the stroke patients in the present study, who experienced care routines as a constraining factor for autonomy.

\section{During rehabilitation}

During rehabilitation patient autonomy increases due to patient factors and environmental factors (chapter 5). During rehabilitation patients are in a state of transition regarding autonomy: patients need support to enhance autonomy, gradually regain autonomy, and thereby need less support. These results relate to the concept 'actual autonomy' (Agich, 1993) which entails that autonomy is not a static concept, but one that changes over time. Although facilitating environmental factors were discovered (e.g. a personal atmosphere, a consistent approach, support, therapy, attentiveness and respect, patemalism regarding treatment, information, giving evaluation, and deliberation, patients also experienced constraining factors regarding patient autonomy. Care routines, lack of privacy, time constraints, and lack of familiar activities to spend time, and lack of information, evaluation and deliberation constrain autonomy, as does paternalism regarding aspects other than treatment. These results showed that health professionals take on a paternalist attitude, which involves deciding for patients regarding their rehabilitation in view of restoring the patients' autonomy in the long-term. Caplan (1988) discussing the problematic status of autonomy in the context of rehabilitation argued that autonomy as the only principle would sometimes be inappropriate, in particular when patients have undergone a sudden and unexpected course of severe impairment. According to Caplan, in these cases it is required that paternalistic actions be viewed to some extent as morally justified.

\section{At discharge}

Stroke patients experienced an increase in their autonomy (the three dimensions) in the last weeks before discharge from nursing home (chapter 6). The change in autonomy was found to be related to patient factors (regained abilities and selfconfidence, and patients' strategies, such as taking initiative, and being assertive). Patients experienced several constraining environmental factors for autonomy (overprotection, paternalism, care routines and an inconsistent approach). Attentiveness, tailored interventions and a respectful dialogue facilitate autonomy, like moderate instrumental and emotional support by the family. Attentiveness as important factor for tailoring strategies has been described before (Tronto, 1994). Involwing patients in the decision-making process facilitates the discharge process (Unsworth, 1996). Regarding social 
support it was found that with emotional social support "more is better", but for instrumental social support "moderation in all things" seems beneficial for optimal recovery from stroke (Glass \& Maddox, 1992). In a study among geriatric stroke patients it appeared that patients reporting a greater variety of problems concerning the receipt of instrumental support from their family also reported a decline in self-care after discharge from hospital Norris, Parris Stephens \& Kinney, 1990). In the long time social support may be too heavy a burden. At 3 years after stroke, patients" partners experienced feelings among others that they bore a heavy responsibility and that the patient relied on their care only (Scholte op Reimer, de Haan, Rijnders, Limburg, \& van den Bos, 1998). Concerning the nursing home, care routines, lack of familiar activities and lack of privacy appeared, in our study, to hinder patients from getting used to the activities they will have to do after discharge, which may impede a gradual transition from the nursing home to the discharge enwironment. Conversely, if an enviromment challenges stroke patients' initiative and responsibility, and stimulates patients to practise everyday tasks, this might improve the outcone of rehabilitation (Ada, Canning \& Westwood, 1990).

The studies among stroke patients indicated that the respective rehabilitative phase (admission, rehabilitation or discharge) has a relation with patients' experiences in autonomy, and with the strategies patients used to express their autonomy. Conversely, the results did not suggest a relation between demographic or clinical characteristics (other than the rehabilitative phase) and patients' experiences and strategies concerning their autonomy.

\section{Patterns}

In a longitudinal study aimed at uncovering which patterns in the health professionals' approach facilitate the stroke patients' autonomy throughout the rehabilitative process as a whole, a changing approach regarding the patients' changing autonomy was found to be helpful for the restoration of the patients" autonomy (chapter 7). In the stroke patients' view two patterns in health professionals" approach appeared to be facilitating: 1) from full support on admission through moderate support and supervision, to reduced supervision at discharge; and 2) from paternalism on admission through partial paternalism (only regarding treatment) to shared decision-making at discharge. Support includes instrumental and emotional support, and relates in particular to the dimensions self-care and independence. Paternalism concerns choices and decision-making, and therefore thas to do particularly with the dimensions selfdetermination and independence. Partial paternalism expresses that the stroke patients in the present study did not strive for an 'either-or' situation (all decisions made by themselves or all decisions made by the health professionals). They need a 'both-and' situation (some decisions made by themselves, and other decisions made by the health professionals) to restore their autonomy. These two patterns show the importance of a social concept of autonomy as framework for the providers" approach to the stroke patients" regaining autonomy, particularly 
during early rehabilitation. When the patients" autonomy improves providers should also bear in mind the individual concepts of autonomy, in order to develop the patients' autonomy further. The approach experienced by the patients did not always match the desired approach regarding autonomy. Support and supervision were reduced in time, but paternalism was often continued too long. Providers gave enough attention to the dimension self-care, but, in the patients' perception, they should stimulate and enable the dimensions self-determination and independence more than they do now. This situation was also mentioned with regard to other patient groups in the literature (Banja, 1993; Pool, 1995).

\section{Empirical ethics}

The results of the empirical studies were discussed in the light of the strengths and limitations of empirical ethics mentioned in the bioethical literature (chapter 8). In the literature the following research aims are mentioned which can be addressed by empirical ethical studies: 1) to uncover theoretical points that are unworkable in practice; 2) to evaluate health professionals' ability to operationalize ethical principles; 3) to develop hypotheses for theoretical moral reasoning. The present study illustrated that these research aims can be addressed. It appeared that the prevailing theoretical concepts of autonomy (selfgovernance, Beauchamp \& Childress, 1994; self-realization, Miller, 1981) partly fell short in the setting studied, in particular during early rehabilitation. The study revealed that health professionals had a limited interpretation of patient autonomy, and that a shared language to discuss the patient's autonomy was lacking. Two new concepts were developed, namely "changing autonomy" and "partial paternalism', which should be further studied. Several questions regarding these (tentative) concepts were formulated, which could be a starting point for theoretical moral reasoning and future studies:

- Does the concept of 'changing autonomy' provide a sufficient framework for the rehabilitation of stroke patients?

- Which implications does the concept of 'changing autonomy' have with regard to the principle of respect for autonomy?

- Does the concept of 'partial paternalism' make sense in rehabilitation and long-term care, and if so, what does this imply for the principle of respect for autonomy?

- Are there serious threats for autonomy if the concept of 'partial paternalism" is implemented, and if so, which precautions should be taken?

The study showed that the limitations of empirical research mentioned in the bioethical literature might be partly overcome by adopting a qualitative research method.

It was concluded that empirical ethics is an important branch of bioethics, which deserves and warrants more attention from ethicists and researchers in the field of bioethics than it was given till now. 


\section{STRENGTHS OF THE STUDY}

The studies presented in this thesis used a qualitative research design, the method and procedures of grounded theory (Strauss \& Corbin, 1990), to explore the phenomenon of patient autonomy in the practice of the stroke patients" rehabilitation in nursing homes. Qualitative research is used when the phenomenon under study has been little studied, which is the case here. In qualitative interviews participants have the opportunity to reflect on their experiences in their own language. In this way theory was built inductively, which gives a better chance that the results will be recognized in practice. This is important because it is intended that the final recommendations of the project are used by health professionals. In the later phases of the analysis the results are confronted with and connected to the (bioethical) literature.

Semi-structured interviews with patients and health professionals were chosen to investigate how respondents themselves describe and value autonomy, and which facilitating and constraining factors they experience and identify. Using a qualitative interview method the interviewer can tune the exact formulation of the questions to the education level of the individual respondent if necessary, and can take into account particular disabilities (e.g. speech impairments) of the individual patient.

The categories used to organize the results from the study are not derived from theory and predefined, but are based on the orientations and values of patients and providers. The interviews of patients and providers thave been analyzed separately in order to identify different perspectives and needs, if any. The patient interviews have been analyzed on group level (the results of all participating patients on a particular moment, e.g. on admission) to describe specific needs and experiences in a particular phase of the rehabilitation process (see chapters 4-6) and on patient level (longitudinal analysis, three interviews of one particular patient analyzed as a whole) to identify facilitating patterns in the providers" approach towards the patients' changing needs and experiences during the rehabilitation process (see chapter 7). The provider interviews have been analyzed on group level. Data triangulation, investigator triangulation and methodological triangulation (Denzin, 1989) were used to broaden the analysis of the phenomenon of stroke patient"s autonomy, and to secure content validity (Sim \& Sharp. 1998). Respondents admitted to (patients) or working on (providers) the rehabilitation wards of different nursing homes, and with varying sociodemographic variables participated in the study (data triangulation). There were two interviewers, and peer debriefing during analysis was used (investigator triangulation). Apart from individual in-depth interviews, member checks were held (methodological triangulation). 'Member checks' means that group meetings were organized with the respondents (patients and providers separately), where the results of the analysis were discussed. 


\section{LIMITATIONS OF THE STUDY}

The study focussed on exploration and description of the phenomenon of patient autonomy, and of the factors influencing this phenomenon. A qualitative design like grounded theory is an adequate approach for exploration and description. but cannot be used to test whether there are significant differences between patients from different nursing homes, or differences in the approach of disciplines. The study was limited to interviews. No observations were made to verify if, for example, the constraining and facilitating factors discussed by the respondents were really at stake. Nevertheless, qualitative interview techniques provide the possibility to verify the respondent's answers, for example, by asking further questions, and by asking for illustrating examples and situations. There were no indications that respondents fantasized during the interviews. Providers did not paint an ideal picture of their approach to the patients" autonomy; on the contrary, they showed their doubts and questions in the interviews. The patients' answers could have been influenced by their dependency on the providers. However, in the interviews patients mentioned several examples of providers constraining patient autonomy, even on admission, when patients were highly dependent on the support of the providers. It is arguable whether the patients' autonomy has been really increased. In the stroke patients' perspectives their autonomy was improved during rehabilitation in the nursing home, but the patients' autonomy 'in vivo' was not observed or measured in this study. Consideration could be given to whether the results of this study could be used to develop an autonomy assessment instrument, including the three dimensions of patient autonomy.

Tuning the exact formulation of the interview questions to the education level of the respondent may encompass the risk of the interviewer affecting the respondent's answers, e.g. by using leading questions. It could also be questioned if the interviewers' theoretical backgrounds influenced the way of interviewing, because theoretical backgrounds cannot simply be 'deleted'. By formulating a list with so-called sensitizing concepts, (theoretical) ideas on patient autonomy were made explicit in advance, but they were not integrated in the interview guides. Furthermore, the risk of leading questions was reduced to a minimum by training the two interwiewers in open interviewing, by debriefing frequently after the interviews and by commenting the interview transcripts. During the analysis the risk of 'being blinkered' (the risk that the researcher was trapped in one-way thinking and lost creativity and openness) was reduced by peer debriefing and by member checks.

The study was limited to interviews with respondents admitted to or working in three nursing homes in the province of Limburg, the Netherlands. However, the reactions of providers working in nursing homes in other parts of the Netherlands to oral and written presentations gave no indications that the results were limited to the Limburg region. Nevertheless, the results are limited to a particular group of stroke patients (see chapter 4, selection criteria): patients admitted to a rehabilitation ward of a nursing home, in particular older patients 
with serious impairments post-stroke, with relatively good rehabilitation prospects, and expected to leave the nursing home, participated in the study. Generalization of the results to patients in other settings, for example, stroke patients rehabilitating in rehabilitation centers, or stroke patients staying at residential wards in nursing homes, requires additional research.

The study focussed on the phase in which patients were in the nursing home. This has to do with the scope of the study and the financial resources available. If patients could also have been interviewed when they were back at home, this could have provided useful additional information regarding the adequate approach of the patient's autonony during rehabilitation in the nursing home.

\section{IMPLICATIONS AND RECOMMENDATIONS}

\section{Implications and recommendations for clinical practice}

\section{Three dimensions of autonomy}

Attention to the three dimensions of patient autonomy may improve patients' active participation in rehabilitation, quality of life, and autonomous living after discharge. Health professionals participating in the interviews noted that their work had so far been particularly focussed on self-care, which they feel was not appropriate. Providers hardly mentioned particular strategies regarding the restoration of other dimensions of patient autonomy.

\section{A differentiated approach}

Tailoring interventions to patients' progress in autonomy in a broad sense, gradually reducing support and paternalism, and giving information, will stimulate the patients" active participation in rehabilitation and in decisionmaking, and will improve the patients' preparation for antonomous living after discharge. Differentiating the approach to the stroke patients" autonomy could prevent negative consequences of the prevailing concept of autonomy (selfgovernance). Giving the patient information about rehabilitation methods on admission, and expecting, for example, that the patient is able to make a choice consciously, is not an aclequate approach to all stroke patients rehabilitating in nursing homes. For a number of patients simply starting a particular therapeutic activity is an adequate approach on admission, after having informed the patient about the activity.

\section{Knowledge, attitude and skills}

Improving knowledge, attitude and skills of health professionals with regard to patient autonomy is recommended. In this way a conscious assessment and intervention regarding the three dimensions of autonomy may be stimulated. In the nursing homes participating in the study an insight into these matters was gained. 


\section{Teamwork}

Teamwork and co-ordination of the process of changing autonony may support the providers in the approach of patient autonomy. A consistent approach by all team members stimulates and facilitates patient autonomy, whereas discontinuity in this respect highly constrains autonomy, causing confusion and diminishing self-confidence. The study showed that patient autonomy is often discussed during team meetings, but that all team members use their own languages to express their ideas. A shared language may highly improve the discussion of the patients' autonomy, and may stimulate a team approach. This study contributes to the development of a shared language. Co-ordination of the process of changing autonomy may support the providers in an adequate approach towards patient autonomy. In most cases the nurse or practical nurse has already a co-ordinating role in daily care on the ward; therefore he or she might be the most appropriate person to take this role.

\section{The family's role}

In the interviews with providers and patients the role of the stroke patient's family members appeared to be of crucial importance for the stroke patient regaining his or her autonomy. The study showed merely positive influences on patient autonomy; nevertheless there are also negative influences reported by patients and providers. Giving attention to the family's role in rehabilitation is recommended, to prevent the families' insecurity regarding what support they should give by instructing the patient and the family together.

\section{Implications and recommendations for education and training}

\section{Guidelines}

Multidisciplinary guidelines and courses based on the results of the study can be used to improve the providers' knowledge, attitude and skills with regard to patient autonomy. The guidelines to be developed should be in a format that stimulates the providers' reflection on daily practice. In this way providers can learn from their own experiences and problems, which can motivate them to adopt an autonomy-enhancing approach in their daily work. This implementation strategy (multidisciplinary guidelines) involves both education and social interaction (Grol, 1997), and may stimulate a coordinated interdisciplinary approach and a shared language regarding the patients' changing autonomy.

\section{Education and training}

On a local level, multidisciplinary teams in nursing homes can be trained in using these guidelines in daily work. After such a course providers can deal with patient autonomy on a regular basis in so-called 'toolbox meetings': for example, once in a month the multidisciplinary team discusses patient autonomy, eventual problems, and their experiences with the guidelines, in an 
informal setting on the ward. Both basic-level and postgraduate level education of the different disciplines involved in stroke rehabilitation should give attention to patient autonomy, in particular with regard to the different dimensions of autonomy and to the process of the stroke patient's regaining autonomy. Many textbooks on neurological rehabilitation are centered around the methodological phases in the work of the health professionals (e.g. assessment, goal planning, treatment). More attention is warranted on the phases of 'the patient's work' on autonomy. Integrating the results of the study in textbooks is recommended in order to recognize the patient's autonomy and role in rehabilitation. Implementation of the results in family counseling, education and training may be concerned.

\section{Implications and recommendations for policies in nursing home care}

Nursing homes can integrate the results in local guidelines on stroke rehabilitation (e.g. guidelines for stroke units, rehabilitation wards, transmural care). Furthermore, the results can be implemented in local policies such as client-centered care, in care contracts and in exit interviews for patients discharged from a rehabilitation ward or stroke unit. Nursing homes can enhance autonomy by minimizing care routines and by providing room (literally) and aids for doing activities independently and privately.

In the Netherlands the guidelines to be developed may contribute to a further description of the quality assurance criteria for nursing home care (Van Oldeniel, 1993; Van Oldeniel \& van der Kooy, 1993) and to the description of hospital-related care by nursing homes (De Beer, 1996). Integrating the results in national guidelines on the rehabilitation of stroke patients may be considered, e.g. the stroke guideline developed by the Dutch Institute for Health Care Improvement $\mathrm{CBO}(\mathrm{CBO}, 2000)$, and guidelines on stroke rehabilitation to be developed by the Netherlands Heart Foundation [Nederlandse Hartstichting].

\section{Implications and recommendations for future research}

\section{Bioethics}

In chapter 8 research on particular ethical topics is recommended, such as on the concepts 'changing autonomy' and 'partial paternalism'. Several questions were developed concerning the stroke patients" autonomy in the practice of rehabilitation and long-term care, such as: Which implications does the concept of 'changing autonomy' have with regard to the principle of respect for autonomy? Does the notion of 'partial paternalism' make sense in long-term care, and if so, what does this imply for the principle of respect for autonomy? These questions can function as starting points for future debate and research. 


\section{Guidelines}

Additional research is warranted directed at intervention development (multidisciplinary guidelines and courses), at studying the effects of the intervention, and at the implementation of the intervention. For the future a project aimed at developing guidelines based on the results of the present study is planned. Integration of these guidelines in stroke guidelines, e.g. the stroke guideline developed by the Dutch Institute for Health Care Improvement $\mathrm{CBO}$, and guidelines on stroke rehabilitation to be developed by the Netherlands Heart Foundation, is recommended. Given the particular group and setting, the guidelines on the approach to autonomy should provide alternative actions and their possible consequences in a particular situation. Such guidelines will enlarge the health providers' understanding of the stroke patients' autonomy, and stimulate reflection on daily practice. In addition, a guideline for individual talks with patients on their own autonomy could be developed and tested as an intervention, which could be part of the guidelines for providers. It could also be considered whether the results of the present study could be used to develop an autonomy assessment instrument.

\section{Autonomy post-discharge}

A study focussing on the patients' autonomy after discharge from nursing home is recommended to provide additional information regarding the approach of the patient's autonomy during rehabilitation in the nursing home.

\section{Patient autonomy and social support}

In the interviews with providers and stroke patients the role of family members appeared to be of crucial importance for the stroke patient regaining his or her autonomy. The study showed merely positive influences on patient autonomy; nevertheless there are also negative influences reported by patients and providers. Studies on the tensions between patient autonomy and social support in stroke rehabilitation are warranted.

\section{Autonomy in other patient groups}

The results concern a particular group of stroke patients, namely older stroke patients with serious impairments, but with relatively good rehabilitation prospects, and expected to leave the nursing home. Studies on the applicability of the results in other settings, such as stroke patients rehabilitating in rehabilitation centers, or stroke patients staying at residential wards in nursing homes, are strongly recommended. Also stuclies into experiences on autonomy of patients with other diagnoses, such as multiple sclerosis, spinal cord injury, cardiovascular disease, and visual impairments are warranted. What dimensions of autonomy do they identify, what dimension(s) have priority, at what moment and why? A better understanding of these matters can be used to facilitate the process of maintaining and regaining autonomy, and to optimize the approach and strategies of the providers involved. 


\section{REFERENCES}

Ada, L., Canning, C., \& Westwood, P. (1990). The patient as an active leamer. In L. Ada, C. Canning (Eds.), Key issues in newrological physiotherapy (99-124). Oxford: Butterworth Heinemann.

Agich, G.J. (1993). Autonomy and Long-term came. Oxford: Oxford University Press.

Anderson, R. (1992). The aftermath of stroke. The experiences of parients and their families. Cambridge: Cambridge University Press.

Banja, J.D. (1993). Ethical issues in staff development. In C.J. Durgin, N.D. Sichmidt, \& L.J. Fryer (Eds.), Staff development and clinical intervention in brain injury (23-41). Maryland: Aspen.

Beauchamp, T.L., \& Childress, J.F. (1994). Principles of biomedical ethics. Oxford: Oxford University Press.

Caplan, A.L. (1988). Informed consent and provider-patient relationships in rehabilitation medicine. Archives of Physical Medicine and Rehabilitation, 69, 312-317.

De Been, M.F.I.M. (1996). Ziekenhuisgerelateerde zorg door verpleeghuizen. Deel A. Onderzoek naar de mogelijkheden van verpleeghwiszorg aan ziekenhispatiënten. [Hospital-related care in nursing homes. Part A. A study into the possibilities of aursing home care for hospital patients]. Utrecht, NVVz.

Deci, E. L. (1980). The psychology of self-determination. Lexington, Massachusetts: Lexington.

Denzin, N. K. (1989). The research act: a theoretical introduction ro sociological methods. Englewood Cliffs: Prentice Hall.

Dutch Institute for Health Care Improvement CBO. (2000). Richtijn Beroerte. [Stroke guideline]. Utrecht: CBO.

Glass, T.A., \& Maddox, G.L. (1992). The quality and quantity of social support: stroke recovery as psycho-social transition. Social Science and Medicine, 34, 1.249-1261.

Grol, R. (1997). Belliefs and evidence in changing clinical practice. British Medical Journat, $315,418-421$.

Mattiasson, A., \& Andersson, L. (1995). Quality of nursing home care assessed by competent nursing home patients. In A. Mattiasson (Ed.), Autonomy in nursing home settings. Shudy 5 (1-14). Stockholm: Karolinska Institute.

Miller, B.L. (1981). Autonony \& the refusal of lifesaving treatment. Hastings Center Repart, $1 /(4), 22-28$

Nolan, M., \& Nolan, J. (1998), Stroke I: a paradigm case in nursing rehabilitation. Britssh Journal of Nursing. 7, 316-322.

Norris, V.K., Parris Stephens, M.A., \& Kinney, J.M. (1990). The impact of family interactions on recovery from stroke: help or hindrance? The Geromtologist, 30, 535-542.

Orem, D.E. (1995), Nursing: concepts of practice. St. Louis: Mosby.

Pool, A. (1995). Antonomie, afhamkelikheid en langdurige zorgherlening. [Autonomy, dependence and long-term care]. Utrecht: Lemma.

Pound, P., Bury, M., Gompentz, P., \& Ebrahim, S. (1995). Stroke patients" views on their admission to hospital. British Medical Hownal, 3/1, 18-22.

Scholte op Reimer, W.J.M., de Handn, R.J., Rijnders, P.T., Limburg, M., van den Bos, G.A.M. (1998). The burden of caregiving in partners of long-term stroke survivors. Sroke. 29, $1605-1611$.

Sim, J., \& Slarp, K. (1998). A critical appraisal of the role of triangulation in nursing research. International Joumal of Nursing Stadies, 35, 23-31.

Strauss, A., \& Corbin, J. (1990). Basics of qualitative research: grounded theory procedures and techniques. Newbury Park: Sage.

Tronto, J.C. (1994). Moral boundaries: a political argument for an ethic of care. New York: Routledge. 
Van Oldeniel, H. (1993). Kwaliteiskenmerken werpleghhiszorg. Deel II. Kwaliteisinstrument. [Quality criteria for nursing home care. Part III. A quality instrument]. Utrecht: NVVz.

Van Oldeniel, H., \& Kooif, van der, C. (1993). Kwaliteitskenmerken verplegghuiszorg. Deel I. Onderzoeksrapport. [Quality criteria for nursing home care. Part I. Study report]. Utrecht: NVVz.

Unsworth, C. (1996). Clients' perceptions of discharge housing decisions after stroke rehabilitation. American Journal of Occupational Therapy, 50, 207-216. 



\section{Chapter 10}

\section{Summary}

This thesis concerns a study into the stroke patients' autonomy. Patients who survive a stroke (or cerebrovascular accident) experience problems post-stroke, such as impairments, disabilities, and handicaps. They have to deal with the new situation, a process that is often supported by rehabilitation in hospital, rehabilitation center or nursing home. In most cases patient autonomy will be decreased post-stroke; not only are the physical, communicative and/or cognitive capabilities of the patient diminished, but also the patient's life plans are suddenly interrupted as a result of the stroke. In the present project patient autonomy was explored in the setting of rehabilitation wards in nursing homes. The thesis sheds more light on the stroke patients' changing autonomy during rehabilitation, and on the approaches used by health professionals regarding the restoration of patient autonomy during rehabilitation.

The initiative for the research project underlying this thesis was taken by the Institute for Bioethics in collaboration with Maastricht University. The project started in June 1995 and ended in April 1998, and was financially supported by the National Center for Nursing and Care (LCVV) in Utrecht, and by the Province of Limburg, the Netherlands. The project was carried out on the rehabilitation wards of three nursing homes in Limburg: Martinushof in Tegelen, Schuttershof in Brunssum, and St. Camillus in Roermond.

Chapter 1 provides an introduction in the field of investigation. Autonomy, stroke and long-term care are discussed related to the rehabilitation of stroke patients. Existing empirical studies on autonomy and long-term care are discussed, and the aims, research question and method of the study are described.

Chapter 2 reports on a concept analysis on the phenomenon of autonomy in relation to the rehabilitation of stroke patients. The following questions were investigated. What is meant precisely by patient autonomy? What are the theoretical underpinnings of this concept? And what is the role of caregivers regarding patient autonomy? A survey on medical and psychological literature yielded scarcely any literature concerning autonomy and the rehabilitation of stroke patients. Secondary literature, however, was found about patient autonomy and related concepts in rehabilitation practices and residential longterm care. Most studies regarding patient autonomy appeared to be primarily based on theoretical reflections. The existing empirical studies concerned residential long-term care. The analysis showed that there are individual and social concepts of autonomy. An individual concept of autonomy stresses independence and authenticity, a social concept includes support by the environment. The literature indicates the importance of the social environment for the restoration of autonomy, which suggests that a social concept of autonomy makes more sense in stroke rehabilitation than does an individual 
concept. The question whether a social concept of autonomy is suitable for all phases of the rehabilitation remains unanswered. It is concluded that patient autonomy in stroke rehabilitation warrants further investigation.

In chapter 3 the perspectives of providers working in nursing homes on patient autonomy are described. Which aspects of the stroke patient's autonomy and which factors influencing patient autonomy during rehabilitation do providers identify? In a study among 27 providers the core category "Changing autonomy' was developed. This category identifies the process of stroke patients regaining their autonomy, and the factors affecting this process. These factors can be divided into patient and environmental factors. Patient factors concern conditions and strategies of the patient. Environmental factors concern the nursing home as a context, and the strategies of the providers and the family. Three dimensions of autonomy were identified, self-determination, independence and self-care. Self-determination points at making choices and decisions about one's own life and health, and includes freedom of choice. Independence (physical, psychological, and social) concerns planning and organizing one's own life, including social contacts and role-taking, and refers to responsibility for one's own life and health care. Self-care includes skills (mobility, communication, cognition) and activities of daily living, necessary for functioning. Providers said that their work had so far been particularly focussed on the dimension self-care, which they felt was not appropriate. They tended to hesitate about how to approach patient autonomy, and about which dimensions of autonomy need priority in the different phases of rehabilitation.

In the project several studies into the experiences of the stroke patients were undertaken (chapters 4-7). With regard to the patients' perceptions of autonomy a longitudinal approach was chosen to see whether perceptions and needs changed during the course of rehabilitation. Twenty-two patients were interviewed shortly after admission, during rehabilitation, and just before discharge. These interviews provided important information about the process of regaining autonomy. In the different phases of rehabilitation patient and environmental factors change and have a different effect on changing autonomy.

Independent from the study focussing on providers, the same core category and dimensions of autonomy were identified in the stroke patients' study on admission: self-determination, independence and self-care (chapter 4). On admission the patients" conditions (disabilities, multi-morbidity, emotional state, and feeling like a layperson) and the patients" strategies (waiting and seeing, and acting as subordinate) constrain autonomy (the three dimensions). According to the stroke patients in our study, several environmental factors facilitate patient autonomy. The nursing home sustains patient autonomy by providing a hopeful atmosphere and room for autonomy. The providers facilitate autonomy by giving therapy, support and information, by attentiveness and respect, by teamwork, and, paradoxically, by paternalism (deciding for patients). The family gives emotional and instrumental support. Constraining environmental factors for autonomy on admission are, care routines, lack of privacy, an unfamiliar environment, waiting periods, "hotel" function and lack of information. 
During rehabilitation patient autonomy increases (in particular the dimension self-care) due to patient factors and environmental factors (chapter 5). During rehabilitation patients are in a state of transition regarding autonomy (the three dimensions): patients need support to enhance autonomy, gradually regain autonomy, and thereby need less support. Facilitating environmental factors fot autonomy are: a personal atmosphere, a consistent approach, support, therapy, attentiveness and respect, patemalism regarding treatment, information, giving evaluation, and deliberation. Constraining environmental factors for autonomy are: care routines, time constraints, lack of privacy, paternalism regarding other aspects than treatment, lack of familiar activities to spend time on, and lack of information, evaluation and deliberation.

In the last weeks before discharge stroke patients experienced an increase in their autonomy (in particular the dimensions independence and selfdetermination) (chapter 6). The change in autonomy was found to be related to patient factors (regained abilities and self-confidence, and patients'strategies, such as taking initiative, and being assertive). Patients experienced several constraining environmental factors for autonomy (overprotection, paternalism, care routines and an inconsistent approach). Care routines, lack of familiar activities to spend time on, and lack of privacy appeared to hinder patients from getting used to the activities they will have to do after discharge, which may impede a gradual transition from the vursing home to the home situation. Attentiveness, tailored interventions and a respectfull dialogue facilitate autonomy, like moderate instrumental and emotional support by the family.

In addition to the analysis of particular phases of the rehabilitation process (chapter 4-6), the three patient interviews were analyzed longitudinally to explore how health professionals can facilitate the process of restoration of the stroke patients' autonomy (chapter 7). A changing approach towards the patients' changing autonomy was found to be helpful for the restoration of patient autonomy. In the stroke patients" view two patterns in the health professionais" approach appeared to be facilitating: 1) from full support on admission through moderate support and supervision, to reduced supervision att discharge; and 2) from patemalism on admission through partial patemalism (only regarding treatment) to shared decision-making at discharge.

Support includes instrumental and emotional support, and relates in particular to the dimensions self-care and independence. Patemalism means that providers make choices and take decisions for patients, and therefore has to do particularly with the dimensions self-determination and independence. Partial paternalism expresses that the stroke patients in our study did not strive for an "either-or' situation (all decisions made by themselves or all decisions made by the providers). They need a 'both-and' situation (some decisions made by themselves, and other decisions made by the providers) to restore their autonomy. These two patterns showed the importance of a social concept of autonomy (see chapter 2) as framework for the providers' approach to the stroke patients' regaining autonomy, particularly during early rehabilitation. When the patient's autonomy improves providers should also bear in mind the individual 
concepts of autonomy (see chapter 2), in order to foster the patient's developing autonomy. The approach experienced by the patients did not allways match the desired approach regarding autonomy. Support and supervision were reduced in time, but paternalism was often continued too long.

Chapter 8 discusses the results of the study in the light of the strenghts and limitations of empirical ethics described in the bioethical literature. The following research aims are mentioned for empirical ethics: 1) to uncover theoretical points that are unworkable in practice; 2) to evaluate health professionals" ability to operationalize ethical principles; 3) to develop hypotheses for theoretical moral reasoning. In the present study these research aims were addressed. First, the prevailing theoretical concepts of autonomy, selfgovernance and self-realization, were shown partly to fall short in the setting studied, in particular during early rehabilitation. Second, the study revealed that health professionals had a limited interpretation of patient autonomy, and that a shared language to discuss the patient's autonomy was lacking. Third, two new concepts were developed, namely 'changing autonomy' and 'partial paternalism". The consequences of these (tentative) concepts should be further studied. Several questions for future debate and research were formulated;

- Does the concept of 'changing autonomy' provide a sufficient framework for the rehabilitation of stroke patients?

- Which implications does the concept of 'changing autonomy' have with regard to the principle of respect for autonomy?

- Does the concept of 'partiall paternalism' make sense in rehabilitation and long-term care, and if so, what does this imply for the principle of respect for autonomy?

- Are there serious threats for autonomy if the concept of "partial paternalism" is implemented, and if so, which precautions should be taken?

The study showed that the limitations of empirical research mentioned in the bioethical literature might be partly overcome by adopting a qualitative research method. It is concluded that empirical ethics warrants more attention from ethicists and researchers in the field of bioethics than it was given till now.

Chapter 9 concerns the main results of the study. Methodological strengths (qualitative design, identifying patients' needs, peer debriefing, triangulation) and limitations (no observations, generalizability) are elaborated. Finally, recommendations are given for clinical practice, for education and training, for policies in nursing home care, and for further research. These recommendations encompass, among others, giving attention to the three dimensions of autonomy, and applying a differentiated approach to autonomy during rehabilitation. Guidelines to be developed might sustain providers in their approach towards patient autonomy. Integrating the results in local and national guidelines on stroke rehabilitation deserves attention. Concerning future research, studies into the bioethical topics mentioned, into the effect of the guidelines to be developed, into the relation between patient autonomy and social support, and into autonomy of patients with other diagnoses are recommended. 


\section{Chapter 11}

\section{Samenvatting}

Dit proefschrift betreft een onderzoek naar de autonomie van CVA-patiënten. Patiënten die een CVA (of cerebrovasculair accident) overleven ondervinden na het CVA vaak problemen in de vorm van stoornissen, beperkingen en handicaps. Zij moeten zich aanpassen aan de nieuwe situatie. Dit proces wordt in de meeste gevallen ondersteund door revalidatie in een ziekenhuis, revalidatiecentrum of verpleeghuis. Dikwijls is de autonomie van de patiënt verminderd ten opzichte van de situatie voor het CVA; de patient heeft niet alleen beperkingen op het gebied van mobiliteit, communicatie en/of cognitie, maar ook toekomstplannen zijn onverwacht doorkruist door het optreden van het CVA. Het proefschrift belicht de veranderende autonomie van CVA-patiënten tijdens revalidatie in het verpleeghuis, en de wijze waarop hulpverleners trachten patiënten te ondersteunen bij het herwinnen van hun autonomie.

Het onderzoek dat de basis vormde voor het proefschrift kwam tot stand door een gezamenlijk initiatief van het Instituut voor Gezondheidsethiek en de Universiteit Maastricht. Het project vond plaats ussen juni 1995 en april 1998, en werd gesubsidieerd door het Landelijk Centrum voor Verpleging en Verzorging (LCVV) te Utrecht, en door de Provincie Limburg. Het project werd uitgevoerd op de revalidatieafdelingen van drie verpleeghuizen in de provincie Limburg, te weten Martinushof in Tegelen, Schuttershof in Brunssum en St. Camillus in Roermond.

Hoofdstuk 1 bevat een korte introductie in het onderwerp van de studie. De thema's autonomie, CVA en langdurige zorgverlening worden besproken tegen de achtergrond van de revalidatie van CVA-patiënten in de verpleeghuissetting. Reeds uitgevoerde empirische studies op het gebied van autonomie en langdurige zorgverlening worden belicht, en de doelen, vraagstelling on mothode van het huidige project worden besproken.

Hoofdstuk 2 betreft een conceptuele analyse van het begrip autonomie in de context van de revalidatie van CVA-patiënten. De volgende vragen vormden het uitgangspunt voor deze analyse. Wat wordt precies bedoeld met de autonomie van de patiënt? Wat is de theoretische onderbouwing van dit concept? En, wat is de rol van zorgverleners ten aanzien van de autonomie van de patiënt? Een search in verschillende geautomatiseerde literatuurbestanden op medisch en psychosociaal gebied leverde nauwelijks specifieke literatuur op betreffende autonomie en de revalidatie van CVA-patiënten. Wel werd secundaire literatuur gevonden over aanpalende begrippen uit de praktijk van de revalidatie en de langdurige zorgverlening. De meeste studies over autonomie van de patiënt bleken theoretisch van aard. Daarnaast werden enkele empirische studies gevonden, met name over autonomie van en langdurige zorgverlening aan verblijfspatiënten in verpleeghuizen. De literatuuranalyse laat zien dat er in- 
dividuele en sociale concepten van autonomie zijn. Een individueel concept van autonomie benadrukt zelfstandigheid en authenticiteit, terwijl een sociaal concept van autonomie sociale steun meerekent. In de literatuur wordt het belang van de sociale omgeving voor het herwinnen van autonomie benadrukt, wat zou betekenen dat een sociaal concept van autonomie beter past bij de praktijk van revalidatie van CVA-patiënten dan een individueel concept. Echter, de vraag of een sociaal concept wan autonomie als uitgangspunt kan dienen voor alle fasen van de revalidatie is hiermee nog niet beantwoord. De conclusie luidt dat de autonomie van CVA-patiënten nader onderzoek vergt.

Hoofdstuk 3 beschrijft een studie naar het perspectief van zorgverleners betreffende de autonomie van CVA-patiënten. Welke aspecten onderscheiden zorgverleners aan de autonomie van CVA-patiënten, en welke factoren beïnvloeden volgens zorgverleners de autonomie van de patiënt tijdens het revalidatieproces? In een studie onder 27 zorgverleners werkzaam in verpleeghuizen is het kernbegrip 'veranderende autonomie' ontwikkeld. Dit kernbegrip omvat het proces waarin CVA-patiënten hun autonomie trachten te herwinnen, met inbegrip van de factoren die dit proces beïnvloeden. Deze factoren kunnen verdeeld worden in patiëntfactoren en omgevingsfactoren. Patiëntfactoren bestaan uit de omstandigheden en strategieën van de patiënt. Omgevingsfactoren betreffen het verpleeghuis als context, en de strategieën van hulpverleners en familie. In de studie zijn drie dimensies van autonomie onderscheiden: zelfbeschikking, zelfstandigheid en zelfredzaamheid. Zelfbeschikking betreft het maken van keuzes en het nemen van beslissingen aangaande eigen leven en gezondheid, inclusief keuzevrijheid. Zelfstandigheid (op fysiek, psychisch en sociaal gebied) betreft het plannen en organiseren van het eigen leven, inclusief sociale contacten en rollen, en refereert aan het nemen van verantwoordelijkheid voor eigen leven en gezondheid. Zelfredzaamheid betreft vaardigheden (op het gebied van mobiliteit, communicatie en cognitie) en activiteiten van het dagelijks leven, die noodzakelijk zijn om te kunnen functioneren. Zorgverleners in ons onderzoek geven aan dat zij in hun werk vooral aandacht geven aan de dimensie zelfredzaamheid, wat naar hun gevoel niet voldoende is. Zij twijfelen over hoe zij patiënten in hun autonomie moeten ondersteunen, en welke dimensies van autonomic prioriteit moeten krijgen in de verschillende fasen van het revalidatieproces.

In het kader van het onderzoek zijn verschillende studies uitgevoerd naar de ervaringen van CVA-patiënten (hoofdstukken 4-7). Gekozen is voor een longitudinale aanpak, om te bekijken of percepties en behoeften van patiënten aangaande autonomie veranderen in de loop van het revalidatieproces. Tweeëntwintig patiënten werden geïnterviewd kort na opname, tijdens de revalidatie en kort voor ontslag. De interviews met patiënten verschaffen belangrijke informatic over het proces waarin patiënten hun autonomie herwinnen. Patiënt- en ongevingsfactoren hebben in de verschillende fasen van de revalidatie een wisselend effect op de veranderende autonomie (hoofdstukken 4-6). 
In de studie bij CVA-patiẽnten in de opnamefase zijn, onafhankelijk van de studie bij zorgverleners, hetzelfde kernbegrip en dezelfde dimensies van autonomie geîdentificeerd, namelijk zelfbeschikking, zelfstandigheid en zelfredzaamheid (hoofdstuk 4). In de opnamefase wordt de autonomie (de drie dimensies) van de patiënt belemmerd door zijn omstandigheden (beperkingen, multi-morbiditeit, emotionele toestand, en zichzelf een 'leek' voelen) en door zijn strategieën (afwachten, en zich gedragen als 'ondergeschikte'). Volgens de CVA-patiënten in ons onderzoek zijn er verschillende ongevingsfactoren die hun autonomie tijdens de opnamefase bevorderen. Het verpleeghuis ondersteunt de autonomie van de patiënt door het bieden van een sfeer die gekenmerkt wordt door hoop, en door het bieden van ruimte voor autonomie. De zorgverleners bevorderen autonomie door het bieden van therapie, steun en informatie, door attentiviteit en respect, en door een teambenadering. Daarnaast wordt autonomie, paradoxaal genoeg, ondersteund door paternalisme (het nemen van beslissingen vóór de patiënt). Emotionele en instrumentele steun van familie bevorderen de autonomie eveneens. Omgevingsfactoren die autonomie tijdens de opnamefase belemmeren zijn verzorgingsregimes, gebrek aan privacy, een vreemde omgeving, wachttijden, 'hotelfunctie', en gebrek aan informatic.

Tijdens de revalidatiefase blijkt de autonomie (vooral de dimensie zelfredzaamheid) van de patiënt toe te nemen door zowel patiëntfactoren als omgevingsfactoren (hoofdlstuk 5). Patiënten bevinden zich tijdens de revalidatiefase in een overgangsperiode wat betreft hun autonomie (de drie dimensies): zij hebben hulp nodig bij het vergroten ervan, en herwinnen hum autonomie geleidelijk, waardoor zij minder ondersteuning nodig hebben. Omgevingsfactoren die autonomie bevorderen zijn: een persoonlijke sfeer, een consistente benadering, steun, therapie, attentiviteit en respect, paternalisme op het gebied van de behandeling, bieden van informatie, evalueren, en overleg. Omgevingsfactoren die autonomie belemmeren zijn: verzorgingsregimes, tijdsdruk, gebrek aan privacy, gebrek aan voor de patiënt bekende activiteiten, paternalisme op andere gebieden dan de behandeling, en gebrek aan informatie, evaluatie en overleg.

In de ontslagfase ondervinden de CVA-patiënten in ons onderzoek een toename van hun autonomie (vooral de dimensies zelfstandigheid en zelfbeschikking) (hoofdstuk 6). Deze toename blijkt te maken te hebben met patiëntfactoren (herwonnen mogelijkheden en zelfvertrouwen, en strategieën van de patiënt, zoals initiatief nemen en assertiviteit). Vanuit het perspectief van patiënten vormt een aantal omgevingsfactoren een belemmering voor hun autonomie, zoals overbezorgdheid, paternalisme, verzorgingsregimes en een inconsistente benadering. Verzorgingsregimes, gebrek aan voor de patiënt bekende activiteiten, en gebrek aan privacy blijken patiënten te hinderen bij hun voorbereiding op de dagelijkse gang van zaken na ontslag, wat een socpele overgang tussen verpleeghuis en thuissituatie in de weg kan staan. Daaremtegen wordt autonomie bevorderd door attentiviteit, door op de individuele patiënt toegesneden interventies en door een respectvolle benadering, evenals door beperkte instrumentele en emotionele steun van familie. 
In aanvulling op de analyse van verschillende fasen van het revalidatieproces (hoofdstukken 4-6), zijn de drie patientinterviews longitudinaal geanalyseerd wanuit de vraag hoe zorgverleners het proces waarin patiënten hun autonomie herwinnen kunnen ondersteunen (hoofdstuk 7). Patienten worden bij het herwinnen van hun autonomie gesteund door een benadering die mee verandert met de wederom toenemende autonomie van patienten. Vanuit het perspectief wan de CVA-patienten in ons onderzoek blijken twee patronen in de benadering van de zorgverleners bevorderlijk te zijn voor autonomie: 1) van volledige hulp in de opnamefase, via beperkte hulp en supervisie, naar geringe supervisie in de ontslagfase; en 2) van paternalisme in de opnamefase, via gedeeltelijk paternalisme (alléén omtrent beslissingen over de behandeling), naar gezamenlijke besluitvorming in de ontslagfase. Hulp omvat instrumentele en emotionele steun, en heeft vooral te maken met de dimensies zelfredzaamheid en zelfstandigheid. Paternalisme houdt in dat zorgverleners keuzes maken en. beslissingen nemen vóór de patiënt, en heeft vooral betrekking op de dimensies zelfbeschikking en zelfstandigheid. Met gedeeltelijk paternalisme wordt uitgedrukt dat de CVA-patiënten in ons onderzoek niet streven naar een "of-ofsituatie' (óf alle beslissingen zelf nemen, of alle beslissingen overlaten aan de zorgverleners). De patiënten hebben behoefte aan een 'en-en-situatie' (sommige beslissingen zelf nemen, en andere beslissingen overlaten aan de zorgverleners) in het kader van het herwinnen van hun autonomie.

Deze twee patronen bevestigen het belang wan een sociaal concept van autonomie (zie hoofdstuk 2) als uitgangspunt voor de wijze waarop zorgverleners, met name tijdens de eerste fase van de revalidatie, patiënten ondersteunen bij het herwinnen van hun autonomie. Wanneer de autonomie van de patiënt zich uitbreidt dienen zorgverleners daarnaast een individueel concept van autonomie (zie hoofdstuk 2) in gedachten te houden om de toenemende autonomie van de patiënt te stimuleren. De benadering van de zorgverleners zoals die door de patiënten ervaren werd kwam niet altijd overeen met de door patiènten wenselijk geachte benadering. Vanuit het perspectief van de patiènten werden hulp en supervisie op tijd verminderd, maar werd paternalisme vaak te lang voortgezet.

In hoofdstuk 8 worden de resultaten van de studie besproken tegen de achtergrond van de mogelijkheden en beperkingen van empirisch-ethisch onderzoek beschreven in de medisch-ethische literatuur. De volgende bijdragen voor empirisch-ethisch onderzoek worden genoemd: 1) het blootleggen van theoretische gezichtspunten die in de praktijk onwerkbaar blijken te zijn; 2) het evalueren van de capaciteiten van hulpverleners om ethische principes te operationaliseren; 3 y het ontwikkelen van hypothesen voor theoretisch-ethische reflectie. Ad I: In de studie wordt aangetoond dat de meest gangbare theoretische concepten wan autonomie, namelijk zelfsturing en zelfrealisatie, voor een deel te kort schieten in de bestudeerde praktijk, vooral in de eerste fase van revalidatie. Ad 2: De studie laat zien dat zorgverleners een beperkte interpretatie hanteren van het begrip 'autonomie van de patiënt', en dat een gezamenlijke taal ontbreekt om te praten over autonomie van patiënten. Ad 3: In 
de studie zijn twee nieuwe concepten ontwikkeld, nameligk 'veranderende autonomie' en 'gedeeltelijk paternalisme', De consequenties van deze (voorlopige) concepten dienen verder bestudeerd te worden. Een aantal vragen voor verder onderzoek en discussie is geformuleerd:

- Biedt het concept "veranderende autonomie" voldoende structuur voor de revalidatie van CVA-patiënten?

- Welke implicaties heeft het concept "veranderende autonomie" voor het principe van respect voor autonomie?

- Is het concept 'gedeeltelijk paternalisme' steekhoudend in revalidatie en langdurige zorgverlening, en zo ja, wat betekent dit voor het principe van respect voor autonomie?

- Wordt autonomie bedreigd wanneer het concept "gedeeltelijk paternalisme" wordt geïmplementeerd en zo ja, welke voorzorgsmaatregelen moeten dan worden genomen?

De studie laat zien dat de beperkingen van empirisch-ethisch onderzoek die in de medisch-ethische literatuur genoend worden, deels kunnen worden ondervangen door het gebruik van een kwalitatieve onderzoeksmethode. Geconchudeerd wordt dat empirisch-ethisch onderzoek meer aandacht verdiend van ethici en onderzoekers uit het veld van de medische ethiek dan zij tot nu toe gekregen heeft.

In hoofdstuk 9 worden de belangrijkste resultaten wit het onderzoek besproken. Methodologisch sterke kanten (een kwalitatief design, aandacht voor het perspectief van patiënten, bespreken van resultaten met collega-deskundigen, triangulatie) en beperkingen van het onderzoek (geen observaties, mate van generaliseerbaarheid) worden onder de loep genomen. Het hoofdstuk wordt afgesloten met aanbevelingen voor de klinische praktijk, educatie en training, beleid in verpleeghuizen, en verder onderzoek. De aanbevelingen betreffen ondermeer aandacht voor de drie dimensies van autonomie en een gedifferentieerde benadering van autonomie gedurende het revalidatieproces. Nog te ontwikkelen richtlijnen kunnen zorgverleners ondersteunen in de wijze waarop zij mel de autonomie van patiënten omgaan. Ook behoeft het integreren van de resultaten in localle en nationale richtijnen op het gebied van CVArevalidatie nadere aandacht. Verder onderzoek wordt aanbevolen op het gebied van genoemde medisch-ethische thema"s, en naar het effect van de nog te ontwikkelen richtlijnen. Tevens is nader onderzoek noodzakelijk op het gebied van autonomie van patiënten met andere diagnosen dan CVA, en naar de relatie tussen autonomie van de patięnt en sociale steun. 



\section{Dankwoord / Acknowledgement}

Aan het onderzoek en de totstandkoming van dit proefschrift hebben velen bijgedragen. Op deze plaats wil ik een ieder die direct of indirect heeft bijgedragen daarvoor bedanken.

In het bijzonder wil ik mijn dank uitspreken aan de CVA-patiènten en familieleden die hun medewerking verleend hebben aan de interviews, en hun ervaringen tijdens de revalidatie met ons hebben willen delen.

Het was onmogelijk geweest het onderzoek op te zetten en tot een goed einde te brengen zonder de hulp van de "contactpersonen" van de verpleeghuizen die bij het onderzoek waren betrokken, namelijk Martinushof in Tegelen, Schuttershof in Brunssum en St. Camillus in Roermond. Ton Macor, Jos Stevens en. Gijs van Oorsouw hebben de basisvoorwaarden geschapen voor het onderzoek, en mij wegwijs gemaakt binnen de organisaties. Tevens waren zij bereid zitting te nemen in de begeleidingscommissie van het onderzoek, het Nederlandstalige eindrapport van commentaar te voorzien en als coauteur van diverse internationale artikelen op te treden. Beste Ton, Jos en Gijs, heel hartelijk dank daarvoor.

Voorts ben ik veel dank verschuldigd aan de medewerkers in de verpleeghuizen die bereid waren om de selectie van de patiënten op zich te nemen. In het bijzonder dank ik Ton Macor, Saskia Fasen-Spätjens, Jacques Smit, Irma Knippenberg, en Annette Mensink. Al zag het er eerst naar uit dat het onderzoek niet van de grond kwam door de snel invallende strenge winter van 1996/1997 (toen bijna alle bedden op de revalidatieafdelingen waren bezet door patiënten met een collumfractuur), het is toch goed gekomen mede dankzij jullie inspanningen. Tevens wil ik alle zorgverleners bedanken die enthousiast hebben deelgenomen aan de interviews en de groepsbijeenkomsten.

Mijn promotoren Prof. dr. Ruud ter Meulen, Prof. dr. Harry Crebolder en Prof. dr. Huda Huijer Abu-Saad ben ik erkentelijk voor hun support bij de totstandkoming van het onderzoeksproject dat de basis vorm! voor dit proefschrift. Op zorgvuldige, enthousiaste en saamhorige wijze hebben zij het onderzoek en de 'wording" van bet proefschrift begeleid. Ruud, het interview in 1993 met jou als ethicus heeft verstrekkende gevolgen gehad. Jij hebt mij alle ruimte gegeven die een promovenda zich wensen kan om autonoom, maar niet alléén, een uitdagend traject te doorlopen. Dank ook voor de wijze waarop je mij gestimuleerd hebt om over de geografische grenzen heen te kijken. Harry, reeds tijdens mijn afstudeeronderzoek hield jij de betekenis van het onderzoek voor de praktijk van de zorg kritisch in de gaten. Je toonde je een waar supporter van empirisch ethisch onderzoek. lk dank je voor de wijze waarop je altijd net de vinger wist te leggen op zaken waar ik nog niet helemaal uit was, en voor je zorgzaamheid. Huda, jouw ervaring op het gebied van kwalitatief onderzoek is voor mij een bron van inspiratic en steun geweest. Ook heb ik veel van je kunnen leren omtrent het schrijven en aanbieden van internationale artikelen. 
Fijn dat we de samenwerking op het gebied van palliatieve zorg hebben kunnen voortzetten.

Veel werk is verzet door degenen die de interviewbanden hebben uitgetypt. Wilma de Esch-Janssen, Rian Obdeijn-van den Boogaart en Annette Paques hebben op vrijwillige basis de interviewbanden wan de zorgverleners uitgewerkt. Mw. L. Aerts-de Bont, Margot de Boer, Angelique Heijnen en Carla Laarakkers hebben vaart gezet achter de uitwerking van de interviews met patiënten. Ik dank jullie heel hartelijk voor de zorgvuldige wijze waarop jullie je van je taak gekweten hebt.

Wilma de Esch-Janssen, aangesteld als onderzoeksassistente voor de periode van de interviews met de patiënten, heeft een groot deel van het veldwerk voor haar rekening genomen. Wilma, je was een heel betrokken interviewer en een steunpilaar bij de organisatie van deze fase van het onderzoek. Dank daarvoor.

Het Instituut voor Gezondheidsethiek vormde de thuisbasis voor mijn promotieonderzoek. Diverse (ex-)collega"s hebben mijn reilen en zeilen in de loop der tijd met interesse gevolgd en van commentaar voorzien. Daarnaast hebben zij mij afleiding bezorgd door te relativeren, te plagen, en to cen wandeling te verleiden. Ron Berghmans, Masja van den Burg, Wilma de EschJanssen, Angelique Heijnen, Antina de Jong, Rick Mertens, Marie-Josée Mourmans, Eefke Poels, Carlo Sohl en Guido de Wert, dank daarvoor.

Diverse collega's van de capaciteitsgroepen gezondheidsethiek en wijsbegeerte, verplegingswetenschap en huisartsgeneeskunde hebben mij gevraagd of ongevraagd gesteund, naar de vorderingen geinformeerd en van informatie voorzien. Enkele mensen wil ik daarbij in het bijzonder bedanken: Amold van Alphen, Arie van der Arend, Jan Hamers, Frans van der Horst, Rob Houtepen, Tiny Jaarsma, Agnes Meershoek, Marie-Josée Smits en Trudy wan der Weijden.

De werkgroepen 'ethiek en empirisch onderzoek' en 'onderzoek kwaliteit huisartsgeneeskunde' vormden fora om resultaten in wording te presenteren. Ook fungeerden zij als plek om afstand te nemen en nieuwe inspiratie op te doen.

Ook buiten de Universiteit Maastricht was er support en bereidheid om op gezette tijden mee te denken. Speciarl will ik bedanken: Puck Sickinger en Els Bransen (Stichting Hoofd, Hart en Vaten), Ed Baten en Paul van Keeken (NVNV), Caroline van Heugten en Luc de Witte (iRv), Aart Pood, Wilma Scholte Opreimer en Lidwien Schure.

Degenen die hebben bijgedragen aan de witeindelijke witvoering en vormgeving van het proefschrift ben ik veel dank verschuldigd. Bob Wilkinson corrigeerde nawwgezet de Engelse tekst, en stond altijd klaar met goede adviezen. Marian Proot vertaalde met grote inzet de Nederlandse interviewfragmenten, wardoor de nuances niet verlonen gingen. Angelique Heijnen nam de lay-out en de laatste afwerking van het gehelle manuscript voor haar rekening, en deed dat op uiterst zorgvuldige wijze. Jean Bouvrie gaf grafische adviezen en zorgde ervoor dat de kaft gezien mag worden.

Jet Lancée en Frits Prinzen zijn mij als vrienden/paranimfen in de laatste fase voor de promotie tot steun geweest. Jet, ooit togen wij maandelijks naar 
Nijmegen voor de nascholingscursus 'Ergotherapie en Onderzoek', waar je van nabij meemaakte hoe ik enthousiast raakte voor het wetenschappelijk onderzock. Frits, toen wij elkaar leerden kennen was jij aan een promotietraject bezig. Geen van ons kon toen bevroeden dat dat mijn voorland zou zijn. Hoewel jij in een heel ander vakgebied 'opereert', hebben we in de afgelopen jaren veel ervaringen kunnen delen. Jet en Frits, ik waardeer het enorm jullie als paranimfen naast mij te weten.

Andere vriendinnen en vrienden hebben de afgelopen jaren voor de broodnodige ontspanning gezorgd, belangstelling getoond, en steeds weer een luisterend oor geboden. Dank daarvoor.

Mijn moeder dank ik voor het vertrouwen dat zij altijd in mij heeft gesteld. Lieve mammie, al was je wel eens bezorgd over het feit dat ik zo druk bezig was, toch was je net zo benieuwd als ik naar de afloop van deze onderneming. Mijn vader, die tot mijn spijt mijn 'loopbaan" na de lagere school niet meer heeft mogen meemaken, heeft vroeger zeker een steentje bijgedragen aan mijn vorming als onderzoeker, ook al was ik mij daar toen nog niet van bewust. Mijn schoonouders bedank ik voor de wijze waarop zij hebben meegeleefd. Mijn broer en zussen, zwagers en schoonzussen dank ik voor hun belangstelling en relativerende opmerkingen. $\mathrm{Jk}$ kon niet vermoeden dat het thema CVA juist in deze periode een grote rol zou gaan spelen in mijn eigen familie.

Frans heeft mij gedurende het hele traject mijn gang laten gaan, maar gelukkig ook op tijd afgeremd. Lieve Frans, je was een prima klankbord, zorgde voor de inwendige mens en hebt op vele fronten de honneurs waargenomen. Ik ben je daarvoor dankbaar. Je was bereid mij te delen met een altijd aanwezige 'derde' in huis. Het wordt tijd dat die kostganger op zichzelf gaat wonen. 


\section{Curriculum Vitae}

Ireen Proot was born on March 15, 1955 in Arnhem, the Netherlands. In 1973 she completed secondary school at the "Thorbeckelyceum' (gymnasium alpha) in Amhem. Next she studied occupational therapy at the 'Revalidatie Academie Hoensbroeck' in Hoensbroek (1973-1976). From 1977 till 1979 she worked as an occupational therapist at 'Franciscusoord', a rehabilitation center for children, in Houthem. From 1980 till 1989 she worked as a taacher in occupational therapy at the 'Revalidatie Academie Hoensbroeck' (later 'Hogeschool Heerlen') in Hoensbroek.

In 1989 she started as a research-assistant in a NWO-project on somatization in frequent attenders of general practice, which project was performed in collaboration of the Departments of Social Psychiatry and General Practice, Maastricht University (1989-1994). At the same time she studied Health Sciences at Maastricht University (1992-1994), focussing on theory of health care sciences (bioethics and philosophy). After graduation (cum laude) in 1994 she worked as a researcher at the Department of Bioethics and Philosophy, Maastricht University. She was detached to the Institute for Bioethics, Maastricht, for a study on medical-ethical aspects of guidelines in the care for patients with remmatoid arthritis (1994-1995).

In 1995 she started with her Ph.D. study at the Institute for Bioethics. In addition to her Ph.D. study she has collaborated on several other projects, including a project on developing an instrument for moral reasoning in nursing homes, and a study on spinal muscular atrophy of the Institute for Rehabilitation Research (iRv) in Hoensbroek. Since 1999 she has been detached to the Center for Nursing Research, Faculty of Health Sciences, Maastricht University, for a project on palliative care in the home care situation.

Ireen Proot lives together with Frans Rauwenhoff, engraver, in Maastricht, the Netherlands. 



\section{List of publications}

Proot, I. (1992). Ergotherapie: onderzoek waard? Nederlands Tijdschrift voor Ergotherapie, 20, 16-19.

Proot, I. (1994). Protocol, autonomie en verantwoordelijkheid in de zorg voor CVA-patiënten. De invloed van protocollering van zorg op de autonomie en verantwoordelijkheid van de CVA-patiënt, diens omgeving en hulpverleners in het verpleeghuis. IGE Bulletin, 8(2), 6-8.

Proot, I.M., Crebolder, H.F.J.M., \& ter Meulen, R.H.J. (1995). Autonomy, responsibility and the development of guidelines in the care for stroke patients. In D.L. Knook (Ed.), Ageing in a changing Europe, III European Congress of Gerontology, 30 augustus - I september 1995. Utrecht: NIO.

Proot, I., \& Ritzen, W. (Red.). (1996). Protocollering van Zorg. Verslag van de werkconferentie over multidisciplinaire protocollen in de zorg voor mensen met CVA, reuma en diabetes. Hoensbroek: Synchron, waarin opgenomen: Proot, I. Gezocht: multidisciplinaire protocollen (5-8), en: Proot, I. Protocollering van zorg bij rheumatoïde arthritis: medische en ethische aspecten (55-61).

Proot, I.M., Crebolder, H.F.J.M., \& ter Meulen, R.H.J. (1996). Protocollaire zorgverlening aan CVA-patiënten in een verpleeghuis: autonomie en verantwoordelijkheid. Een exploratieve studie. Neuronieuws, 11, 567-571.

Proot, I.M. (1996). Autonomie van CVA-patiënten in verpleeghuizen. In Landelijk Centrum voor Verpleging en Verzorging, Onderzoek in de verpleging en verzorging in relatie tot de praktijk. Congresbundel (222227). Utrecht: Tijdstroom.

Proot, I.M., ter Meulen, R.H.J., Crebolder, H.F.J.M., van der Linden, J.M.J.P., \& Reerink, E. (1996). Protocollering van zorg bij reumatoide arthritis: medisch-ethische aspecten. Onderzoeksrapport. Maastricht: Instituut voor Gezondheidsethiek.

Portegijs, P.J.M., van der Horst, F.G., Proot, I.M., Kraan, H.F., \& Gunther, N.C.H.F. (1996). Somatization in frequent attenders of general practice. Social Psychiatry and Psychiarric Epidemiology, 3/, 29-37.

Portegijs, P.J.M., van der Horst, F.G., Proot, I.M., Kraan, H.F., \& Gunther, N.C.H.F. (1996). Somatisatie bij patiënten met een hoge consultffequentic. Huisarts en Wetenschap, 39, 604-612.

Proot, I., \& Stevens, J. (1997). Autonomie van CVA-patiënten. In Zorg voor de CVA-patient in de revalidatie- en chronische fase. Verslag van het CVAsymposium 'Samen Verder Werken' op 4 december 1996 te Sittard (47-49). Hoensbroek: Synchron.

Proot, I.M., ter Meulen, R.H.J., Crebolder, H.F.J.M., \& Huijer Abu-Saad, H. (1998). Autonomie in de zorg voor CVA-patiënten in het verpleeghuis. Verslag op hoofdlinnen. Eindrapportage ten belioeve van het Landelijk Centrum voor Verpleging en Verzorging (LCVV) en de Provincie Limburg. Maastricht: Instituut voor Gezondheidsethiek. 
Proot, I.M., Crebolder, H.F.J.M., Huijer Abu-Saad, H. \& ter Meulen, R.H.J. (1998). "Autonomy in the rehabilitation of stroke patients in nursing homes. A concept analysis". Scandinavian Jounal of Caring Siciences, 12, 139-145.

Proot, 1.M., Huijer Abu-Saad, H., de Esch-Janssen, W.P., Crebolder, H.F.J.M., \& ter Meulen, R.H.J. (2000). Patient autonomy during rehabilitation: the experiences of stroke patients in nursing homes. Intenational Jounal of Nursing Studies, 37, 267-276.

Proot, I.M., Crebolder, H.F.J.M., Huijer Abu-Saad, H., Macor, T.H.G.M., \& ter Meulen, R.H.J. (2000). Stroke patients' needs and experiences regarding autonomy at discharge from nursing home. Patient Education and Counseling, 41, 275-283.

Proot, 1.M., Crebolder, H.F.J.M., Huijer Abu-Saad, H., Macor, T.H.G.M., \& ter Meulen, R.H.J. (2000). Facilitating and constraining factors on autonomy: the vilews of stroke patients on admission into nursing homes. Clinical Nursing Research, 9, 460-478.

Witte, de, L.P., Tilli, D.J.P., Diederiks, J.P.M., van "t Hoofd, W.L., \& Proot, 1.M. (2000). Late gevolgen van newromusculaire aandoeningen: een verkeming bij mensen met spinale musculaire atrofie (SMA). Hoensbroek: iR.

Proot, H.M., Crebolder, H.F.J.M., Huijer Abu-Saad, H., \& ter Meulen, R.H.J. Autonomie bei der rehabilitation von schlaganfallpatienten in pflegeheimen eine Konzeptanalyse. In B.M. Hack (Ed.), Ethik in der ergotherapie. Berlin/Heidelberg: Springer, 2001. In press.

Proot, I.M., Crebolder, H.F.J.M., Huijer Abu-Saad, H., \& ter Meulen, R.H.J. (2001). Autonomy in the care of stroke patients in nursing homes. Research abstract. Nursing Ethics, 8, 85-86. In press.

Proot, I.M., Huijer Abu-Saad, H., van Oorsouw, G.G.J., \& Stevens, J.J.A.M. Autonomy in stroke rehabilitation: the perceptions of health professionals in nursing homes. Submitted for publication in Nursing Ethics.

Proot, I.M., ter Meulen, R.H.J., Hujjer Abu-Saad, H., \& Crebolder, H.F.J.M. Changing autonomy. Facilitating stroke patients' autonomy in the different phases of rehabilitation. Submitted for publication. 